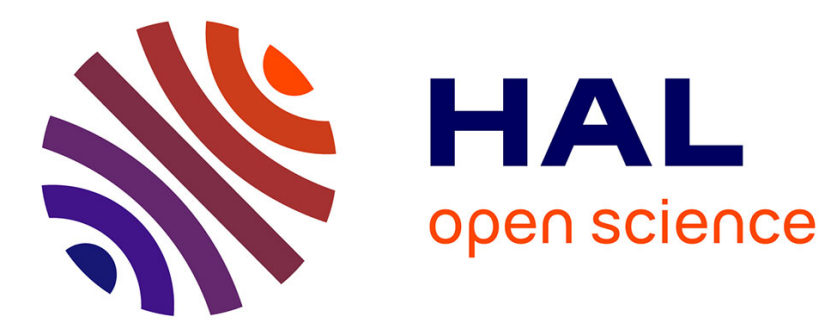

\title{
Le dépôt cultuel du sanctuaire gaulois de Tintignac à Naves (Corrèze)
}

\author{
Christophe Maniquet
}

\section{To cite this version:}

Christophe Maniquet. Le dépôt cultuel du sanctuaire gaulois de Tintignac à Naves (Corrèze). Gallia - Archéologie de la France antique, 2008, 65, pp.273-326. 10.3406/galia.2008.3346 . hal-01899112

\section{HAL Id: hal-01899112 \\ https://hal.science/hal-01899112}

Submitted on 19 Dec 2019

HAL is a multi-disciplinary open access archive for the deposit and dissemination of scientific research documents, whether they are published or not. The documents may come from teaching and research institutions in France or abroad, or from public or private research centers.
L'archive ouverte pluridisciplinaire HAL, est destinée au dépôt et à la diffusion de documents scientifiques de niveau recherche, publiés ou non, émanant des établissements d'enseignement et de recherche français ou étrangers, des laboratoires publics ou privés.

\section{(ㅇ)(1) $\$$}

Distributed under a Creative Commons Attribution - NonCommercial - NoDerivatives| 4.0 


\title{
LE DÉPÔT CULTUEL DU SANCTUAIRE GAULOIS DE TINTIGNAC À NAVES (CORRÈZE)
}

\author{
Christophe MANIQUET*
}

Mots-clés. Lémovices, fossés, palissades, épées, fers de lance, casques, carnyx, rituel.

Résumé. Le site de Tintignac fouillé au XIX ${ }^{e}$ s. fait l'objet, depuis 2001, de nouvelles interventions estivales dans le cadre d'un projet de mise en valeur culturel et touristique initié par la commune. Jusqu'alors, le sanctuaire était matérialisé par quatre édifices monumentaux gallo-romains. Sous les niveaux de circulation de la cour du temple, à l'ouest, les vestiges du sanctuaire protohistorique ont été mis au jour. Le premier enclos semble avoir été édifié au plus tôt au II $s$. av. J.-C. Il est composé d'un fossé cernant une plateforme de 25 m de côté, sur laquelle ont été dégagées les empreintes d'un édifice en bois reconstruit plusieurs fois. À l'intérieur, un foyer et de nombreuses monnaies en argent mutilées ont été découverts. Dans l'un des angles de la plate-forme sacrée, près du fossé d'enclos, une petite fosse, dégagée en 2004, a livré une grande quantité d'objets métalliques, en fer et en bronze. Parmi ces objets, on retiendra la présence d'armes, d'un chaudron ainsi que d'éléments liés au harnachement. Des têtes d'animaux en bronze étaient accompagnées de plusieurs pattes ou fragments de corps en tôle de bronze. À ceci s'ajoutent neuf casques en alliage cuivreux et un en fer, dont certains possèdent une morphologie jusqu'alors inconnue. Enfin, au fond de la fosse reposaient d'importantes portions de carnyx, ces trompettes de guerre celtiques dotées de pavillons en forme de gueules d'animaux. Bien que certains objets remontent à La Tène moyenne, l'enfouissement n'a été réalisé qu'au moment de la transformation du sanctuaire, dans les dernières décennies avant notre ère.

Key-words. Lemovices, ditches, palisades, swords, iron spears, helmets, carnyx, ritual.

Abstract. New investigations are being conducted since 2001 on the site of Tintignac, previously excavated in the $19^{\text {th }}$ century, for a cultural and touristic development project on the municipality intiative. The sanctuary was so far materialized by four Gallo-Roman monumental buildings. Under the circulation level of the temple open area, remains of a Protohistoric cult place have been recovered on the west side. The first enclosure seems to be set in the $2^{\text {nd }}$ century B.C. at the earliest. It is constituted of a ditch surrounding a platform, of $25 \mathrm{~m}$ sides, above which the traces of a wooden building, rebuilt several times, have been uncovered. An hearth and numerous mutilated silver coins were found inside. At one corner of the sacred platform, near the enclosure ditch, a small pit, excavated in 2004, has yielded a vast amount of metal items (iron and bronze). Among them, is noted the presence of a cauldron, of weapons and harness fittings. Bronze zoomorphic heads were found altogether with metal sheets of legs and body pieces. Must be added nine copper alloy helmets and one iron made, some of which present a morphology unknown until now. At last, at the bottom of the pit, big pieces of carnyx, military Celtic trumpets with zoomorphic head terminals. Although some of the objects seem to be dated from the mid La Tène period, they have been buried in the last decades before the $1^{\text {st }}$ century A.D. at the time of the development of the temple complex.

Translation: Isabelle FAUDUET

Schlüsselwörter. Lemovicer, gallisches Heiligtum, Gräben, Palisaden, Schwerter, Speerspitzen, Helme, carnyx, Ritual.

Zusammenfassung. Das im 19. Jh. ausgegrabene Heiligtum von Tintignac wird seit 2001 während der Sommermonate im Rahmen eines kommunalen Projektes erneut untersucht, um es für den Tourismus zu erschließen und seine kulturelle Bedeutung herauszustellen. Bisher waren von dem Heiligtum vier monumentale gallorömische Bauwerke bekannt. Unter den Laufhorizonten des westlichen Tempelinnenhofes wurden die Überreste des frühgeschichtlichen Heiligtums freigelegt. Die erste Umfriedung scheint frühestens im 2. Jh. v.u.Z. geschaffen worden zu sein. Sie besteht aus einem Grabengeviert um eine Plattform mit einer Seitenlänge von 25 m, auf der die Abdrücke eines wiederholt neu errichteten Holzbaus freigelegt wurden. Im Inneren wurden eine Feuerstelle sowie zahlreiche unbrauchbar gemachte Silbermünzen entdeckt. In einer der Ecken des Kultplatzes, in der Nähe des Grabengevierts, wurde in einer kleinen, im 2004 freigelegten Grube eine bedeutende Anzahl von Metallgegenständen gefunden. Zu erwähnen sind besonders Waffen,

\footnotetext{
*INRAP Grand Sud-Ouest, Limousin, 18 allée des Gravelles, F-87280 Limoges. Courriel : christophe.maniquet@inrap.fr
} 
ein Kessel sowie Teile von Pferdegeschirr. Neben bronzenen Tierköpfen wurden mehrere Tierfüße oder Fragmente von Tierkörpern aus Bronzeblech entdeckt, außerdem neun Helme aus Kupferlegierung und einer aus Eisen, darunter einige Helme einer bislang unbekannten Form. Schließlich lagen auf dem Grund der Grube bedeutende Teile eines carnyx, dieser keltischen Kriegstrompete mit einem Schalltrichter in Form eines Tiermauls. Obwohl manche Gegenstände aus der Mittellatènezeit stammen, kamen sie erst in die Erde, als das Heiligtum in den letzten Jahrzehnten vor unserer Zeit umgebaut wurde.

Übersetzung: Isa ODENHARDT-DONVEZ

\section{ÉTAT DE LA RECHERCHE}

\section{LES RECHERGHES ANGIENNES}

Le souvenir du site dit des Arènes de Tintignac ne s'est jamais perdu du fait de l'émergence de certaines maçonneries au-dessus du sol depuis l'Antiquité. Les premiers textes qui en font état ne remontent cependant pas au-delà du XVII ${ }^{\mathrm{e}}$ s. (Latour, 1633 ; Baluze, 1717). Des découvertes isolées sont évoquées : fragments de sculptures, céramique, monnaies. Ce n'est qu'après le passage de Prosper Mérimée sur le site (Mérimée, 1838) que les premières fouilles officielles sont engagées en 1842. Elles sont suivies de trois autres interventions dont la dernière, en 1884 , révèle la présence sur ce terrain de quatre édifices monumentaux (fig. 1) dont un temple à l'ouest - un fanum à deux cellae associé à une cour - et un théâtre à l'est. Entre les deux se développent deux autres édifices présentant des similitudes dont l'un possède une forme semi-circulaire (Lalande, 1885). L'absence de comparaison et de recherche récente empêche d'octroyer une fonction à ces bâtiments, même si leur attribution cultuelle peut sérieusement être envisagée au vu du contexte environnant.

Seuls les vestiges gallo-romains étaient donc connus par les fouilles anciennes, aucune découverte ne permettant de soupçonner une occupation antérieure. Il apparaissait de plus que l'ensemble monumental fut abandonné vers la fin du $\mathrm{III}^{\mathrm{e}}$ s., après l'incendie de plusieurs édifices. Aucune autre construction, religieuse ou civile, ne sera édifiée à cet emplacement.

\section{LA REPRISE DES FOUILLES}

Des sondages mécaniques ont été réalisés en janvier 2001 afin de vérifier la fiabilité du plan très contesté de $1884^{1}$. Depuis lors, chaque été voit se dégager davantage les

1. La municipalité de Naves a été à l'origine d'un projet important de mise en valeur des " ruines » et de création d'un pôle culturel et touris- édifices gallo-romains. Ainsi, en 2001 et 2002, les fouilles menées sur le temple à l'ouest ont permis d'identifier six états successifs de construction, de reconstruction et de remaniement plus ou moins importants. Les quatre états les plus récents s'inscrivent dans les trois premiers siècles de notre ère, avec la mise en place de deux fana maçonnés indépendants, inclus dans un même espace sacré délimité par un mur de péribole. Les deux états d'occupation initiaux sont, quant à eux, antérieurs à notre ère et matérialisés par les empreintes de constructions en matériaux périssables. En 2003, la fouille a porté sur la moitié nord du bâtiment en hémicycle dont la mise en place ne semble pas antérieure au $\mathrm{II}^{\mathrm{e}}$ s. apr. J.-C. (fig. 2).

Faute d'intervention rapide de consolidation des maçonneries dégagées entre 2001 et 2003, le choix a été fait de ne plus les dégager. La recherche s'est alors à nouveau tournée en 2004 et 2005 vers la cour du fanum et l'exploration approfondie des vestiges précoces.

\section{LA DÉCOUVERTE DU DÉPÔT}

C'est en recherchant l'angle nord-est de l'enclos protohistorique que les premiers objets de bronze du dépôt sont apparus le 20 septembre 2004. Quelques jours supplémentaires de travail ont permis de percevoir en plan la superficie de la fosse. La question de la méthode à employer (prélever l'ensemble en bloc imposé par les délais et le financement ou poursuivre le dégagement in situ) s'est alors posée. Les archéologues, le Service régional de l'archéologie du Limousin $^{2}$ et le laboratoire Materia Viva de Toulouse ${ }^{3}$ ont pris de concert la décision de poursuivre l'intervention sur le terrain. Celle-ci a duré plus de cinq semaines et s'est

tique local. Situé à près de $500 \mathrm{~m}$ de la nouvelle autoroute A 89 reliant Bordeaux à Clermont-Ferrand, le site devenait un centre attractif de premier ordre.

2. Sous la direction de M. Fabioux, conservateur régional de l'Archéologie.

3. Dirigé par M. Drieux que je tiens ici à remercier ainsi que ses collaboratrices $\mathrm{V}$. Uzel et $\mathrm{T}$. Eyermann qui sont intervenues sur le terrain. 

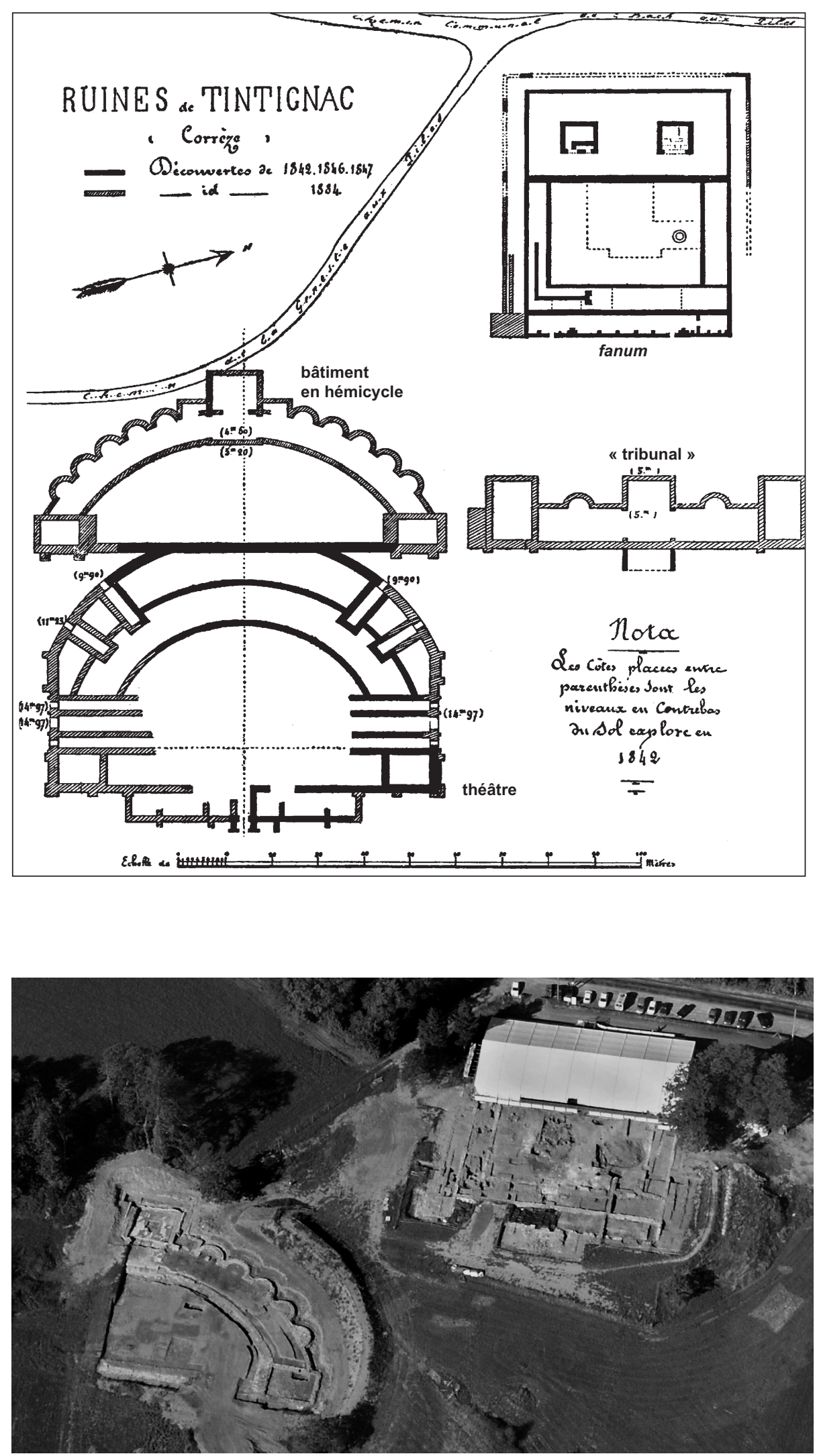

Fig. 1 - Plan des vestiges dressé en 1884, réalisé par MM. Guillot et Ferrière.
Fig. 2 - Vue aérienne du site fouillé en 2003 (cliché : C. Maniquet, INRAP). 
donc poursuivie jusqu'au 27 octobre 2004 ${ }^{4}$. L'exiguïté de la structure et la densité et l'imbrication des divers éléments métalliques limitaient le nombre d'intervenants ${ }^{5}$. La gestion des phases successives de dégagement, de relevés, de prises de vue et de prélèvement ne permettait qu'une progression lente de la fouille ${ }^{6}$.

En ce qui concerne le prélèvement, la corrosion des métaux avait contribué à l'adhérence des objets entre eux. Certaines pièces, constituées de fines tôles métalliques, étaient très fragiles. L'ensemble était sensible à la sécheresse, à l'humidité et aux manipulations diverses. Les précautions élémentaires lors du dégagement consistaient donc à préserver les matériaux existants et l'intégrité physique des objets ${ }^{7}$.

\section{LE TRAVAIL EN LABORATOIRE}

Après prélèvement, tous les objets du dépôt ont été stockés au laboratoire de Toulouse où ils sont soumis à une surveillance constante. Ils ont tous été radiographiés aux rayons $\mathrm{X}^{8}$. Fin 2005, certains d'entre eux (casques et carnyx) ont été nettoyés du sédiment qui les recouvrait ou qu'ils contenaient. Ce sédiment, relativement argileux,

4. Le site est resté sous la surveillance constante d'un vigile durant toute la période de dégagement du dépôt.

5. Avec l'aide de fouilleurs bénévoles, d'étudiants ou de retraités : F. Loubignac, A. Maroote, C. Parent, B. Simonnot, E. Walthert et tous ceux qui sont intervenus plus ponctuellement.

6. L'ensemble du dépôt a été subdivisé en carrés de 0,40 m de côté pour faciliter le repérage en plan des divers éléments et le relevé de terrain. Chaque objet, après son dégagement superficiel, a été reporté sur un plan d'ensemble et coté en trois dimensions ; sa position et son inclinaison ont été scrupuleusement notées. Avant ou après le prélèvement, chaque pièce a été sommairement décrite et associée à un numéro d'isolation. Ainsi, 480 objets ont été enregistrés sur le terrain et 17 plans successifs ont été dressés, correspondant chacun à un niveau de dégagement.

7. Pour cela, deux restauratrices du laboratoire Materia Viva de Toulouse sont intervenues pour la consolidation in situ. Celle-ci a été réalisée sur les parties très fragmentaires, par infiltration en cours de fouille de résine acrylique (Primal AC33) ou bien par renfort de fibre non tissée polyester imprégnée de Paraloïd B72 (résine acrylique) après séchage naturel des objets. Le prélèvement des objets fragiles ou en fragments a été opéré par pose de cyclododécane, hydrocarbure sauré appliqué à chaud, avec renfort de gaze de coton. Les objets ont ensuite été enveloppés dans du film étirable polyéthylène. Le stockage a été conçu dès la fouille pour le transport en bacs gerbables. Les produits chimiques utilisés sont facilement réversibles et les matériaux d'emballage sont imputrescibles, hydrophobes et chimiquement neutres pour la conservation de ces pièces ; en outre, ils sont radiotransparents et permettent la radiographie et l'examen des pièces en limitant les manipulations.

8. Les radiographies ont été réalisées par C. Gargam du laboratoire Materia Viva. risquait en séchant de les fissurer et de les endommager. Au milieu de l'année 2006, ils ont été placés temporairement en atmosphère anaérobie afin d'éviter toute reprise de la corrosion. Les premières véritables restaurations et consolidations ont été engagées au début de l'année $2008^{9}$. Ce n'est que parallèlement à la consolidation des objets que l'étude pourra réellement débuter ${ }^{10}$.

\section{LE SANCTUAIRE LATÉNIEN}

\section{LE CONTEXTE}

Le lieu de culte a été implanté sur la bordure sud-ouest du Massif central, dans une zone charnière entre le bassin d'Aquitaine et la montagne limousine. Le relief local est constitué d'une succession de collines aux sommets érodés entre lesquelles circule un réseau hydrographique dense. Ce réseau, formé de petits cours d'eau, est drainé par la vallée de la Corrèze qui entaille profondément le paysage. Les monuments antiques des "Arènes de Tintignac » ont été construits à mi-coteau d'une de ces collines, le puy de l'Aiguille, le plus haut sommet des environs, culminant à 509 m NGF. L'ensemble monumental est implanté, sur un terrain dont le pendage, léger au niveau du fanum, s'accentue à l'est au niveau des autres édifices, à l'approche du vallon. Dans ce dernier, l'eau du ruisseau de la Vigne jaillit de sources superposées dont l'une est située au sud-est du théâtre. Le site est implanté sur un terrain protégé des vents d'ouest par le puy de l'Aiguille et dont l'orientation est favorable à l'ensoleillement.

Selon J.-M. Desbordes, une voie très ancienne, protohistorique, dont la localisation semble se situer à l'emplacement de l'actuelle RN 120, c'est-à-dire en contrebas des bâtiments qui nous concernent, à l'est et au nord, traversait l'espace lémovice du sud au nord-ouest et menait de Narbonnaise en Armorique (fig. 3) (Desbordes, 1982). Cet itinéraire majeur est jalonné par plusieurs dépôts de haches à talon armoricaines, datées du Bronze final, et par des tumulus de la fin du premier âge du Fer, dont le mobilier témoigne d'influences aquitaines (fibules). Des petites forteresses du second âge du fer contrôlaient cet axe

9. Des bains de stabilisation empêcheront la reprise de la corrosion. Ces bains peuvent se révéler très longs, parfois plusieurs mois, en particulier pour le fer. On comprendra dès lors que ces éléments si fragiles ne peuvent guère être manipulés, ce qui empêche provisoirement des observations plus poussées.

10. L'étude à venir sera menée par une équipe pluridisciplinaire associant, entre autres, archéologues et métallurgistes. 


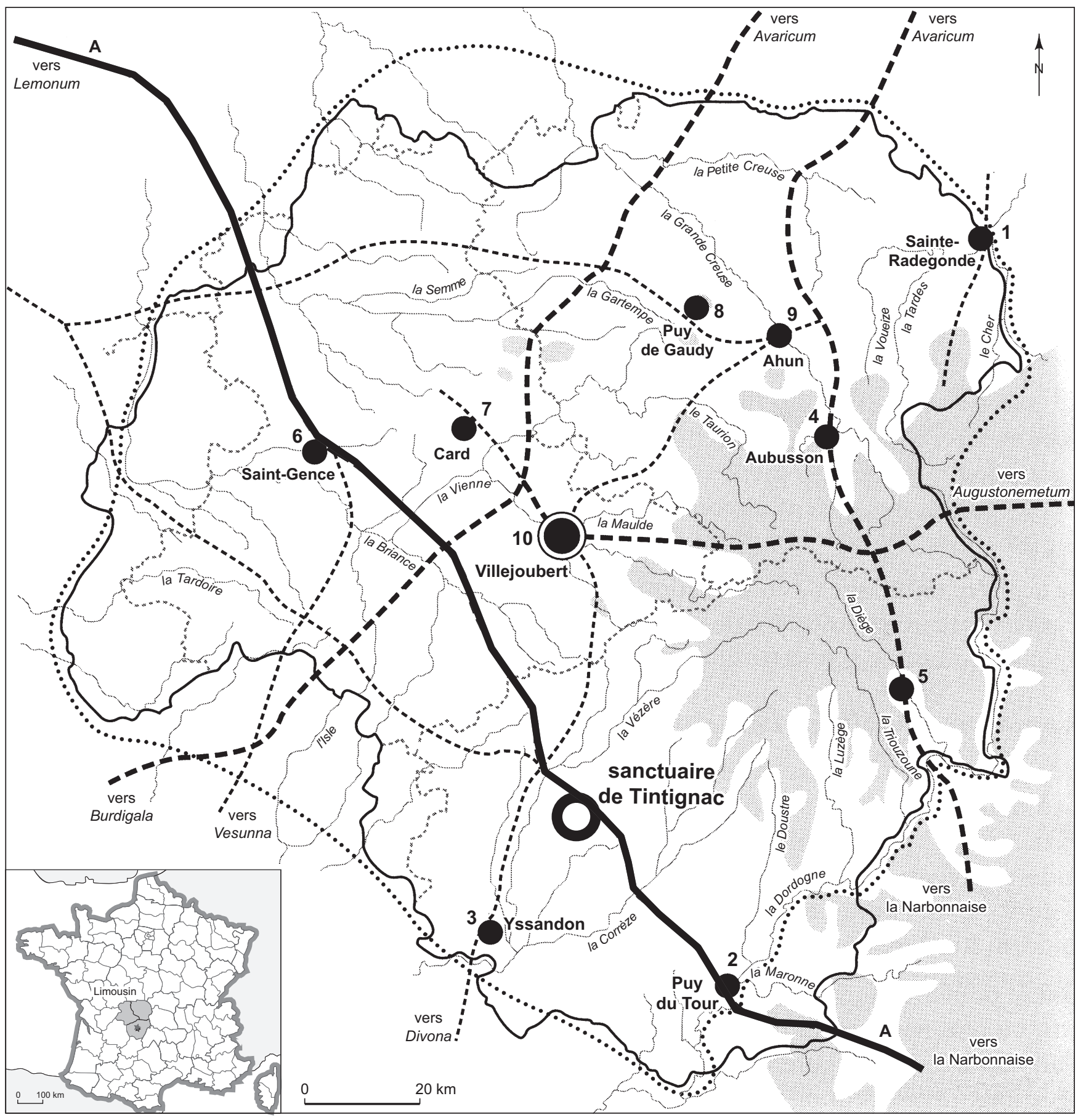

1 à 3 enceintes de frontières

4 à 9 enceintes de contrôle routier

10 oppidum central de Villejoubert

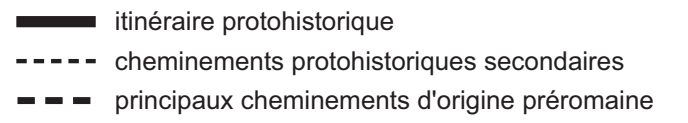

_L limite de l'ancien diocèse de Limoges

...... restitution de l'espace lémovice

- - - principaux cheminements d'origine préromaine

Fig. 3 - Localisation du sanctuaire de Tintignac dans l'espace lémovice (DAO : C. Maniquet, d'après Desbordes, 1995, p. 15). 
qui longeait les grands districts miniers du Limousin, et en particulier, au sud du sanctuaire, une zone d'extraction aurifère laténienne reconnue récemment par des fouilles archéologiques (Toledo i Mur, 2005). La présence de cette voie, en plus des éléments géologiques et topographiques favorables, pourrait avoir été l'une des raisons majeures pour l'implantation du site en ce lieu.

\section{LES FOSSÉS}

La première occupation sur le site est représentée par trois fossés successifs qui entourent un espace carré de près de 24 m de côté, sur lequel des structures ont été creusées (fig. 4 et 5). Ces fossés, aux parois verticales et au fond plat, ne se superposaient pas exactement. De dimensions réduites (moins de $0,90 \mathrm{~m}$ de large sur $0,80 \mathrm{~m}$ de profondeur au maximum), ils constituaient des tranchées de fondation pour l'installation de palissades.

Alors que le remplissage des fossés les plus anciens était composé essentiellement de sédiment naturel remanié, stérile en mobilier archéologique, celui du dernier fossé est apparu plus organique et plus riche en mobilier (céramique et ossements animaux très abîmés), en particulier dans certaines zones comme à l'approche de l'angle nord-est.

Les fossés quadrangulaires étaient cernés par une aire de circulation empierrée, repérée en divers points du site. Stratigraphiquement contemporaine des fossés, elle était matérialisée par une bande de près de $8 \mathrm{~m}$ de large de petites pierres d'éclogite usées en surface, ancrées à la surface du terrain naturel décapé.

\section{LA PALISSADE SUR POTEAUX}

Les fossés protohistoriques ont été ponctués, vraisemblablement avant l'époque augustéenne, d'une série de trous de poteau qui perçaient leur comblement. Ces creusements sont tous faits sur le même modèle. Ils mesurent entre $1 \mathrm{~m}$ et $1,30 \mathrm{~m}$ de diamètre et leur profondeur oscille autour de 0,80 m. Leur remplissage est systématiquement constitué d'une " couronne », qui couvre les parois de la structure, composée de la terre extraite du creusement. Ceci explique la présence de mobilier parfois plus ancien dans ce comblement. Au centre de chacune de ces structures, un sédiment généralement meuble, relativement aéré et parfois riche en fragments de tuiles, signale l'emplacement du poteau originel dont la base était calée latéralement par la «couronne ». Ces poteaux, de 0,50 m à 0,60 m de diamètre, avaient parfois été calés à la base par un amas de blocs de pierres. Il faut voir dans l'ensemble de ces trous de poteau la mise en place d'une imposante palissade reprenant le tracé des fossés antérieurs.

C'est peut-être au moment de l'installation de cette palissade qu'un petit bâtiment en bois, fondé sur quatre poteaux identiques aux précédents, a été édifié à proximité de la palissade, près de son angle sud-est. Après une première destruction par incendie, les quatre fosses ont été recreusées mais avec un décalage vers le sud. Ce type d'édifice, de plan carré, fondé sur quatre poteaux porteurs, est généralement associé à des greniers, souvent surélevés au-dessus du sol. Des bâtiments de cette sorte existent dans le sanctuaire de Mirebeau-sur-Bèze (Côte-d'Or), à la phase 3, associés à des dépôts de faune (Joly, Barral, 2007, p. 64).

La présence, à Tintignac, de peinture sur le torchis cuit par l'incendie permet plutôt d'interpréter la structure comme un bâtiment associé à l'enceinte cultuelle voisine. Ceci pourrait être confirmé par la présence, à l'intérieur, d'une fosse dont le comblement renfermait neuf monnaies et un coin monétaire. Il est impossible de préciser si ce dernier constitue une offrande ou s'il doit être mis en rapport avec une activité de frappe monétaire dans l'enceinte du site. D'autres fosses alentours, dont l'organisation n'a pas pu être déterminée, ont livré quelques fragments d'armes : des lames et des fourreaux d'épée en particulier.

\section{LE BÂTIMENT EN BOIS}

Les niveaux d'occupation précoces n'ont été dégagés que sur près de la moitié de l'espace cerné par les fossés. Creusées dans le paléosol brun argilo-limoneux, de nombreuses structures en creux, comblées d'un sédiment peu différenciable, percent cette couche et le substrat sousjacent. À peine certains remplissages se distinguaient-ils grâce à une concentration un peu plus importante en blocs de roche en décomposition et en nodules d'arène. Pour dégager ces structures, il a été nécessaire de décaper manuellement le paléosol brun qui couvrait le terrain naturel orangé. Leur densité et leur imbrication extrême ont rendu complexe la compréhension de l'organisation et de l'évolution de l'ensemble.

Les creusements protohistoriques se concentraient visiblement dans la partie centrale de la plate-forme, cependant légèrement décalés vers l'angle nord-ouest. Ceci est-il dû à la présence d'affleurements rocheux importants au cour de l'étendue cultuelle ? Les diverses fosses forment un cercle de près de $8,75 \mathrm{~m}$ de diamètre externe (fig. 6 et 7 ), avec une petite interruption à l'est pouvant marquer 


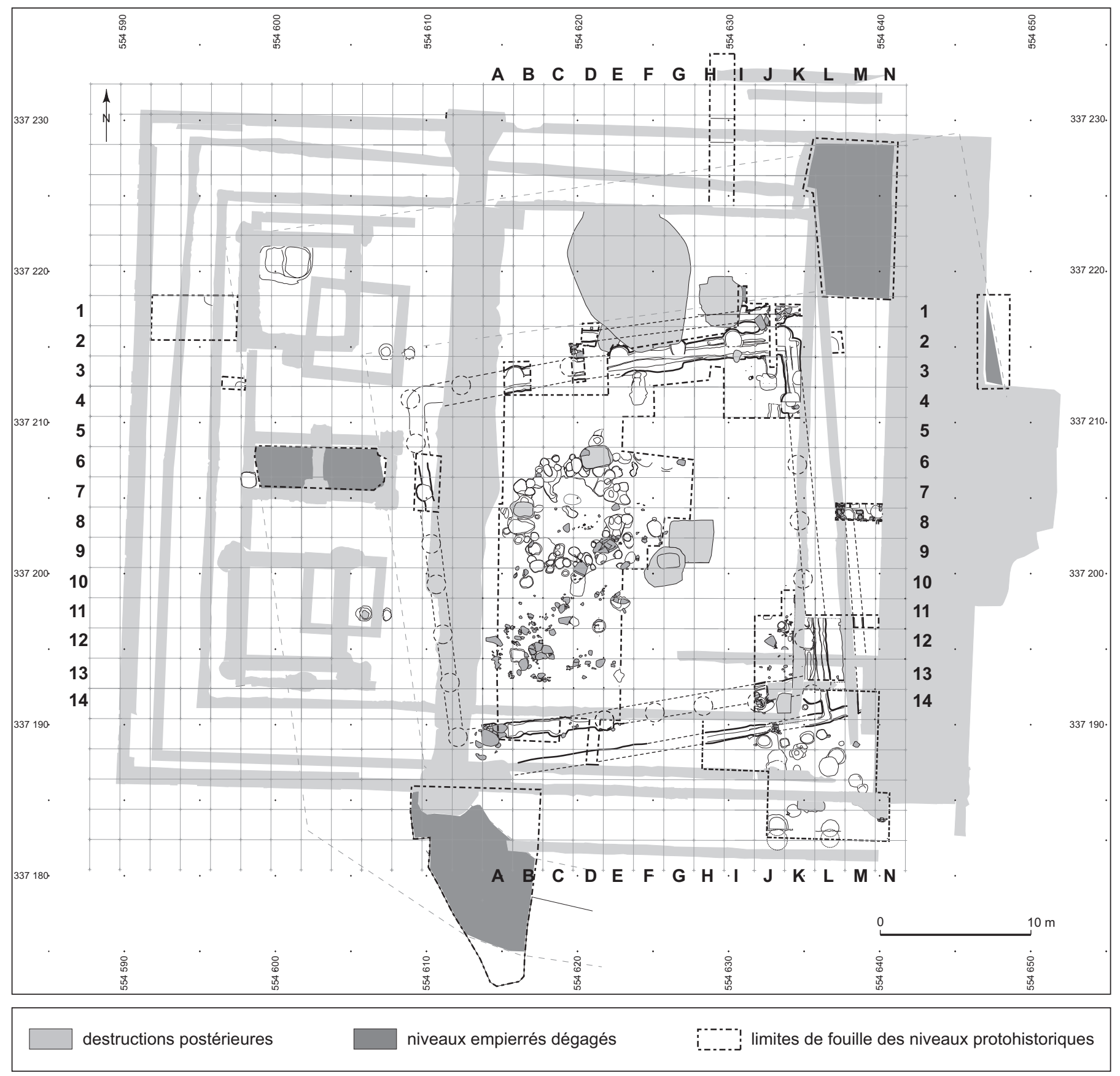

Fig. 4 - Plan des états protohistoriques du sanctuaire de Tintignac (relevé et DAO : J.-L. Courtadon, T. Lepaon, C. Maniquet).

une entrée. Seul un petit foyer occupait vraisemblablement l'espace intérieur. Nous avons pu constater la quasi-absence de creusements à proximité et à l'extérieur de ce cercle. La morphologie de la plupart des fosses correspond à celle de trous de poteau. En l'état actuel de la recherche, il semble que le bâtiment sur poteaux a subi deux ou trois reconstructions. Son plan pourrait avoir été circulaire à l'origine avant de devenir quadrangulaire dans sa phase ultime et être rapproché de celui de certains édifices d'Acy-Romance (Ardennes) (Lambot, 2002).

La datation de ces structures est fournie principalement par les monnaies éparses, jonchant le sol ou intégrées de façon anarchique dans le comblement des diverses structures. Aucune ne semblait avoir été délibérément déposée au 


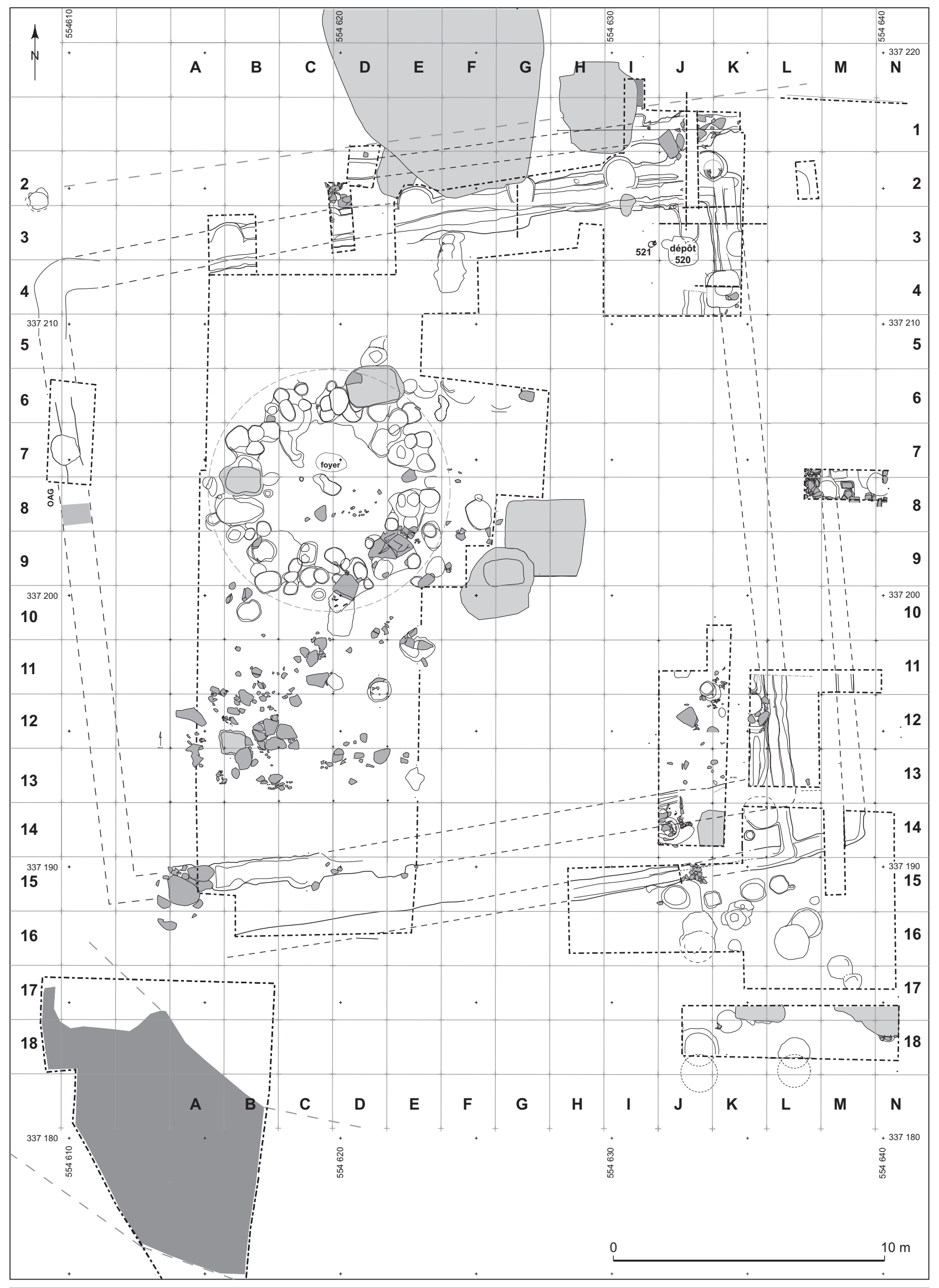

Fig. 5 - Plan du sanctuaire protohistorique de Tintignac (relevé et DAO :J.-L. Courtadon, T. Lepaon, C. Maniquet). 


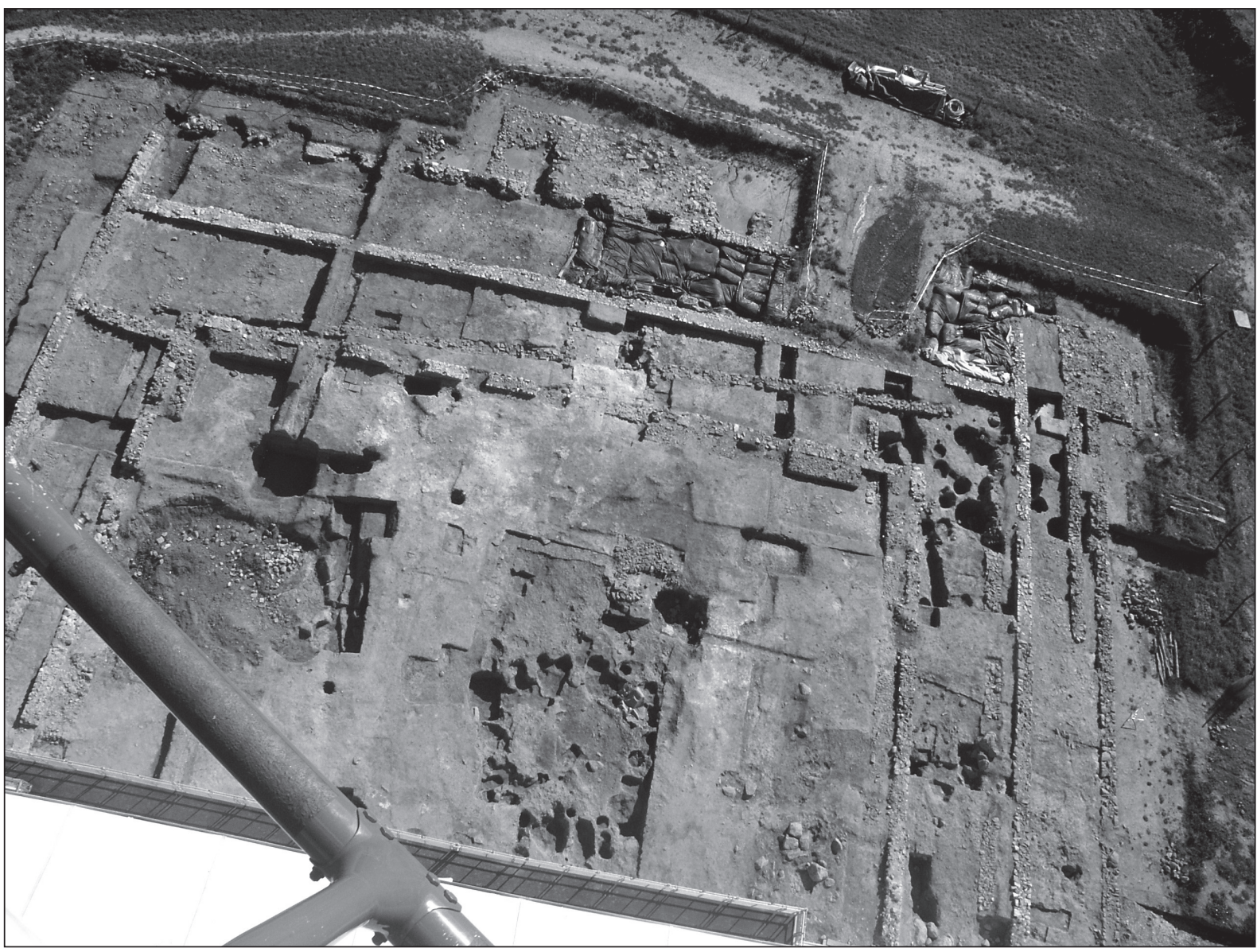

Fig. 6 - Vue aérienne de la partie orientale du temple. Les fosses protohistoriques de plan circulaire apparaissent au premier plan (cliché : C. Maniquet, INRAP).

fond des fosses. Dès lors, elles ne permettent pas de dater la construction, mais plutôt les divers réaménagements, voire l'abandon de l'édifice. Elles sont quasiment toutes mutilées à coup d'outils et doivent être considérées comme des offrandes. On notera cependant que les monnaies paraissaient plus concentrées à l'est, de part et d'autre de l'espace interprété comme l'entrée. De rares fragments de céramique modelée à gros dégraissant ou d'amphores accompagnaient ces monnaies. D'après l'étude céramique, cette occupation protohistorique s'intègre dans le $\mathrm{I}^{\mathrm{er}} \mathrm{s}$. av. J.-C. et semble être antérieure à la période augustéenne.

Ce type d'aménagement au sein d'enclos protohistoriques cultuels reste assez peu représenté dans le monde celtique. Cependant quelques exemples existent. En effet, plusieurs sanctuaires recevaient sur l'espace cultuel des bâtiments en bois. Seuls certains apparaissent distinctement de plan circulaire. On citera en particulier le sanctuaire de Hayling Island en Grande-Bretagne (King, Soffe, 1994) ou un bâtiment de plan hexagonal de la phase 3 du sanctuaire de Mirebeau-sur-Bèze (Joly, Barral, 2007, fig. 9, bât. 2, p. 64).

\section{LE DÉPÔT CULTUEL}

Dans l'angle nord-est de l'espace sacré, une petite fosse a été mise au jour près de la palissade. Elle a livré une quantité étonnante d'objets en fer ou en alliage cuivreux attribuables au second âge du Fer (fig. 8).

\section{LA FOSSE VOTIVE}

La fosse votive, peu profonde $(0,30 \mathrm{~m})$, s'ouvrait directement dans le niveau de paléosol et n'entamait le substrat sous-jacent que très superficiellement. De forme grossièrement carrée (de près de $1,10 \mathrm{~m}$ de côté), avec des angles arrondis, elle présentait, près de son angle nord-ouest, une 


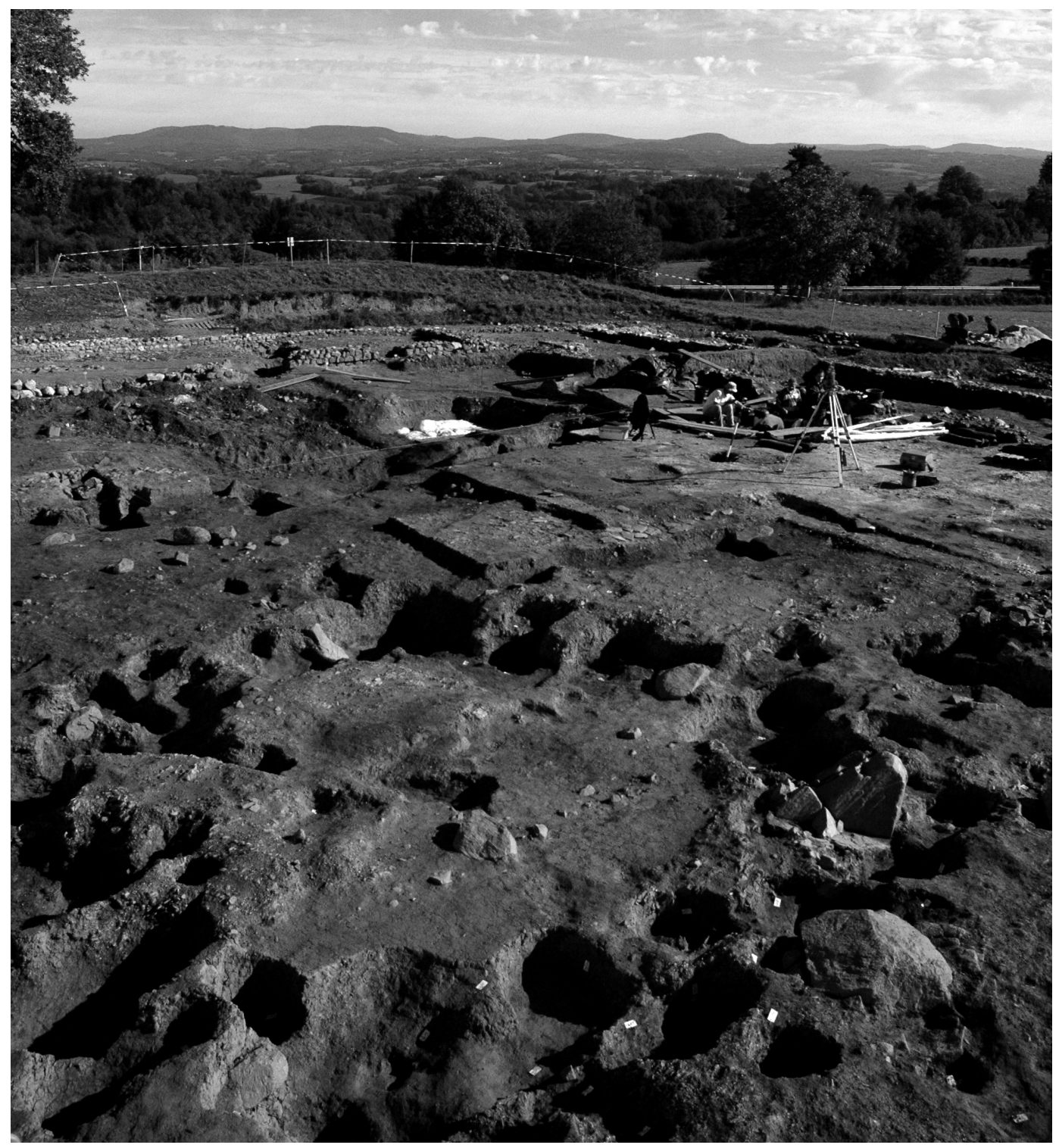

Fig. 7 - Les vestiges du temple en bois installé au cœur de l'espace délimité par les fossés protohistoriques. Au fond, le panorama s'ouvrant vers le nord-est sur le massif des Monédières (cliché : P. Ernaux, INRAP).

excroissance circulaire de $0,35 \mathrm{~m}$ de diamètre. Ses parois étaient verticales et son fond relativement plat.

Elle renfermait près de 500 fragments d'objets métalliques englobés dans un sédiment argilo-limoneux brun foncé à brun orangé contenant d'assez nombreux nodules d'arène, des blocs de roche en décomposition et quelques petits charbons de bois épars. Dans sa partie centrale, la matrice de ce remplissage devenait plutôt sablo-limoneuse, mais ceci paraît lié aux perturbations postérieures. La distinction des limites entre le remplissage de cette structure et le paléosol environnant s'est révélée plutôt délicate.

\section{LA STRATIGRAPHIE}

L'emplacement du dépôt dans l'espace et dans l'enceinte du sanctuaire protohistorique a été bien repéré, ainsi que sa position en stratigraphie.

Le terrain naturel se compose d'arène d'éclogite de couleur jaune à orange, tantôt limoneuse, tantôt très argileuse. On observe la présence d'affleurements rocheux importants composés de «boules " d'éclogite. Ces blocs sont en général ancrés ou noyés dans l'arène issue de la désagrégation de la roche superficielle. Ce socle géo- 


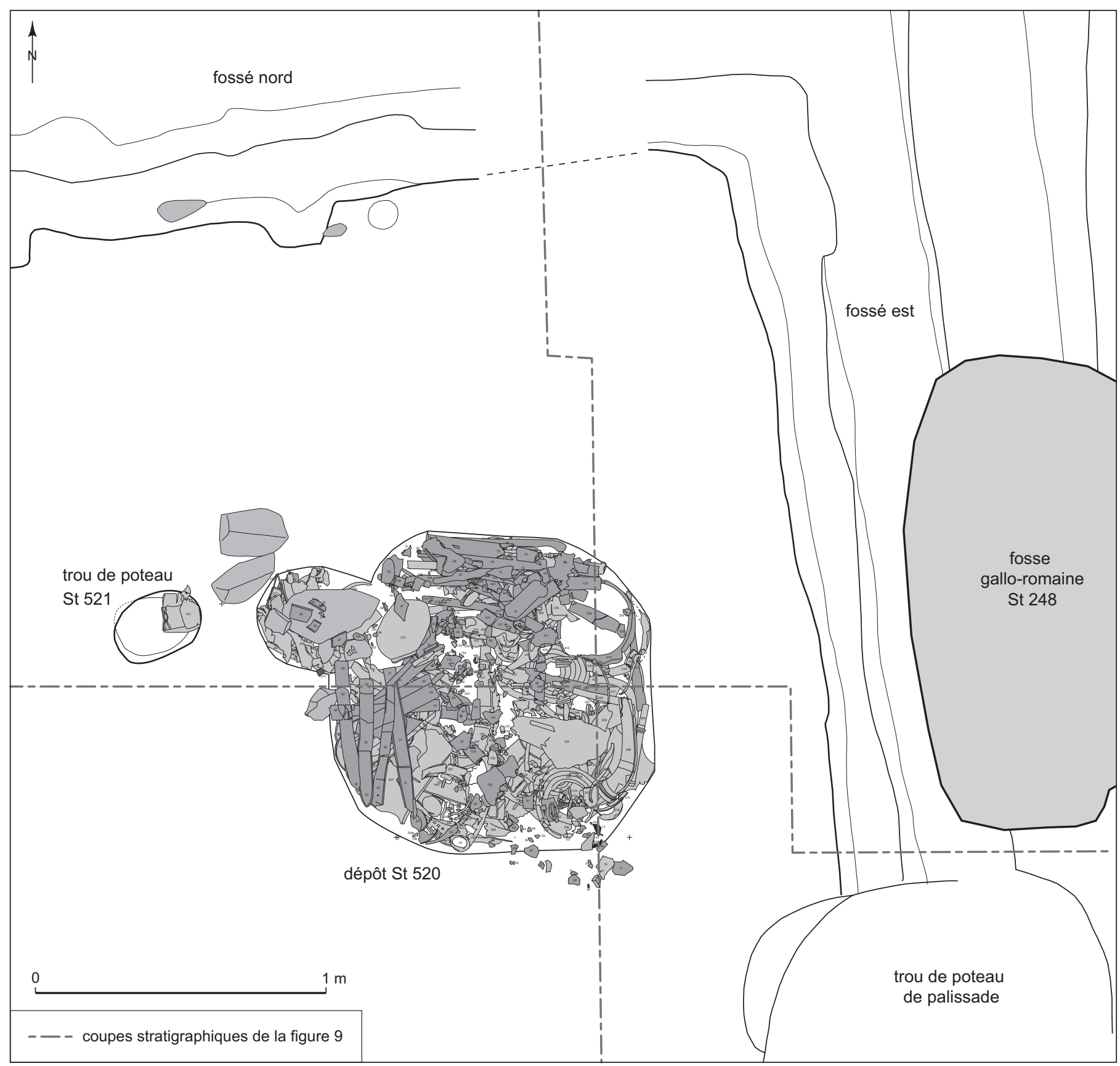

Fig. 8 - Plan du dépôt à l'angle nord-est de l'enclos protohistorique (relevé et DAO : T. Lepaon, B. Simonnot, E. Walthert, C. Maniquet).

logique est recouvert par une couche brune argilo-limoneuse à limono-argileuse, épaisse d'une dizaine à une vingtaine de centimètres, homogène et compacte, intégrant des nodules d'arène et des charbons de bois épars. Cette couche, stérile en mobilier archéologique, qui peut être interprétée comme un paléosol, résulte de la désagrégation de la roche alliée à la pénétration de matériaux organiques (vers, racines...). C'est dans cette couche que s'ouvrent les fosses et les fossés associés au sanctuaire gaulois.

La fosse du dépôt et son remplissage étaient scellés par un niveau brun foncé charbonneux. Or, au nord-est de la plate-forme du sanctuaire protohistorique, l'angle des fossés et le paléosol étaient également directement recouverts par cette même couche (fig. 9). Composée de 


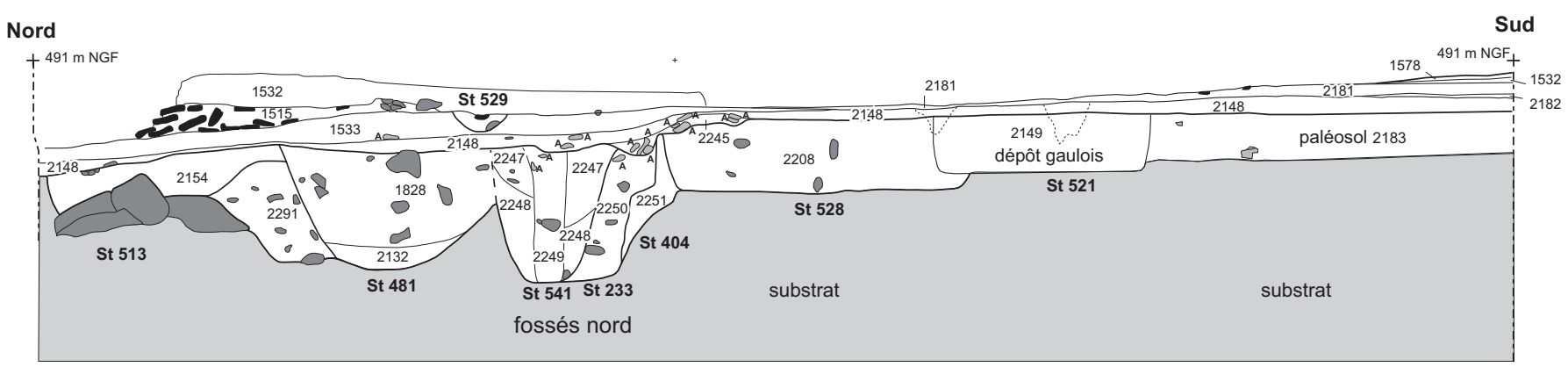

Fig. 9 - Coupes stratigraphiques du dépôt et des fossés successifs de l'enclos protohistorique (relevé et DAO : T. Lepaon, J. Maitre,

A. Maroote, C. Maniquet, B. Simonnot).

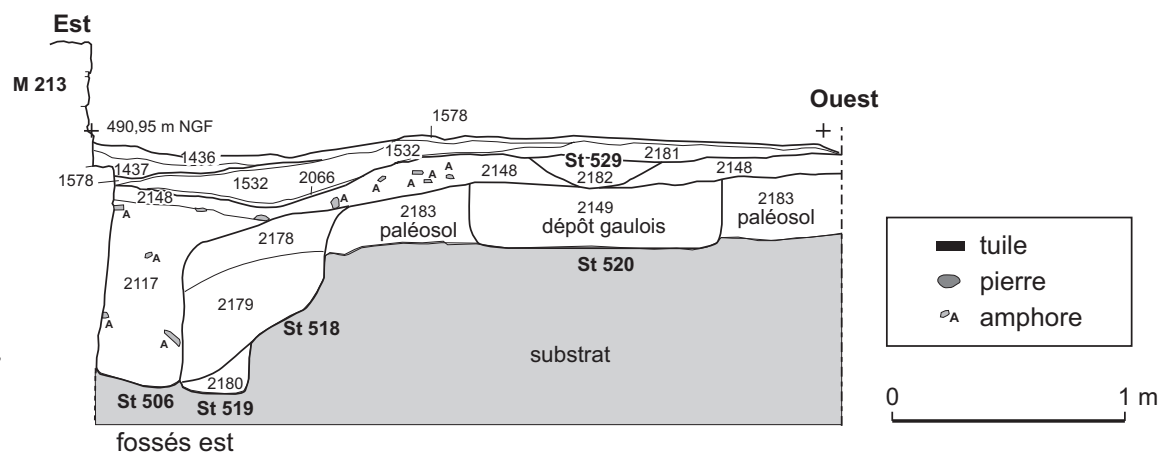

sédiment argilo-limoneux brun foncé riche en charbons de bois, elle contenait quelques blocs de roche en décomposition et recelait, par zones, des nodules de terre rubéfiée. Elle a livré en outre de nombreux tessons d'amphores et de céramique grossière, des objets métalliques en fer ou bronze et quelques ossements animaux. Parmi les éléments métalliques, on mentionnera la découverte de deux monnaies, l'une en argent (un quart de denier gaulois indéterminé), l'autre en or (un statère à la cigogne frappé entre 100 et 50 av. J.-C.), d'une pince de forgeron, de quelques fragments de fourreaux et de lames d'épée épars, d'un burin ou ciseau en fer, d'une fibule en bronze ${ }^{11}$ (fig. 10), de petites tôles de bronze découpées (fragments de crêtes de carnyx) et de petits éléments (barrettes et anneaux) ayant pu appartenir à une balance de précision. Ce niveau peut, grâce à un mobilier abondant, être daté entre 40 et 10 av. J.-C.

Il scelle tous les fossés d'enclos, ce qui indique que la dernière palissade avait déjà disparu. Il correspondrait dès lors à un niveau de destruction du sanctuaire protohisto-

11. Fibule à ressort à corde externe et quatre spires, arc de section circulaire arrondi ; le pied se recourbe et vient se fixer à mi-corps par une bague cannelée. La partie inférieure (porte ardillon) est manquante. Elle s'apparente au type $1 \mathrm{~b} 2$ défini par M. Feugère (Feugère, 1985, p. 185-188) qui est associé au I ${ }^{\text {er }}$ s. av. J.-C., mais certains contextes montrent une possible présence dès le $\mathrm{II}^{\mathrm{e}} \mathrm{s}$. (identification I. Bertrand).

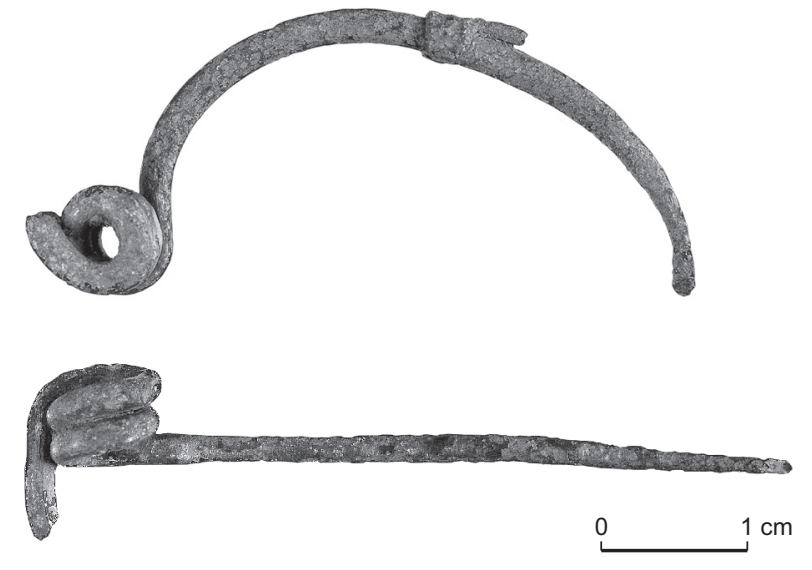

Fig. 10 - Fibule en bronze découverte dans la couche scellant le dépôt (cliché : P. Ernaux, INRAP).

rique. Ce dernier aurait été nivelé avant la reconstruction suivante datée du changement d'ère.

À l'ouest du dépôt, ce niveau recouvrait également un petit trou de poteau circulaire de $0,25 \mathrm{~m}$ de diamètre et profond de $0,38 \mathrm{~m}$, qui perçait le paléosol et le substrat sousjacent (fig. 11). Ce trou de poteau possédait des parois verticales et un fond plat, légèrement concave. Son remplissage, très riche en charbons de bois, a livré, sur le fond du creusement, un objet en alliage cuivreux (fig. 12). Cet élément est constitué d'une tôle enroulée sur elle-même dont les bords 


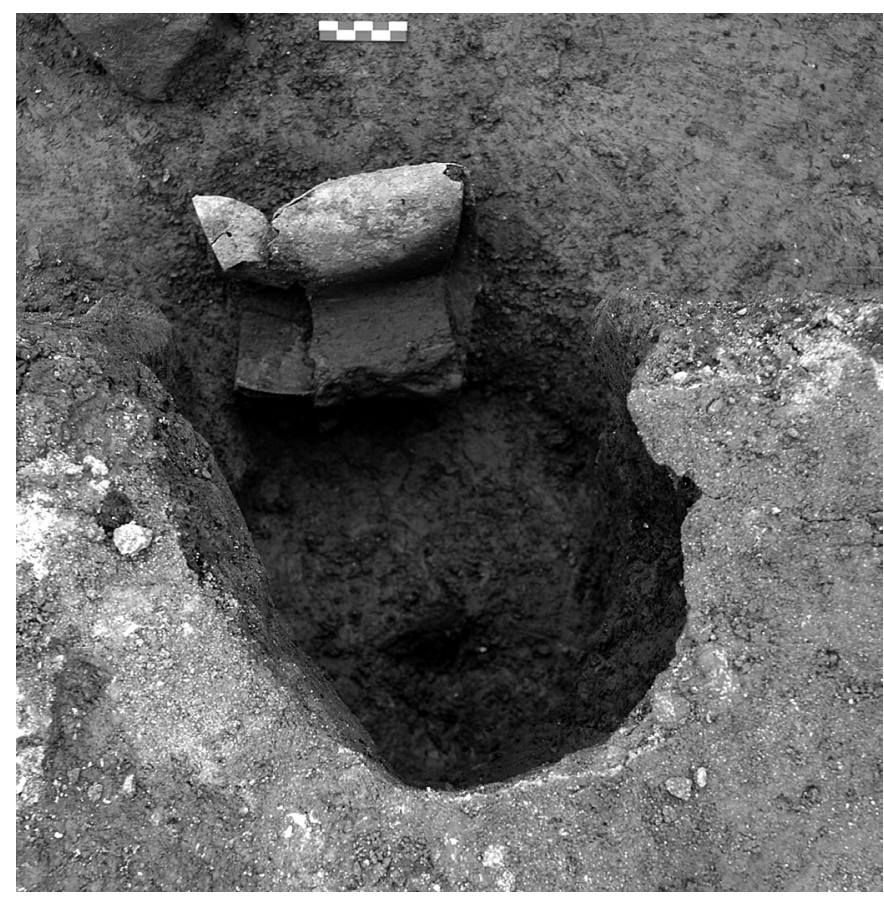

Fig. 11 - Le trou de poteau St 521 (cliché : P. Ernaux, INRAP).

ont été assemblés par une petite plaque (soudée intérieurement). Une sorte de résille décorée et ajourée semblait masquer cette jonction du côté externe.

Le niveau charbonneux qui nous concerne était recouvert par une couche de quelques centimètres d'épaisseur limoneuse, brune et très homogène qui incluait des microfragments de tuiles (fig. 9). Ce niveau, présent dans toute la partie septentrionale du temple gallo-romain, a été identifié jusqu'au mur-péribole à l'est et au nord. Il ne se développait cependant pas jusqu'au dépôt. Il a livré une monnaie en bronze, un quadrans de Tibère à l'autel de Lyon frappé entre 12 et 14 apr. J.-C.

Contemporaines de ce niveau limoneux, deux structures ont été mises au jour (fig. 13). La première, de forme oblongue, longue de $1,50 \mathrm{~m}$, large de $0,30 \mathrm{~m}$ et profonde d'une dizaine de centimètres, possédait des parois évasées et un fond en cuvette. La seconde structure, linéaire, présentait un tracé sinueux. Elle a été dégagée au-dessus du dépôt cultuel et de l'angle nord-est de l'enclos protohistorique. Elle s'apparente à un petit fossé peu profond au profil concave, orienté nord-sud, qui permettait sans doute de canaliser l'eau vers le sud de l'édifice cultuel gallo-romain. Dans la paroi est de ce petit canal, huit petits creusements ont été mis au jour. Six se présentaient comme de petites «perforations » de forme oblongue $(0,23 \mathrm{~m}$ à $0,35 \mathrm{~m}$ de long

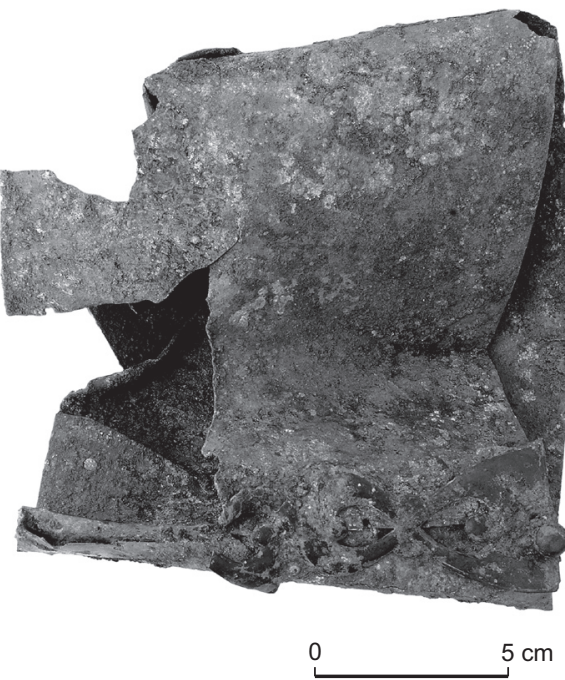

Fig. 12 - L'objet en alliage cuivreux extrait du trou de poteau St 521 (cliché : P. Ernaux, INRAP).

sur 0,04 m de large environ) dont deux pénétraient partiellement dans le remplissage du dépôt sous-jacent. En outre, ce dernier paraissait perturbé dans la partie centrale par un autre creusement peu profond dont les limites n'ont pas pu être définies clairement. Ceci explique l'absence d'objets de dimensions importantes dans cette zone, remplacés par de nombreux petits fragments inorganisés.

L'ensemble de ces creusements était comblé et scellé par un sédiment limoneux orange à base d'arène remaniée, préalablement à la mise en place d'un fin sol de calcaire s'affinant progressivement vers le nord jusqu'à disparaître au nord du dépôt. À cet endroit, un niveau de destruction associait sable grossier gris-blanc issu de la désagrégation de mortier, pierres et gros fragments de tuiles inorganisés (fig. 9). Ce niveau renfermait des tessons de céramique engobée blanc du I ${ }^{\mathrm{er}}$ s. apr. J.-C. Il semble qu'un " tas " ait été constitué à cet emplacement avec les matériaux de destruction d'une structure qui devait se trouver, à peu de distance, dans l'enceinte du sanctuaire. Ce « tas » sera étalé par la suite

\section{LES OBJETS DÉPOSÉS}

Nous ne proposons ici qu'une première approche des divers objets identifiés. De nombreux éléments inventoriés consistent en de petits fragments de tôle de fer ou de bronze indéterminés provenant d'objets plus importants, le plus souvent non reconnaissables. D'autres objets, en raison de leur déformation parfois importante ou de leur rareté, n'ont pas trouvé d'interprétation satisfaisante. Nous présentons ici 


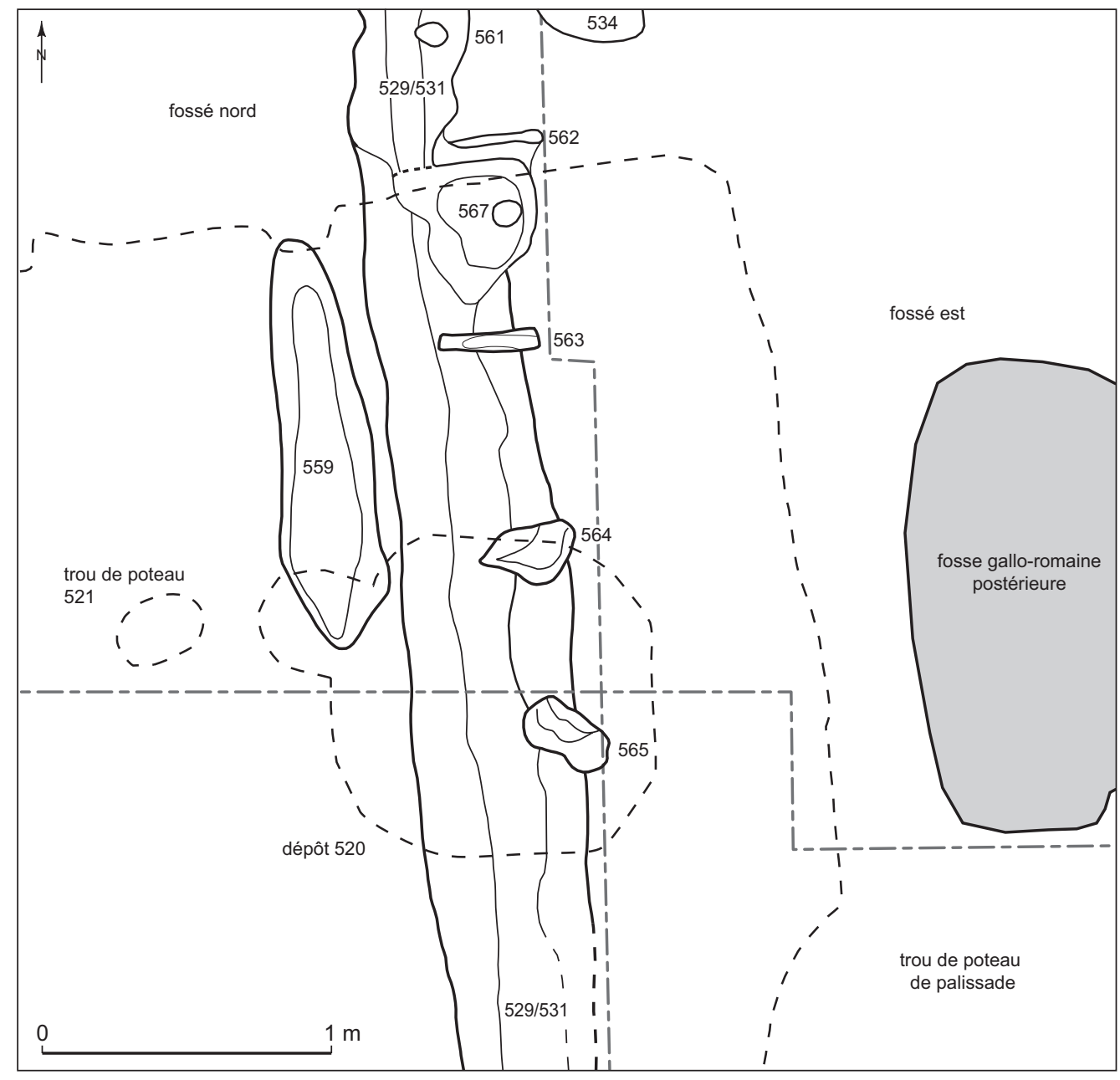

Fig. 13 - Plan des structures du début de notre ère, au-dessus du dépôt gaulois (relevé et DAO : B. Simonnot, T. Lepaon, C. Maniquet).

surtout les objets bien identifiés, comme les lames et fourreaux d'épée, les casques, les fragments de corps d'animaux, les pièces de harnachement et les instruments de musique.

Parmi les 492 pièces répertoriées, 148 ont été interprétées comme des fragments plus ou moins importants de fourreaux d'épée en fer, 42 comme des morceaux de lames d'épée et 17 autres en tant que fragments indéterminés de lames ou de fourreaux. S'y ajoutent, en ce qui concerne les armes, 11 fragments de fers de lance, dont quelquesuns entiers, 1 umbo de bouclier et 33 fragments de casques appartenant à 10 exemplaires mutilés mais entiers. Parmi les objets de bronze, 22 éléments sont des fragments plus ou moins importants de trompettes de guerre celtiques dénommées carnyx, 4 se sont révélés être des têtes d'animaux (entières) en bronze coulé ou martelé ; 4 tôles proviennent de corps d'animaux et 6 de pattes. On peut ajouter à l'ensemble 1 chaudron complet, 2 mors de chevaux, 7 disques de bronze à la surface " ondulée ». Ce sont donc au total près de 300 éléments qui ont été a priori identifiés.

\section{LA DISPOSITION DES OBJETS}

L'observation précise de la position des objets révèle une volonté évidente de les ranger consciencieusement dans l'espace exigu que constitue la fosse, selon un ordre précis qui répond probablement à des exigences d'ordre rituel. Certains tubes de carnyx ont été volontairement enfilés dans les têtes creuses d'animaux ou bien encore à l'intérieur de certains casques. L'un de ces casques, après mutilation, paraît avoir été placé volontairement sous le pavillon d'un carnyx. Enfin, à la surface de la structure, les lames et fourreaux d'épée ont été disposés en faisceaux. 


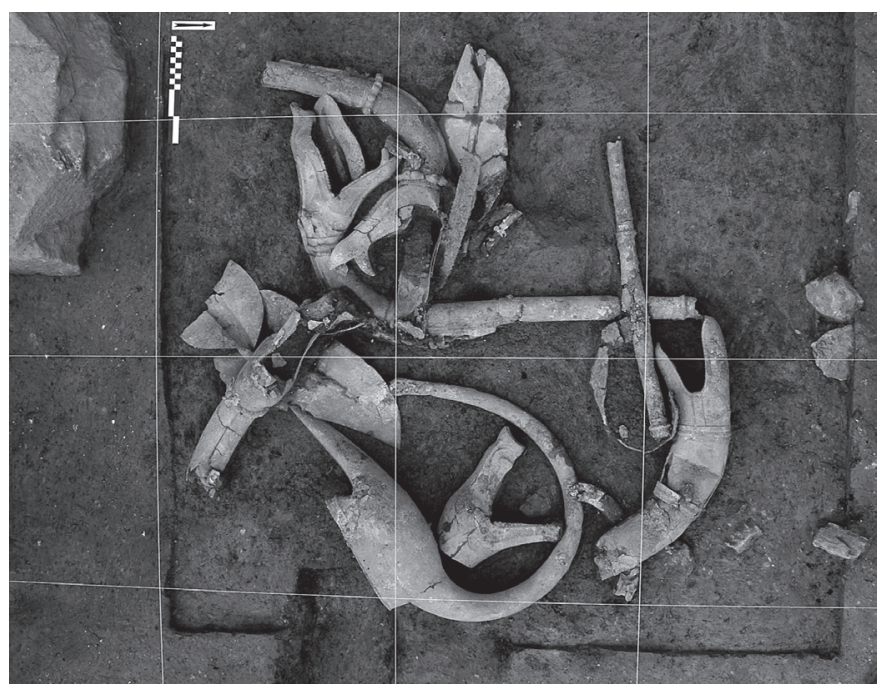

1

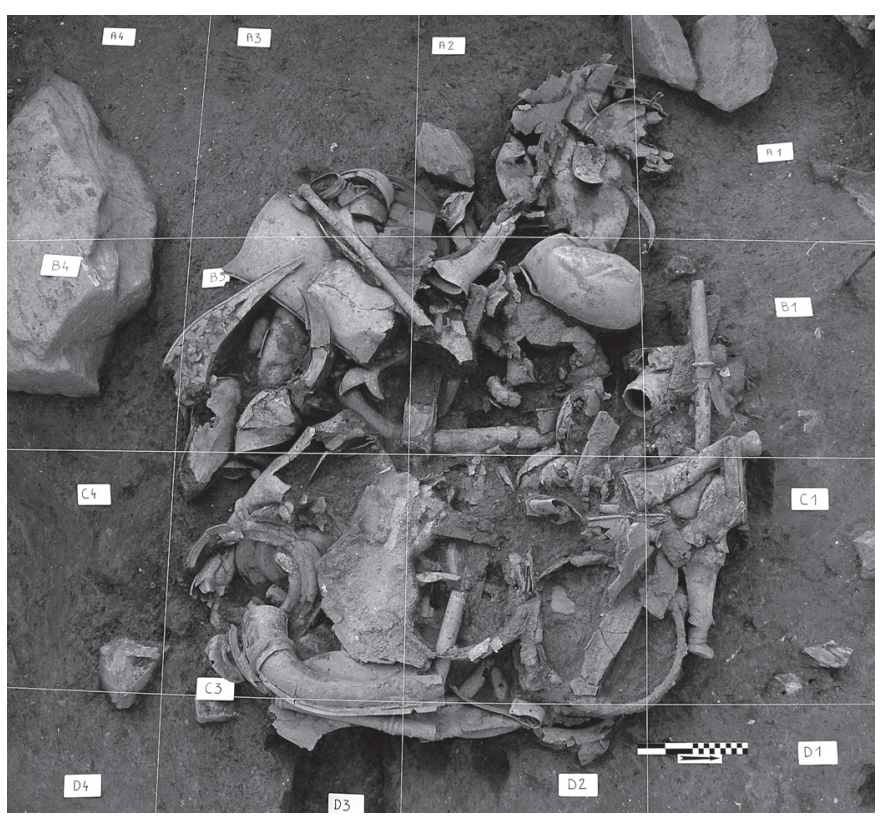

3

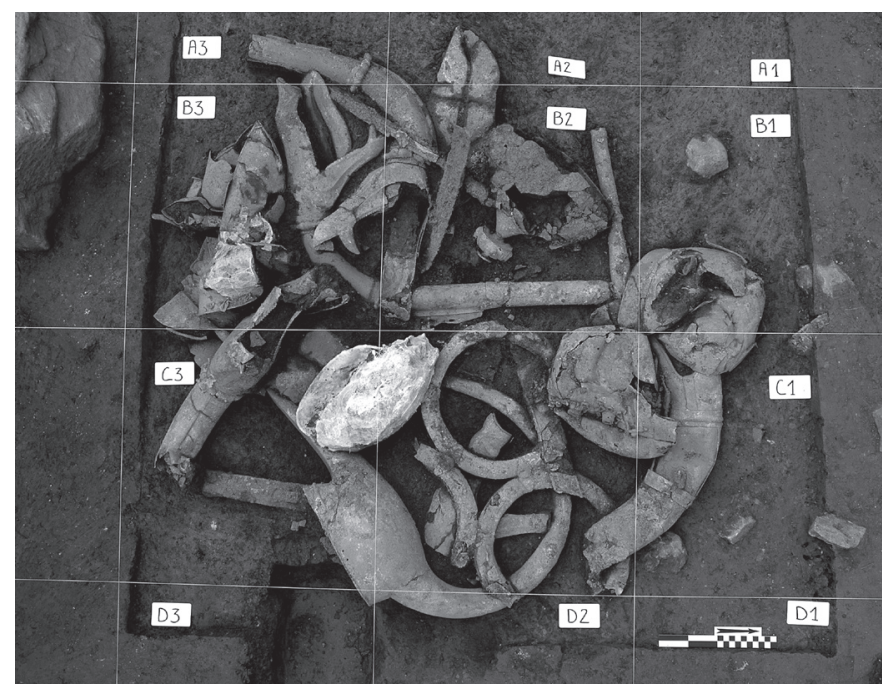

2

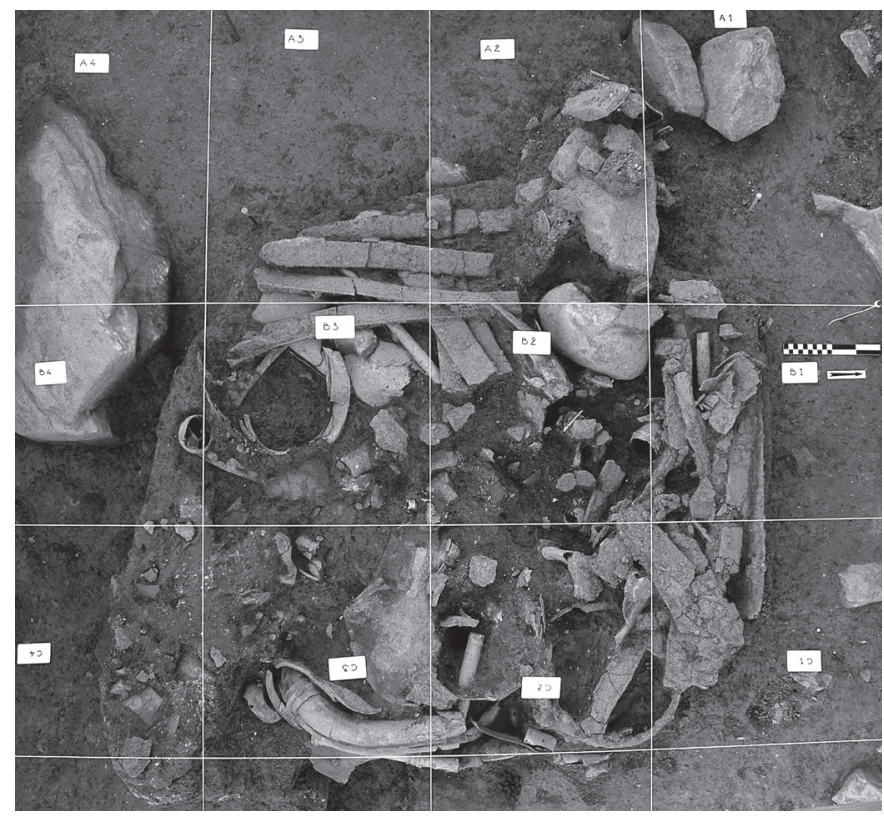

4

Fig. 14 - Les quatre niveaux du dépôt gaulois : 1, carnyx dans le premier niveau ; 2, carnyx et casques dans le deuxième niveau ; 3, chaudron et portions d'animaux en tôle de bronze démontés dans le troisième niveau; 4, dépôt de lames et fourreaux d'épée dans le quatrième et dernier niveau (clichés : P. Ernaux, INRAP).

Le relevé de chaque objet sur le terrain avant prélèvement permet désormais de saisir l'ordre dans lequel les divers éléments ont été déposés et de déterminer quatre étapes principales :

- sur le fond plat de la structure reposait un casque en bronze en forme de cygne et la plupart des fragments de carnyx (fig. 14, $\mathrm{n}^{\mathrm{o}} 1$ ). Les neuf autres casques ont alors été déposés accompagnés de quelques fragments de carnyx et des mors de chevaux (fig. 14, $\mathrm{n}^{\mathrm{o}}$ 2). Ils ont ensuite été recouverts par des fragments d'animaux en tôles de bronze, démontés ;

- c'est dans une autre étape, sans doute immédiatement postérieure, que les sept disques de tôle ondulée ont été déposés, en général par deux, avec des débris de carnyx et de casques et les têtes de sanglier en bronze moulé. Peu après, le dépôt du chaudron dans l'angle nord-est du creusement a été suivi par celui de quelques fragments de lames et de carnyx, et 
de l'umbo de bouclier (fig. 14, no 3). Les tôles appartenant à un autre animal démonté (corps et patte) ont été mises à plat ;

- dans un quatrième temps, après l'apport de nouveaux débris de fer et de bronze, les grands fragments de fourreaux et d'épées ont été placés à plat, sous la forme de trois faisceaux distincts, contre les parois nord et ouest de la structure (fig. 14, no 4).

Le colmatage des derniers objets après leur dépôt a été assez rapide, empêchant leur déplacement après leur enfouissement. En effet, ces derniers ne se sont pas détériorés en espace vide, ce qui se serait inévitablement produit s'ils avaient été placés dans une caisse en bois ou si un couvercle avait recouvert la fosse. Seules quelques lames d'épée semblent avoir glissé en bord de fosse, le long des parois. La présence de matière organique (cuir, bois) en abondance dans la structure, aurait nécessairement entraîné un tassement, même léger, au-dessus du dépôt. Or, les sols postérieurs du début de la période gallo-romaine étaient restés bien plans, sans déformations. Ainsi, aucune trace de coffrage en bois n'a été décelée, ce qui n'exclut cependant nullement l'hypothèse de l'existence d'un contenant.

\section{LES ARMES OFFENSIVES}

\section{LES ÉPÉES ET LES FOURREAUX}

La plupart des lames et fourreaux d'épée reposaient à plat, dans la partie supérieure de la fosse, sous forme de faisceaux (fig. 15, $\mathrm{n}^{\circ} 1$ ). D'autres lames et fers de lance ont été délibérément insérés en biais entre les objets déjà rangés dans la fosse, comblant ainsi les interstices subsistant entre ceux-ci. Au total, 42 fragments proviennent de lames d'épées brisées et 148 sont issus de fourreaux d'épée en fer. Cette fragmentation différentielle est probablement due au fait que les fourreaux, constitués de deux tôles fines serties entre elles, sont plus fragiles.

\section{Les lames}

Huit fragments de lames d'épée dépassent $250 \mathrm{~mm}$ de long ; la plupart ont été déposés dans la partie supérieure de la fosse. Certains d'entre eux atteignent une longueur de $450 \mathrm{~mm}$ et un seul de $610 \mathrm{~mm}$. Ce dernier est le seul élément associant la lame (conservée sur $450 \mathrm{~mm}$ ) avec la soie attenante (longue de $160 \mathrm{~mm}$ ) (fig. 15, $\mathrm{n}^{\circ}$ 2). La poignée, disparue, était en bois. Huit autres éléments pourraient être interprétés comme des soies d'épée mais la corrosion empêche toute certitude en l'état. Deux d'entre eux conser- vent sur leur surface des traces ligneuses, témoins de fusées en bois. L'un des fragments de lame présente encore un départ de soie et un autre correspond à la partie de l'épée située à la jonction de la soie et du départ de la lame. Seules cinq extrémités distales d'épées ont été, pour le moment, identifiées dans l'ensemble du dépôt. Un élément, long de $340 \mathrm{~mm}$, semble encore comporter la lame dans son fourreau. Toutes ces épées possèdent une lame large de $45 \mathrm{~mm}$ à $55 \mathrm{~mm}$, sans pointe, mais dotée d'un bout arrondi. C'est un indice chronologique qui permet une datation de La Tène C ou D (Brunaux, Lambot, 1987, p. 87).

Une première tentative de remontage des divers fragments de lames d'épée s'est soldée par un échec. Presque aucun recollage n'a pu être fait en dehors des cassures déjà repérées sur le terrain. Une seule épée s'est révélée complète (fig. 16, $\left.n^{\circ} 1\right)$. Sur le terrain, elle était appuyée contre la paroi orientale de la structure et paraissait avoir été déposée avant le chaudron, à moins qu'elle n'ait glissé par la suite. Cette épée est très différente des autres : sa longueur totale atteint seulement $544 \mathrm{~mm}$, sa lame paraît moins épaisse et sa largeur varie de $50 \mathrm{~mm}$, près de la garde, à $35 \mathrm{~mm}$, à l'extrémité. Elle est dotée d'une poignée en alliage cuivreux, longue de près de $110 \mathrm{~mm}$. Cette garniture en bronze, bivalve et creuse, était sans doute appliquée sur une âme de bois. Une première radiographie indique la présence d'un décor matérialisé par trois gorges peu profondes réparties sur la longueur de la fusée. L'extrémité de la soie dépasse côté pommeau (fig. 16, $\mathrm{n}^{\mathrm{O}} 2$ ). L'élément (en bois ?) qui recouvrait cette extrémité a disparu.

\section{Les fourreaux}

Au moins 148 fragments de fer découverts dans le dépôt proviennent de fourreaux brisés. Ils sont pour la plupart de petites dimensions et dix d'entre eux dépassent $250 \mathrm{~mm}$ de long. La longueur des fragments les plus importants varie de $290 \mathrm{~mm}$ à $605 \mathrm{~mm}$, leur largeur moyenne étant de $50 \mathrm{~mm}$. Ils sont composés de deux tôles fines de fer assemblées par rabat des bords de l'une des plaques. Les tôles d'avers et de revers ont généralement été retrouvées solidaires dans le dépôt. Ces fourreaux ne paraissent pas présenter de nervure médiane, mais leur pourtour, en dehors de l'entrée, présente une gouttière latérale bien visible malgré la corrosion.

La majorité de ces fourreaux ont été mis au jour à la surface du dépôt, mais certains se trouvaient à mi-hauteur et quelques autres reposaient sur le fond de la structure. Ainsi, un fragment se trouvait-il sous le casque en forme de cygne qui, comme on le verra, est pourtant l'un des premiers objets déposés. 


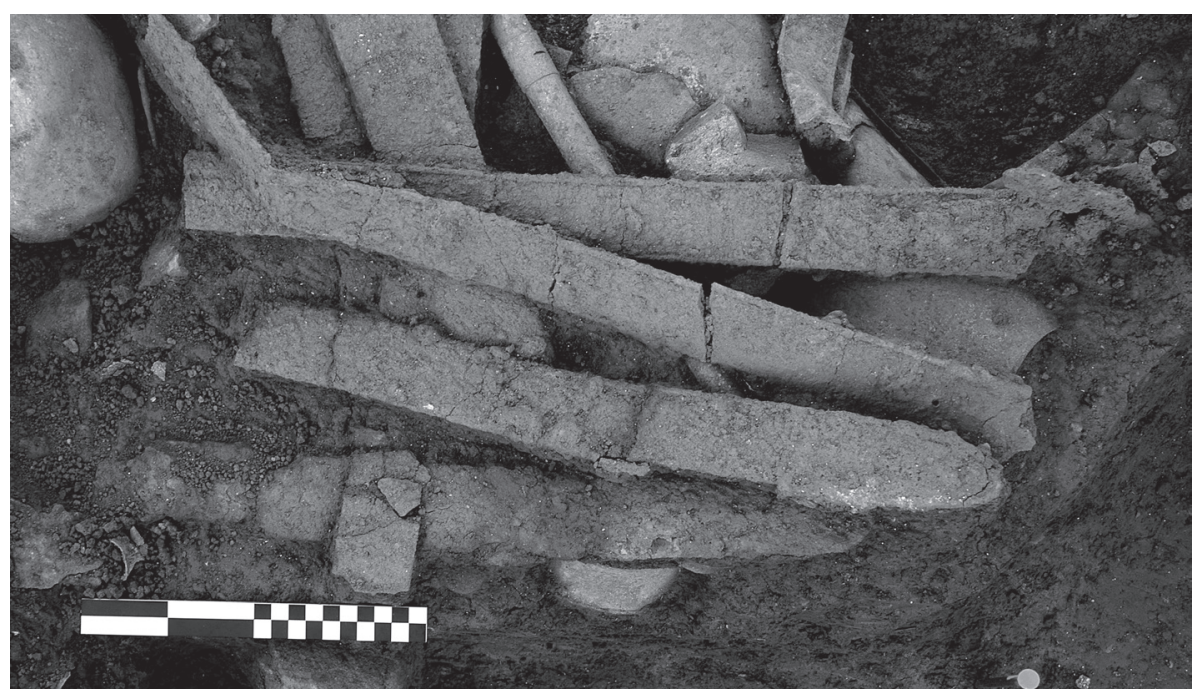

1

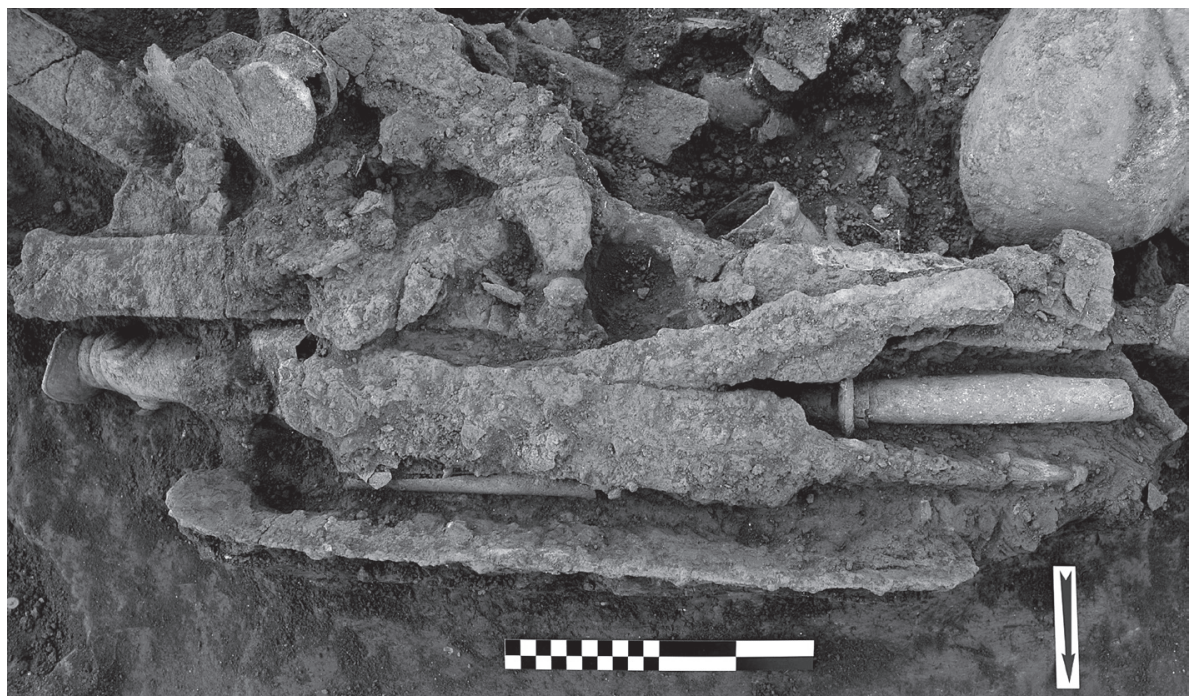

2

Fig. 15 - 1, faisceau de demi-lames et fourreaux disposés contre la paroi occidentale de la fosse; 2, lames, fourreaux et fers de lance disposés en bordure nord de la fosse (clichés : P. Ernaux, INRAP).

En l'état actuel des observations, six extrémités de fourreaux ont été identifiées, dotées ou non de bouterolles. Un élément en particulier présente une bouterolle longue à bords parallèles sans ajours (fig. 17).

Neuf fragments conservent les entrées de fourreaux, campaniformes plus ou moins prononcées, ou bien quasiment triangulaires. Six possèdent encore leur pontet (fig. 18, $\mathrm{n}^{\mathrm{o}} 1$ ). Cet élément qui assurait la liaison avec le ceinturon, placé sous l'entrée, sur la face postérieure, a disparu sur les trois autres (fig. 18, $\mathrm{n}^{\circ}$ 2). Il se compose d'un passant saillant doté de deux attaches rectangulaires, probablement rivetées. Le trou de l'un de ces rivets a été observé sur l'un des fragments. Sur un autre, le pontet mesure $60 \mathrm{~mm}$ de long et $20 \mathrm{~mm}$ de large. Deux autres éléments enfin conservent ce pontet, mais l'entrée du fourreau est brisée. Enfin, certains fourreaux, malgré leur importante corrosion, laissent apparaître des frettes de renforts. D'autres frettes seront sans aucun doute observées lors du nettoyage ultérieur.

Des éléments en bronze pourraient avoir appartenu à un fourreau de bois doté d'une entrée en bronze et de bandes de bronze ayant servi de décoration ou de renfort. L'entrée, de forme triangulaire, conserve à l'intérieur de la 

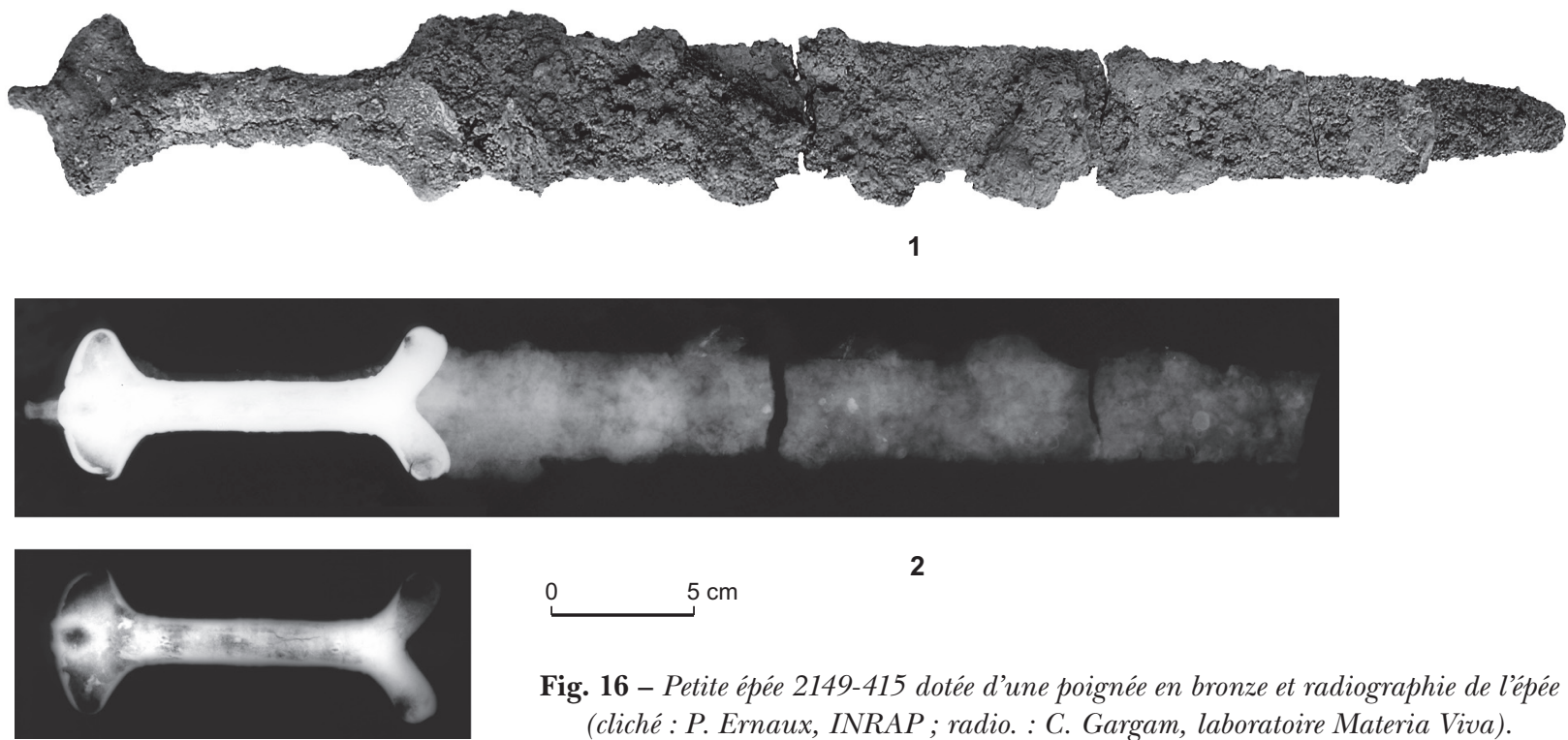

0 $5 \mathrm{~cm}$

2

Fig. 16 - Petite épée 2149-415 dotée d'une poignée en bronze et radiographie de l'épée (cliché : P. Ernaux, INRAP ; radio. : C. Gargam, laboratoire Materia Viva).

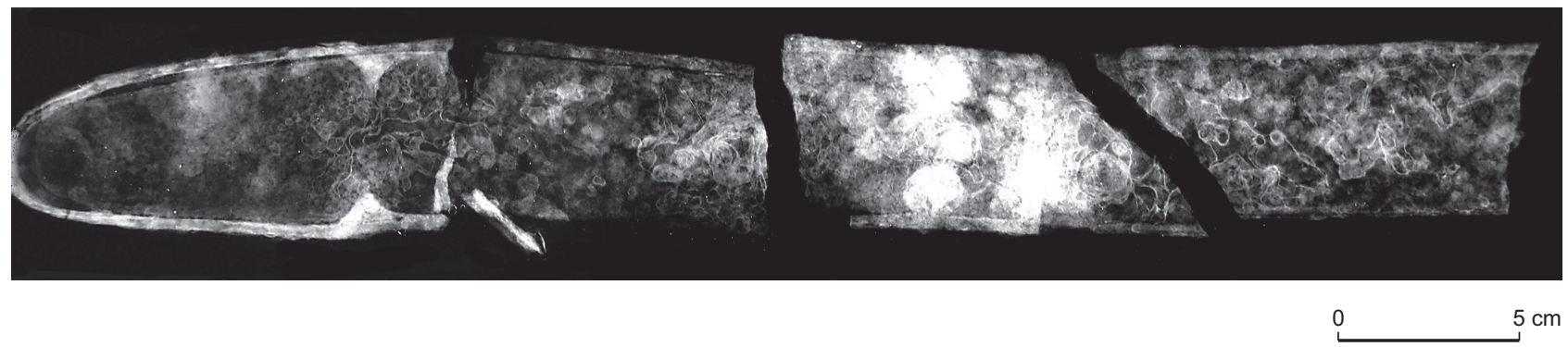

Fig. 17 - Radiographie du fourreau 2149-22 muni de sa bouterolle (radio. : C. Gargam, laboratoire Materia Viva).

tôle repliée des vestiges de bois (fig. 18, no 3). Cet élément a pu fonctionner avec deux pièces de bronze, également constituées d'une tôle repliée dotée de gouttières latérales (fig. 19). Cependant, l'interprétation de ces éléments mérite un examen complémentaire car l'un d'entre eux insère une fine tôle de fer et semble fermé à une extrémité par une série de rivets. Les deux éléments sont percés d'un trou sur une face et enferment des traces de bois. Il serait tentant de voir là les parties d'un fourreau de bois et de bronze fonctionnant avec l'épée courte à poignée de bronze. Cette interprétation reste cependant à vérifier. Le fourreau se trouvait à l'ouest du chaudron et l'épée à l'est.

Aucun élément de la suspension des épées n'a été mis au jour. L'absence de chaîne pourrait être due à la position chronologique basse de l'ensemble, à une époque où le système de suspension métallique avait disparu. Mais l'absence d'anneaux et de crochets, encore utilisés après La Tène $\mathrm{C}$, et jusqu'à la conquête romaine, indique plutôt que les épées et leur fourreau ont été déposés sans la ceinture et le système de suspension.

Le premier décompte des différents fragments de lames et de fourreaux d'épée suggère la présence dans la fosse de 9 épées (d'après le nombre de soies) et d'autant de fourreaux (nombre d'entrées). On s'aperçoit cependant que le nombre de bouterolles ( 5 en tout) et d'extrémités d'épées (6 au total) est insuffisant. Ces chiffres correspondent à un nombre minimum d'individu et rien n'indique par exemple que les bouterolles mises au jour aient appartenu aux mêmes fourreaux que les entrées.

Lames et fourreaux semblent, pour la plupart, avoir été brisés en deux avant d'être déposés à la surface de la fosse sous la forme de trois faisceaux distincts. Ce bris résulte très 


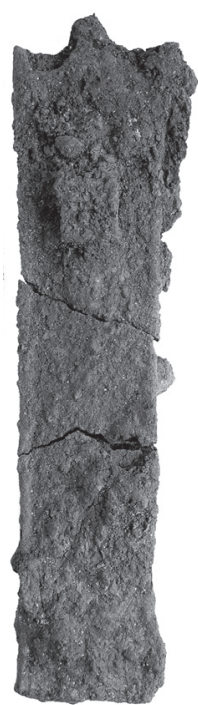

1

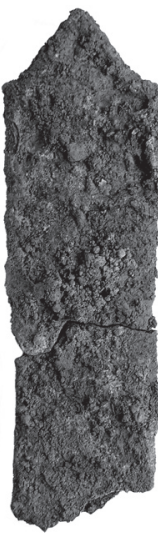

2

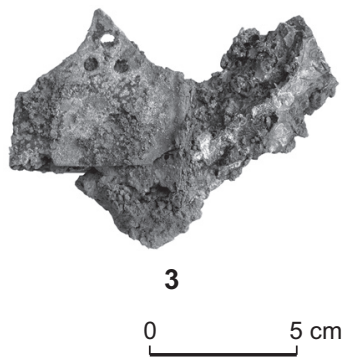

Fig. 18 - Fourreaux : 1, fragment de fourreau 2149-452 conservant son entrée et de son pontet; 2, entrée de fourreau 2149-371; 3, entrée de fourreau (?) triangulaire en bronze 2149-192, collée par la corrosion à un fragment de fer de lance (clichés : P. Ernaux, INRAP).

probablement d'une mutilation volontaire, comme cela est courant sur les armes déposées dans les espaces cultuels ou funéraires.

D'autres traces évidentes de mutilations ont pu être observées sur deux fragments de lames dont les tranchants sont ponctués d'entailles. Ce type de détérioration délibérée a également été observé à Gournay-sur-Aronde (Oise) (Brunaux, 1991b, p. 364). À Tintignac, peu d'éléments paraissent intentionnellement ployés. Un seul fourreau était enroulé sur lui-même ; il accompagnait les fragments de carnyx sur le fond de la fosse.

\section{Éléments de chronologie}

En ce qui concerne la datation de ces épées, on peut d'ores et déjà avancer quelques hypothèses. L'une des bouterolles s'apparente aux exemplaires du groupe 7 de Gournay-sur-Aronde, le plus récent, qui est attribué à la transition La Tène C/La Tène D (Lejars, 1994, p. 38). D'après T. Lejars ${ }^{12}$, la longueur de ces armes à Gournaysur-Aronde, varie entre $810 \mathrm{~mm}$ et $850 \mathrm{~mm}$ et atteint même, dans un cas, $923 \mathrm{~mm}$. Selon lui, le seul décor observé sur

12. Que je remercie ici.

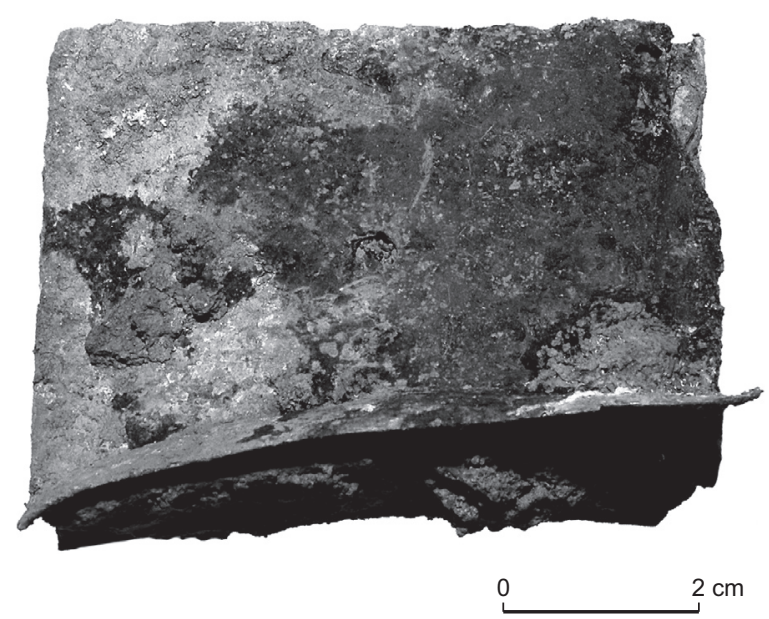

Fig. 19 - Élément décoratif en bronze 2149-342 de fourreau en bois ? (cliché : P. Ernaux, INRAP).

ce type de fourreau apparaît sur l'avers, au niveau de la barrette de renfort, sous la forme de deux esses horizontales et, plus rarement, ces éléments sont combinés avec un triscèle gravé. Sur les fragments de fourreaux de Tintignac, la forte corrosion empêche d'observer les détails de cet éventuel décor.

\section{LES FERS DE LANCE}

Onze éléments ont été interprétés comme des fragments de fers de lance. Ils ont pour la plupart été déposés en même temps que les lames et fourreaux d'épée, à la surface de la fosse. Trois d'entre eux sont complets, conservant leur douille et leur pointe (fig. 20) ; d'autres ont leur pointe brisée. Plusieurs douilles ont été identifiées. Curieusement, on constate que le nombre minimum de fers de lance s'élève à huit, proche du nombre de lames et fourreaux d'épée.

On a pu pour le moment identifier deux types de fers de lance, différenciables par leur longueur. Le premier groupe, représenté par quatre individus, atteint $150 \mathrm{~mm}$ à $220 \mathrm{~mm}$ et possède vraisemblablement un empennage convexe à carène moyenne. Le second groupe, associant deux individus de $350 \mathrm{~mm}$ et $470 \mathrm{~mm}$ de longueur, était doté d'un empennage biconvexe à pointe trapue et d'une nervure médiane plus importante. Aucun élément issu du dépôt n'a pu être interprété comme un talon de lance.

Il est difficile de savoir si ces fers de lance ont subi des mutilations. Un seul avait l'extrémité de la pointe légèrement tordue. Là encore, il est impossible de déterminer si cette torsion résulte d'un bris rituel ou même si ces fers de 


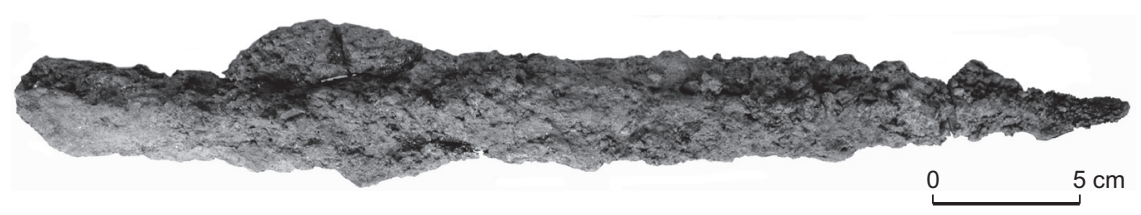

Fig. 20 - Fer de lance 2149-67 (cliché : P. Ernaux, INRAP).

lance ont été déposés seuls ou bien avec une partie de leur hampe. Le cas échéant, cette dernière a nécessairement dû être brisée pour être logée dans la fosse.

\section{Éléments de chronologie}

Les fers de lance demeurent difficiles à dater. Ils ressemblent cependant pour certains aux fers les plus tardifs de Gournay-sur-Aronde, datés au plus tôt de la première moitié du II ${ }^{\mathrm{e}}$ s. : La Tène C2 (Brunaux, Rapin, 1988).

\section{LES ARMES DÉFENSIVES}

\section{LE BOUCLIER}

Un seul umbo de bouclier en fer a été mis au jour dans le dépôt, à mi-hauteur, sous les faisceaux d'épées et de fourreaux placés en bordure occidentale de la structure (fig. 21). Il reposait, légèrement incliné vers l'ouest, sur un disque de bronze. Long de $250 \mathrm{~mm}$ et large de $115 \mathrm{~mm}$, il possède deux ailettes rectangulaires longues de $75 \mathrm{~mm}$ percées chacune de deux petits trous circulaires. La coque, convexe et lisse, sans nervure, mesure quant à elle près de 110 mm de côté. Là encore, étant donné les dimensions réduites de la fosse, ce bouclier n'a probablement pas été déposé entier. Sans doute a-t-il été démonté au préalable. Ceci est confirmé par le fait que les clous maintenant l'umbo à l'origine n'ont pas été retrouvés ; ils ont donc été vraisemblablement retirés avant son dépôt. On signalera qu'aucun élément issu de cette fosse n'a été identifié comme un renfort métallique de manipule. Ce dernier, peut-être en bois, a pu ne pas laisser de trace.

D’autres éléments découverts dans le dépôt sont susceptibles d'appartenir à ce bouclier. Il s'agit de fragments de bandes de tôle de bronze repliées en U qui ont pu servir d'orle.

L'umbo mis au jour a visiblement reçu des coups qui ont fortement déformé la coque. Le caractère rituel de la mutilation paraît plus évident que sur les éléments décrits précédemment. En effet, ces coups, en aplatissant la coque, rendaient le bouclier inutilisable. Les casques évoqués plus loin portent les mêmes stigmates. Les coups portés sur l'umbo de Tintignac trahissent l'usage d'instruments contondants, tels que marteau ou gourdin. À Gournay-sur-Aronde, selon l'étude des mutilations des umbos effectuée par A. Rapin, ce procédé qui vise à supprimer la fonction de l'objet est extrêmement fréquent (Brunaux, Rapin, 1988, p. 47-53).

\section{Éléments de chronologie}

L'umbo appartient, d'après T. Lejars, à la catégorie des « umbos à ailettes à bords convergents ». Une forme plus évoluée de ce type d'umbo avec rebords de coque saillants a été mise au jour à Montmartin (Oise) et à Verna (Isère) où elle a pu être datée d'une période allant de la fin de La Tène C2 à la fin de La Tène D1 (Brunaux, Méniel, 1997).

\section{LES CASQUES}

Au total, 33 éléments découverts dans le dépôt ont été interprétés comme appartenant à dix casques quasiment entiers, quoique fortement mutilés. Neuf de ces casques étaient en alliage cuivreux et un seul en fer. La quasi-totalité a été déposée juste après les premiers carnyx. On notera que l'un des tout premiers objets placés dans la structure est un extraordinaire casque en forme de cygne.

\section{Les casques hémisphériques} en bronze à couvre-nuque riveté

\section{Les exemplaires simples}

Parmi les casques en bronze, six présentent une morphologie assez simple (fig. 22, $\mathrm{n}^{\text {os }} 1$ à 4 ). Ils possèdent une calotte lisse hémisphérique sur laquelle sont fixés par rivetage un couvre-nuque et deux paragnathides.

Dans l'excroissance circulaire au nord-ouest de la fosse, plusieurs objets ont été déposés avant d'être complètement écrasés par une grosse pierre d'éclogite placée là de façon délibérée. Sous cette pierre, un casque en bronze a été mis au jour (fig. 22, $\mathrm{n}^{\mathrm{O}} 4$ ). Il avait subi des mutilations importantes avant son écrasement; il ne possède plus ni ses paragnathides ni son couvre-nuque. Son timbre, initialement 


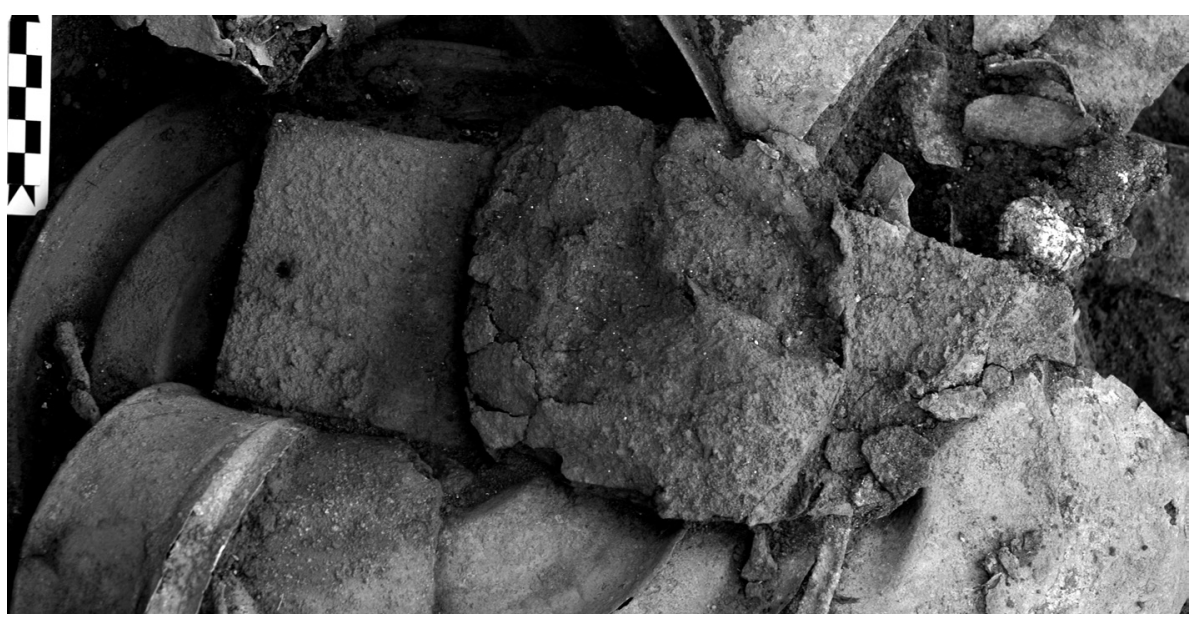

Fig. 21 - Umbo de bouclier 2149-328 (cliché : P. Ernaux, INRAP).

hémisphérique, est percé dans sa partie sommitale d'un petit trou carré, laissant imaginer le passage d'un axe qui pouvait supporter un cimier.

Sur un autre casque, une petite plaque de bronze découpée, de forme ovale, semble soudée (ou collée par la corrosion ?) sur le timbre, en position antéro-supérieure. Percée de part et d'autre de deux petits trous, elle conserve à sa surface l'empreinte d'un élément circulaire disparu (une corne ?). Un autre élément tout à fait identique a été découvert dans le dépôt, un peu au-dessus. Ce casque a été, comme les autres, fortement écrasé et mutilé. Dans l'une des entailles occasionnées alors, une tige creuse de bronze s'est retrouvée piégée mais n'appartient pas au casque lui-même.

\section{Le casque à anneaux}

Un autre casque présente les mêmes caractéristiques que les précédents : un timbre hémisphérique et un couvre-nuque riveté (fig. 22, n 5 ). Ses deux paragnathides, démontées ou arrachées, ont été retrouvées à l'intérieur. Ce casque a été fortement mutilé mais il était encore en connexion avec trois grands anneaux de $280 \mathrm{~mm}$ de diamètre chacun. Ces anneaux, disposés en triangle au-dessus du casque, sont bivalves, composés de deux tôles de bronze très fines. Des pièces de bronze assurent la liaison des anneaux entre eux et avec le casque. Deux des trois anneaux étaient en contact avec le casque ; pour le prélèvement, ils ont dû être désolidarisés de ce dernier. Seule la soudure en assurait visiblement la fixation. Ils étaient disposés latéralement sur la calotte du casque, de façon à ce que les trois anneaux soient vus de face. Cette disposition conférait au casque une hauteur totale voisine de $600 \mathrm{~mm}$ et une largeur maximale de $540 \mathrm{~mm}$. Des petits éléments de bronze coulé semblent fonctionner avec ce casque et ont peut-être servi à tendre ou à fixer des éléments (fils, plumes...) sur les anneaux. Aucun casque de ce type n'avait jusqu'alors été mis au jour. On n'en trouve pas de représentation et le manque de référence empêche toute interprétation.

Trois autres casques méritent une attention particulière. L'un d'eux est décoré dans la partie supérieure et antérieure d'une résille de bronze ajourée ; un autre, en fer, est muni d'un cimier et de tôles en alliage cuivreux, décorées et appliquées sur son pourtour. Le troisième, enfin, déjà mentionné plus haut, a la forme d'un cygne.

\section{Le casque à résille}

Un casque possède une calotte hémisphérique et un couvre-nuque riveté (fig. 22, $\mathrm{n}^{\circ} 6$ ). Son cimier n'a pas été retrouvé. De part et d'autre du porte-cimier se développe vers l'avant et l'arrière une résille de bronze ajourée formant des entrelacs. Sur la partie antérieure, une autre résille reproduisant des entrelacs un peu plus élaborés constitués d'esses affrontés, de palmettes, de petits bourgeons et d'arcatures, s'élargit sous la forme d'un triangle. Les interstices de cette résille semblent comblés de chaque côté du porte-cimier d'une petite tôle dorée. Cette résille en bronze coulé est soudée au timbre du casque, tandis que le matériau disparu occupant initialement les espaces libres était maintenu par de petits clous ou des rivets de bronze.

\section{Le casque en fer}

Le casque en fer est doté d'un timbre en fer de forme hémisphérique sur lequel sont fixés un cimier et des plaques en alliage cuivreux (fig. 23, $n^{\circ} 1$ ). C'est la base du cimier qui 


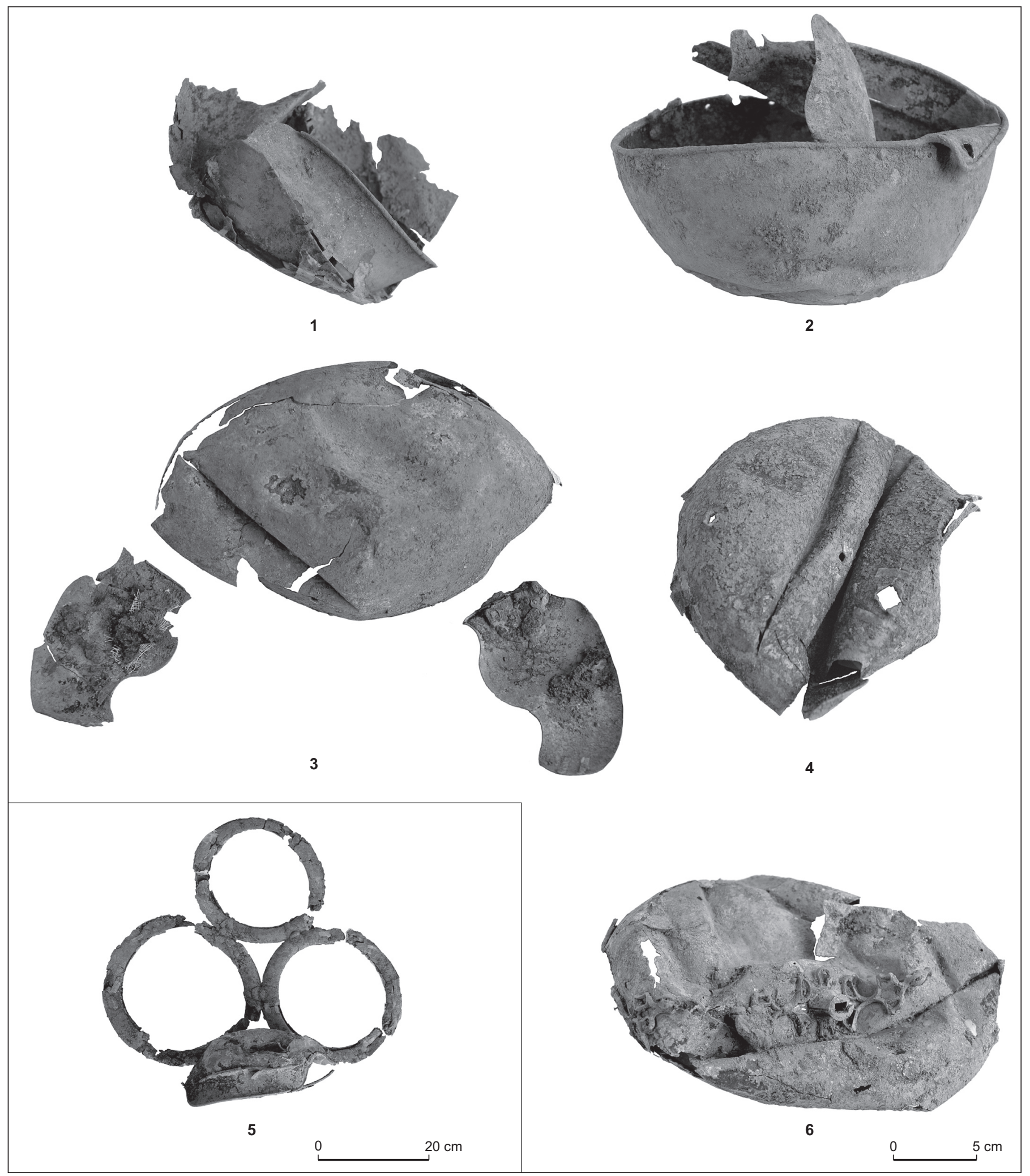

Fig. 22 - Casques après nettoyage et consolidation en laboratoire : 1, casque 2149-255; 2, casque 2149-273 ; 3, casque $2149-446$; 4, casque 2149-391 ; 5, casque 2149-421 doté de trois grands anneaux de bronze ; 6, casque 2149-451 doté d'une résille en bronze et d'un porte-cimier (clichés : P. Ernaux, INRAP). 


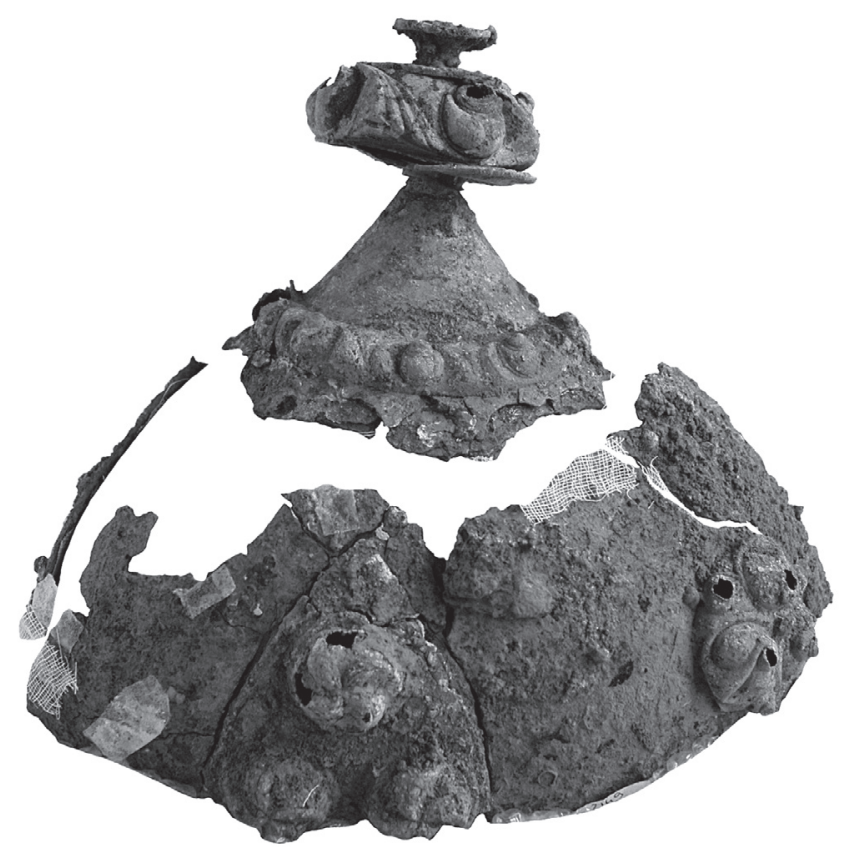

1

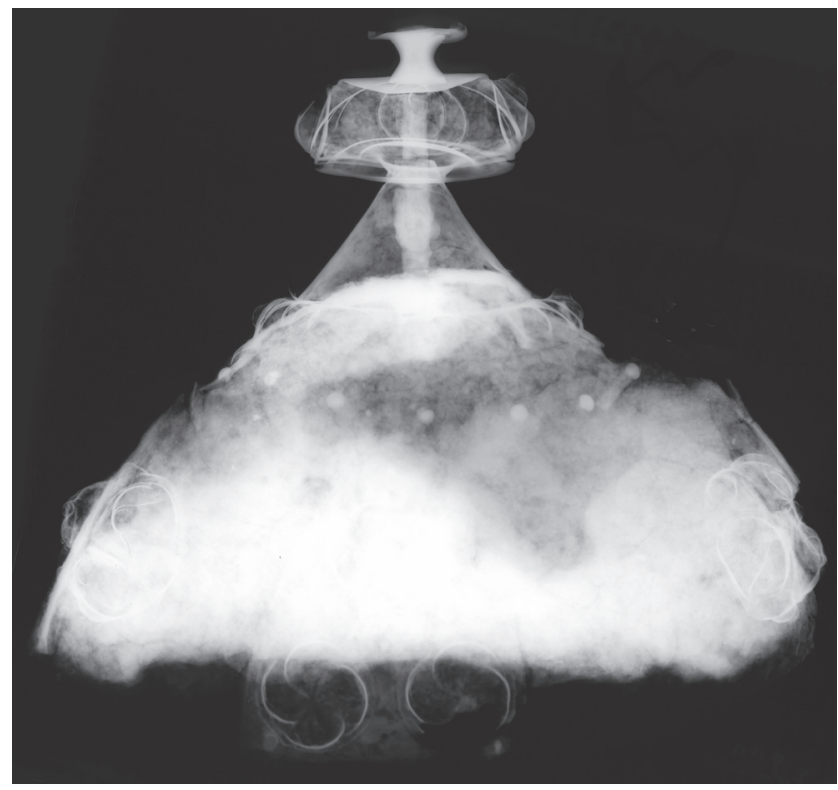

2

\section{0} $5 \mathrm{~cm}$

Fig. 23 - Casque en fer 2149-456 doté de son cimier décoré en alliage cuivreux et radiographie du casque (cliché : P. Ernaux, INRAP ; radio. : C. Gargam, laboratoire Materia Viva).

lui donne ce profil étiré vers le haut terminé par un élément mouluré composite. Grâce à la radiographie, il a été possible de visualiser l'axe en fer qui maintient l'assemblage entre le timbre et le cimier (fig. 23, $n^{\circ} 2$ ). Ce dernier est orné de volutes et de bosses tout comme les plaques qui occupent son pourtour. Aucun couvre-nuque ou couvre-joues n'a pu être associé à ce casque. Deux tôles circulaires ornées ellesmêmes d'un motif basé sur le triscèle se trouvent au-dessus de l'emplacement des paragnathides et une tôle triangulaire occupe la face antérieure. Cette dernière est ornée de trois nodosités disposées en triangle. Son décor appartient sans conteste au style plastique et très vraisemblablement à sa seconde phase qui exploite « les possibilités élémentaires de l'esse et du triscèle, traitées en relief, englobant en plus des motifs de yin-yang » (Kruta, 1975, p. 83).

\section{Le casque en forme de cygne}

Un dernier casque en bronze prend la forme d'un cygne (fig. 24). Il reposait sur le fond de la structure et paraît avoir été déposé en même temps que la majorité des carnyx. Le corps de l'oiseau constitue le timbre du casque. Son long cou prend naissance dans la partie antérieure du casque et s'enroule vers l'arrière à tel point que son bec rejoint

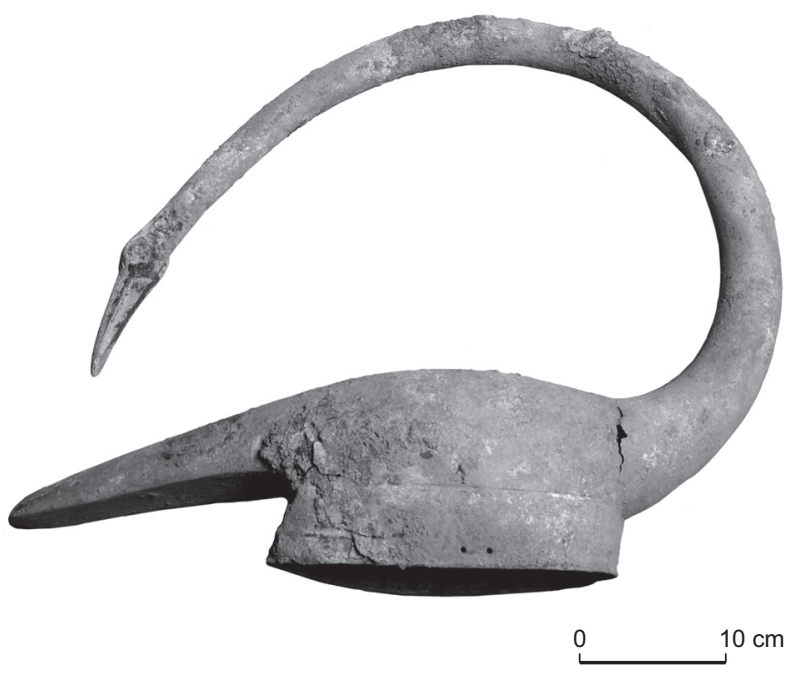

Fig. 24 - Casque 2149-468 en forme de cygne (cliché : P. Ernaux, INRAP).

presque sa queue disposée sur la face postérieure du casque. La longueur totale de ce couvre-chef atteint $530 \mathrm{~mm}$ et sa hauteur $410 \mathrm{~mm}$; la queue est longue de $200 \mathrm{~mm}$, le cou de $780 \mathrm{~mm}$ et la tête de $115 \mathrm{~mm}$. Il semble composé pour partie de bronze coulé et pour partie de tôle travaillée au repoussé. 
Un matériau non encore identifié occupait l'emplacement des yeux. Le port de l'animal et une petite incision en $\mathrm{V}$ sur le bec plat et arrondi confirment qu'il s'agit bien d'un cygne. Les paragnathides et le couvre-nuque manquent. Un bandeau présent sous la queue devait recevoir le couvrenuque. Les trous de rivets de part et d'autre témoignent de l'existence de couvre-joues ou de fixations pour la jugulaire. L'absence de traces d'arrachement indique qu'ils ont dû être volontairement démontés.

\section{Éléments de comparaison}

Selon Diodore de Sicile, qui écrit vers le milieu du $\mathrm{I}^{\mathrm{er}}$ s. av. J.-C. : « les Gaulois portent des casques en bronze qui supportent de grands ornements et leur prêtent ainsi une apparence majestueuse. Sur certains de ces casques sont posées des cornes jumelées, sur d'autres, des protomés d'oiseaux ou de quadrupèdes » (Diodore, Bibliothèque historique, $\mathrm{V}, 30)$. Malgré leur quasi-absence parmi les découvertes archéologiques, ce type de casque en forme d'animal ou surmonté d'un animal devait être assez fréquent. En effet, ils apparaissent sur de nombreux monuments romains de Gaule du Sud (mausolée de Glanum, arc de triomphe d'Orange, reliefs d'Antibes...) (Feugère, 1994, p. 62) ou encore sur le chaudron de Gundestrup (Danemark) où certains supportent un cimier en forme d'oiseau ou de sanglier. Un fragment de petite patte d'animal découverte dans le dépôt de Tintignac a pu appartenir à un casque de ce type.

À Ciumesti (Roumanie), un casque en fer daté de la fin du $\mathrm{IV}^{\mathrm{e}}$ s. ou du début du $\mathrm{III}^{\mathrm{e}}$ s. av. J.-C. était surmonté d'un oiseau en bronze aux ailes déployées et articulées (Rusu, 1969).

On connaît dans la statuaire ligure (petits bronzes étrusco-ligures figurés des $\mathrm{IV}^{\mathrm{e}} \mathrm{s}$. et $\mathrm{III}^{\mathrm{e}} \mathrm{s}$. av. J.-C.) des représentations du roi-cygne (Cygnus/Kyknos) ou de guerriers coiffés de casques ou de couvre-chefs en forme de cygne. On citera encore une statuette en bronze, haute de 0,70 m, découverte fortuitement en 1913 à Kerguilly (Dinéault, Finistère) qui portait un casque surmonté d'un oiseau coiffé d'un cimier (Sanquer, 1973). Cet oiseau à l'envol, le cou tendu, a été interprété comme une oie sauvage ou comme un cygne. Le casque sur lequel il repose est, d'après R. Sanquer, de type romano-corinthien. Le personnage représenté pourrait être la déesse Brigit assimilée à la Minerve romaine. Cette statuette, par son style et son mode de fabrication, pourrait dater de la première moitié du $\mathrm{I}^{\mathrm{er}} \mathrm{s}$. apr. J.-C. Une autre reproduction miniature d'époque romaine, en bronze et en argent, représente le casque de
M. Valerius Corvinus, avec la couronne du vainqueur et un corbeau posé au sommet (Feugère, 1994, p. 64).

\section{Les paragnathides et couvre-nuques}

Une paragnathide et quatre couvre-nuques isolés ont été mis au jour dans la structure. L'un des casques en bronze ne conservait qu'une paragnathide encore en connexion. Pour un autre et celui doté des anneaux, elles ont été retrouvées à l'intérieur, dans le sédiment qui les remplissait. Les autres avaient vraisemblablement disparu. Toutes ces paragnathides sont quasiment identiques, découpées de façon similaire, avec des échancrures peu prononcées, dans de fines tôles en alliage cuivreux et apparemment dépourvues de décors. Certaines conservent la charnière de fer qui les reliait primitivement au casque et le passant en bronze ou en fer destiné à la jugulaire.

Cinq casques conservent leur couvre-nuque riveté ; ce dernier avait été démonté sur deux des casques en bronze, sur celui en fer ou encore sur celui en forme de cygne. Ces couvre-nuques, tous semblables et assez simples, ont été découpés dans des tôles de bronze, dotés d'un ourlet en périphérie et fixés par rivetage sur les casques. Ils sont agrémentés dans leur partie supérieure d'une sorte de bandeau repoussé qui venait s'encastrer sur celui aménagé à l'arrière du casque. Ce type de bandeau a été également observé sur le casque-cygne, sous la queue de l'animal.

\section{Les mutilations}

Tous les casques ont subi des mutilations importantes. Certains, dont le casque-cygne, sont cependant moins abîmés que d'autres qui ont été littéralement écrasés. Deux types de coups ont été identifiés. Certains ont laissé des traces linéaires, résultant peut-être de coups d'épée donnés avec le tranchant. Des perforations circulaires ou de forme carrée pourraient provenir de coups de lance. Ainsi, l'un des casques en bronze porte-t-il deux empreintes linéaires (qui l'ont presque coupé en deux) correspondant à des coups assénés alors que le casque était à l'endroit, et au moins deux perforations, l'une circulaire et l'autre carrée, réalisées depuis l'intérieur du casque. Le casque en forme de cygne a, quant à lui, été marqué moins violemment mais porte les mêmes stigmates. Des coups ont laissé des empreintes linéaires sur le cou et le corps de l'oiseau. Des perforations ont été réalisées près de l'emplacement initial de la paragnathide gauche et sur le dos de l'animal, alors que le casque devait être posé à l'endroit. 


\section{Remarques sur les casques}

La ressemblance de l'ensemble de ces casques, hormis celui en fer, en fait un lot homogène. Ils sont tous dotés de calottes hémisphériques, de couvre-nuques rivetés, de paragnathides identiques, simples et, apparemment, sans ornementation. Or, nous avons vu que les comparaisons pourraient les placer à une période relativement ancienne, en particulier pour le casque doté d'une résille qui s'apparente au casque d'Amfreville-sous-les-Monts (Eure) daté du IV ${ }^{e}$ s. av. J.-C. Néanmoins, ceci mérite d'être nuancé et discuté.

Les casques de Tintignac demeurent en effet difficiles à classer dans les grandes catégories aujourd'hui adoptées pour les couvre-chefs guerriers celtiques. Pour les périodes de La Tène A-B et $\mathrm{C}$, doivent-ils être rattachés à la série issue des nécropoles de Bologne et de Monte Bibele (et plus généralement de l'Apennin) du IV ${ }^{\mathrm{e}} \mathrm{s}$. av. J.-C., différente par la technique et le mode décoratif (timbre et couvrenuque d'une seule pièce, appliques décoratives laminées), ou bien aux exemplaires du $\mathrm{III}^{\mathrm{e}} \mathrm{s}$. plus circonscrits à l'arc alpin oriental (dont le couvre-nuque est riveté) ? Ils présentent également des similitudes avec les casques d'Agris en Charente (Gomez de Soto, 1986) et d'Amfreville-sous-lesMonts dans l'Eure (Kruta, 1976-1977), puis ceux de SaintJean-Trolimon dans le Finistère (Duval, 1990), Montlaurès à Narbonne dans l'Aude (Chazelles et al., 1994) et Canosa di Puglia en Italie (Duval, 1977 ; Antike Helme, 1988) qui forment un groupe à part et constituent un héritage du $\mathrm{V}^{\mathrm{e}} \mathrm{s}$. et du début du IV ${ }^{\mathrm{e}} \mathrm{s}$. av. J.-C. La majorité des casques celtiques anciens connus possèdent une calotte étirée vers le haut terminée par un cimier ou un bouton sommital, ce qui les rapproche de notre casque en fer.

Il semble plus difficile de les associer à La Tène D : les casques de Gaule comportent généralement à cette période un renfort saillant au niveau des tempes ou du front (type Port) et un bord oblique, évasé vers l'extérieur. Les casques de Tintignac pourraient cependant s'apparenter au type celtique oriental dont les casques sont toujours constitués de plaques rivetées.

En ce qui concerne la structure et la composition même du casque en fer, plusieurs références peuvent être trouvées dans le monde celtique et en particulier dans la série apennine. Ainsi, le casque découvert dans la tombe 116 de la nécropole de Monte Bibele était constitué d'un timbre en fer sur lequel des feuilles de bronze ornées au repoussé avaient été appliquées (Vitali, 1982). D'autres casques provenant de la même nécropole sont décorés à l'aide d'émail rouge ou, plus exactement, de verre opaque rouge (on en compte cinq à Monte Bibele, six à Monterenzio Vecchia, etc.). Ils sont datés entre le milieu du $\mathrm{IV}^{\mathrm{e}} \mathrm{s}$. et le milieu du III ${ }^{\mathrm{e}} \mathrm{s}$. av. J.-C.

Les ressemblances avec les casques de l'arc alpin oriental ne manquent pas non plus. Le casque du III $^{\mathrm{e}} \mathbf{s}$., sans contexte précis, découvert à Batina (Yougoslavie), présente en effet des similitudes avec le casque en fer de Tintignac. Sur son timbre en fer sont fixées latéralement des tôles de fer de forme triangulaire à l'aide de rivets à grosse tête disposés en triangle (Szabó, Petres, 1992). Son cimier, également en fer, est composé d'une pièce rapportée sur la calotte hémisphérique. Le couvre-nuque paraît, quant à lui, riveté. Un exemple de casque analogue figure sur une frise de Pergame.

Nous avons vu que le casque orné d'une résille et celui en fer présentent des ressemblances avec le casque d'Agris. On rappellera en effet que ce dernier, daté du dernier tiers du IV ${ }^{\mathrm{e}}$ s. av. J.-C., possède un timbre en fer étiré vers le haut, avec un cimier composite incomplet, un plaquage de bronze coulé ou en feuille travaillée au repoussé, couvert de feuilles d'or, des rivets en argent et une décoration de corail. Selon J. Gomez de Soto, la conception technique qui a présidé à l'élaboration du timbre en fer, dont le couvrenuque est une pièce séparée et rivetée, est clairement alpine (Gomez de Soto, 1986). Suite à la découverte de Tintignac, il affirme cependant plus prudemment que « la technologie de la coque de fer, au couvre-nuque riveté, longtemps tenue pour alpine, paraît plus courante en Occident qu'on ne l'a cru » (Gomez de Soto, 2007). La pureté de l'or employé lui fait ajouter que « des ors comparables ne sont actuellement connus que pour une série de bijoux du quart sud-ouest de la Gaule, dont le métal pourrait venir des mines du Massif central dont on sait que l'exploitation a commencé dès l'âge du Fer. Une réalisation occidentale semble donc probable » (Gomez de Soto, 1991, p. 292).

Rappelons ici que le site de Tintignac est entouré de très nombreuses aurières exploitées à l'époque gauloise (Cauuet, 2004 ; Toledo i Mur, 2005). Le casque d'Agris a dès lors pu être confectionné avec l'or des Lémovices. La fabrication de casques pourvus de couvre-nuques rivetés est généralement concentrée au niveau de l'arc alpin oriental. Les casques de Tintignac et celui d'Agris pourraient avoir été produits par des peuples celtiques occidentaux qui auraient puisé leur inspiration dans les techniques orientales. La rareté des découvertes de casques à l'ouest de la Gaule entre l'Armorique et le Midi toulousain ne permet pas de vérifier cette hypothèse.

Daté de la première moitié du IV ${ }^{\mathrm{e}} \mathrm{s}$. av. J.-C., le casque de Canosa di Puglia, quant à lui de tradition celto-italique, 


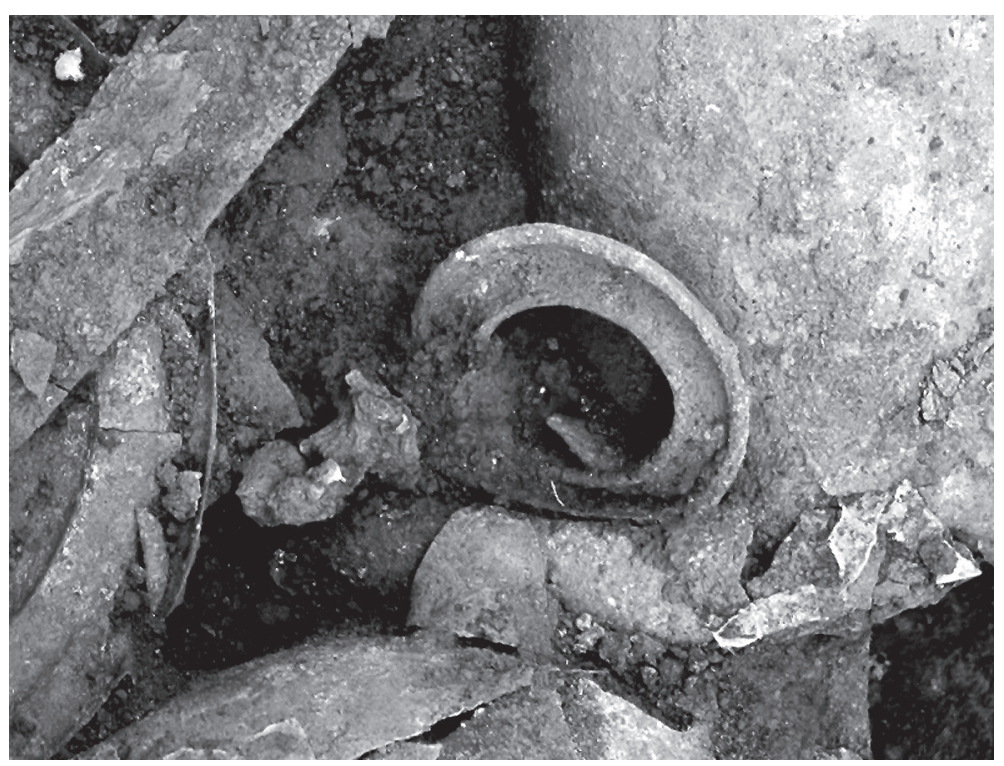

1

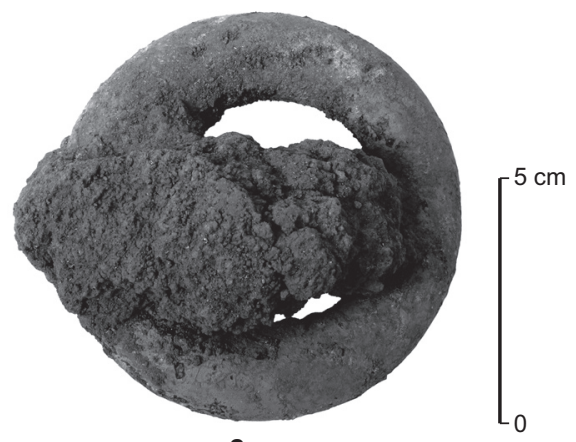

2

Fig. 25 -Demi-mors de cheval en bronze et fer : 1, demi-mors 2149-418; 2, demi-mors 2149-393 (clichés : P. Ernaux, INRAP).

possède, comme certains de ceux de Tintignac, une calotte en fer recouverte d'une tôle de bronze ouvragée aux ajours incrustés de corail (Duval, 1977 ; Antike Helme, 1988). Sur ce casque, timbre et couvre-nuque sont faits d'une seule pièce et deux tiges creuses latérales, en position verticale, recevaient sans doute des plumes.

À Saint-Jean-Trolimon, les fragments de deux casques ont été découverts en 1880-1890 sur le site de Tronoën. L'un d'eux concerne la portion sommitale d'un casque en fer recouvert d'une tôle de bronze richement décorée au repoussé et terminée dans sa partie supérieure par un bouton orné de corail. Sa décoration et la technologie employée ont permis de le dater de la seconde moitié du $\mathrm{V}^{\mathrm{e}} \mathrm{s}$. et il pourrait avoir été produit localement (Schaaff, 1974 ; Lejars, 1991). Le système de fixation du cimier s'apparente tout à fait à celui observé sur le casque en fer de Tintignac.

Le casque de l'oppidum de Montlaurès dont, là encore, seul le sommet est conservé, comporte un timbre en bronze recouvert de nombreux ornements de bronze et de corail (Feugère, 1994, p. 60). Il se termine par un bouton composé de plusieurs disques superposés comme le cimier du casque en fer de Tintignac. Décoré de palmettes et de minuscules têtes coupées, il a été daté du IV ${ }^{\mathrm{e}} \mathrm{s}$. av. J.-C.

Les casques de Tintignac se rapprochent donc davantage des casques de tradition orientale et, plus particulièrement, de deux casques dont le premier, en fer, daté du I ${ }^{\mathrm{er}}$ s. av. J.-C. et découvert dans un puits toulousain, possède un couvrenuque rapporté. L’autre, représenté sur une tête sculptée
d'Entremont, est identique au précédent et muni d'une courte paragnathide. Cette sculpture ne saurait être postérieure à la fin du $\mathrm{III}^{\mathrm{e}} \mathrm{s}$. (Feugère, 1994, p. 73-74). Le manque de référence n'aide pas à la datation de ces casques. Hormis le casque en fer, ceux en bronze ne ressemblent plus guère aux casques celtiques anciens mais pourraient appartenir à une période plus récente.

\section{LES PIÈCES DE HARNACHEMENT}

Deux demi-mors de cheval ont été découverts près de l'angle sud-est de la fosse (fig. $25, n^{\text {os }} 1$ et 2 ). Ils ont vraisemblablement été déposés en même temps que les casques. Il s'agit d'un mors de filet brisé, en fer, doté d'anneaux en bronze, de $85 \mathrm{~mm}$ de diamètre et de section semi-circulaire. Ici, les deux parties du mors, comprenant chacune un anneau et la moitié du filet, étaient distantes d'une vingtaine de centimètres. Généralement, et en particulier dans les tombes à char du $\mathrm{V}^{\mathrm{e}} \mathrm{s}$. av. J.-C., ces mors sont totalement en fer ; cependant, certains sont en bronze tel celui de la Gorge-Meillet à Somme-Tourbe dans la Marne (Kruta, 2000, p. 642) ou bien alors, comme ceux de Tintignac, associent bronze et fer. C'est le cas par exemple de ceux découverts dans une tombe à char de Somme-Bionne dans la Marne (Déchelette, 1927, p. 705).

On intégrera dans ce chapitre les sept disques, de $250 \mathrm{~mm}$ de diamètre, mis au jour dans le dépôt. Ils pourraient avoir servi d'ornements de harnachement, mais 


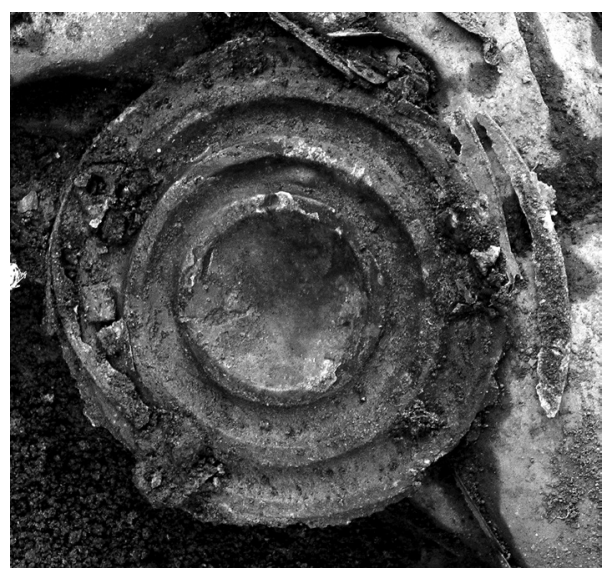

Fig. 26 - Disque en alliage cuivreux 2149-394 doté d'attaches en fer (cliché : P. Ernaux, INRAP).

l'hypothèse de disques de cuirasse n'est pas à écarter car l'armement de la péninsule Ibérique en comporte. Constitués de tôle en alliage cuivreux travaillée au repoussé, ils sont ornés de deux ou trois gorges concentriques (deux modèles différents existent) et d'une " cupule » circulaire centrale. Sur l'un d'eux, trois petites attaches en fer semblent soudées en bordure, disposées en triangle (fig. 26). Elles ont pu servir pour le passage de sangles.

Ces disques semblaient avoir été déposés au cours d'une seule phase, principalement dans la moitié sud de la fosse. Ils étaient emboîtés deux par deux ; un seul était isolé. Deux étaient disposés verticalement contre la paroi orientale de la structure ; deux autres avaient été déposés, légèrement inclinés vers l'ouest, près de la limite occidentale ; enfin les deux derniers se trouvaient près de la bordure méridionale du creusement, inclinés vers le sud-est.

\section{Éléments de comparaison}

Les phalères de chevaux sont en général plus petites, mais quelques-unes, en particulier celles en bronze, de la tombe de Saint-Jean-sur-Tourbe (Marne) datée du IV ${ }^{\mathrm{e}}$ s. av. J.-C., mesurent environ $250 \mathrm{~mm}$ de diamètre (Laing, Laing, 1992, p. 47). Leur ornementation est cependant plus élaborée que celle des « disques » de Tintignac. Parmi celles de Manerbio sul Mella en Italie (Kruta, 1987b), datées par l'analyse stylistique du I ${ }^{\mathrm{er}}$ s. ou du $\mathrm{II}^{\mathrm{e}}$ s. av. J.-C., les plus grandes, décorées de têtes et d'un triscèle, ont un diamètre de $190 \mathrm{~mm}$. Elles étaient cependant accompagnées de phalères plus petites, qui occupaient d'autres croisements des courroies du harnais du cheval. À Tintignac, aucun disque de taille inférieure n'a été mis au jour. S'agit-il réellement de phalères?

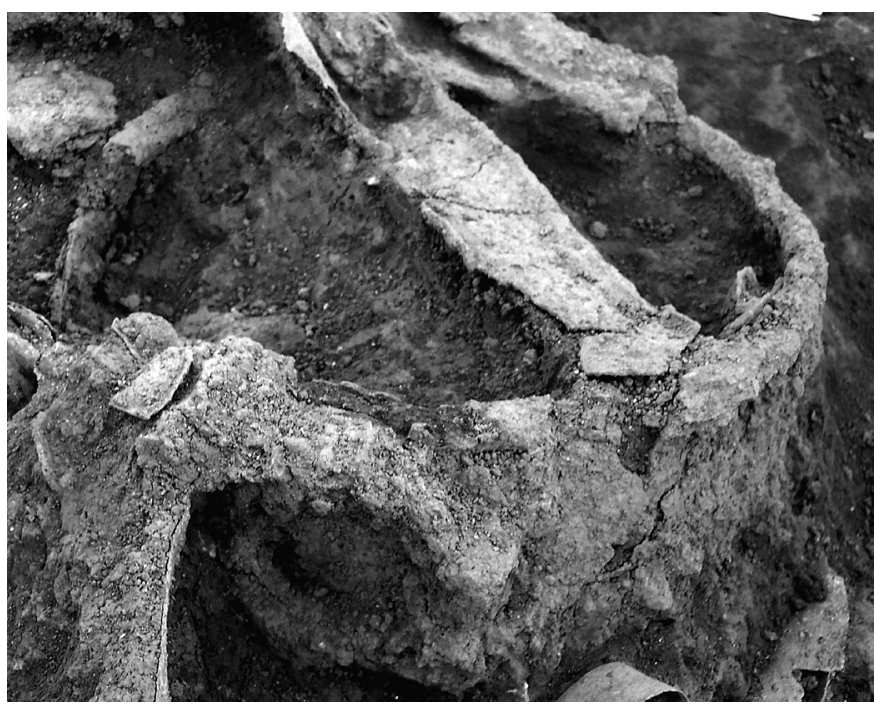

Fig. 27 - Le chaudron 2149-416 doté de deux anneaux de suspension (cliché : F. Loubignac, Université Bordeaux-III).

\section{LE CHAUDRON}

Un chaudron a été déposé dans l'angle nord-est de la fosse cultuelle (fig. 27). Il reposait sur l'une des trompettes de guerre et était recouvert partiellement par les faisceaux de lames et de fourreaux d'épée de surface. Ce chaudron, de $280 \mathrm{~mm}$ de diamètre et $140 \mathrm{~mm}$ de hauteur, est muni de deux anneaux de suspension. Sa partie supérieure en fer, au rebord épaissi, est rivetée sur une tôle en alliage cuivreux constituant la partie inférieure de la panse, fixée elle-même sur le fond de cuve en tôle légèrement plus épaisse. La base du récipient est fortement cabossée mais il est difficile d'attribuer ces déformations à un quelconque acte rituel ${ }^{13}$. Sur le fond, une autre petite tôle de bronze rivetée a sans doute permis une réparation de la cuve. Aucun objet ne peut être interprété comme un élément d'une crémaillère.

\section{Éléments de comparaison}

Ce type de chaudron associant fer et alliage cuivreux est courant dans le domaine laténien. On mentionnera ainsi en particulier plusieurs chaudrons, très similaires au nôtre, découverts sur le site de La Tène et datés du III $^{\mathrm{e}}$ s. ou du

13. Ce chaudron, très fragile, a dû être totalement consolidé extérieurement à l'aide de gaze de coton et de cyclododécane. Il a ensuite été prélevé avec le sédiment qu'il renfermait. Il a été vidé en 2006 ; deux fragments de fourreaux et deux tôles de bronze ont été découverts à l'intérieur. 
II $^{\mathrm{e}}$ s. av. J.-C., celui de Chalon-sur-Saône (Saône-et-Loire) d'un diamètre de 296 mm (Catalogue d'exposition, 1983, p. 187, $\mathrm{n}^{\mathrm{o}}$ 241), ou encore celui de Emmendingen (Allemagne), d'un diamètre de $470 \mathrm{~mm}$, découvert avec sa crémaillère. En revanche, ce dernier dispose d'une anse et donc d'un système de suspension différent (Déchelette, 1927, p. 926).

Le chaudron est présent sur de nombreux sites cultuels, mais à l'état de fragments, par exemple à Allonnes et Aubigné-Racan dans la Sarthe (Brouquier-Reddé, Gruel dir., 2004, p. 305), à Nalliers dans la Vienne (Lejars, 1989), dans le sanctuaire de l'oppidum de Corent en Auvergne (Poux, 2006), etc. Il est cependant parfois retrouvé démonté ou complet. On signalera en particulier le plus connu, le chaudron de Gundestrup, d'une constitution très différente du nôtre (Bémont, 1979), ou encore celui de Brå au Danemark, qui est daté du $\mathrm{III}^{\mathrm{e}}$ s. av. J.-C. (Klindt-Jensen, 1953). Ce dernier présentait un diamètre important de $1,18 \mathrm{~m}$ et avait été brisé avant son dépôt. Il avait à l'origine un rebord en fer revêtu de tôle de bronze, trois anses annulaires en fer et l'ensemble du corps était fait de tôle de bronze. On n'oubliera pas la trouvaille dans une source, à Duchcov en Bohême (République tchèque), de plus de 2000 parures laténiennes en bronze dans un grand chaudron en tôle de bronze portant des traces de réparation. Elle a été datée de la fin du IV ${ }^{\mathrm{e}}$ s. ou du début III ${ }^{\mathrm{e}}$ s. av. J.-C. (Kruta, 1971).

La majorité des chaudrons connus ont cependant été mis au jour en contexte funéraire (Poux, 2004). C'est le cas, en particulier, de deux récipients en bronze munis de deux anneaux, issus des tombes B et UF 14 de Gœblange-Nospelt (Luxembourg) datées de la fin du $\mathrm{I}^{\mathrm{er}}$ s. av. J.-C. (Metzler, Gaeng, 2008). Ce type de récipient est très fréquent en Picardie dans les tombes du $\mathrm{II}^{\mathrm{e}}$ s. av. J.-C. La carte de répartition des chaudrons de bronze et de fer montre une diffusion de ces productions indigènes limitée à la moitié nord-est de la Gaule et à la Germanie (Maguer et al., 2003, p. 230) entre le $\mathrm{II}^{\mathrm{e}}$ s. av. J.-C. et le $\mathrm{I}^{\mathrm{er}}$ s. apr. J.-C. Celui de Tintignac serait donc à ce jour la découverte la plus occidentale et méridionale de ce type de chaudron.

\section{LES ANIMAUX EN TÔLE : DES ENSEIGNES DÉMONTÉES ?}

Plusieurs tôles de bronze disposées à plat ou enroulées sur elles-mêmes peuvent être interprétées comme des fragments de représentations d'animaux en métal. Au total, deux têtes ont pu être identifiées ; trois à cinq tôles correspondent vraisemblablement à des portions de corps et quatre ou cinq à des pattes.

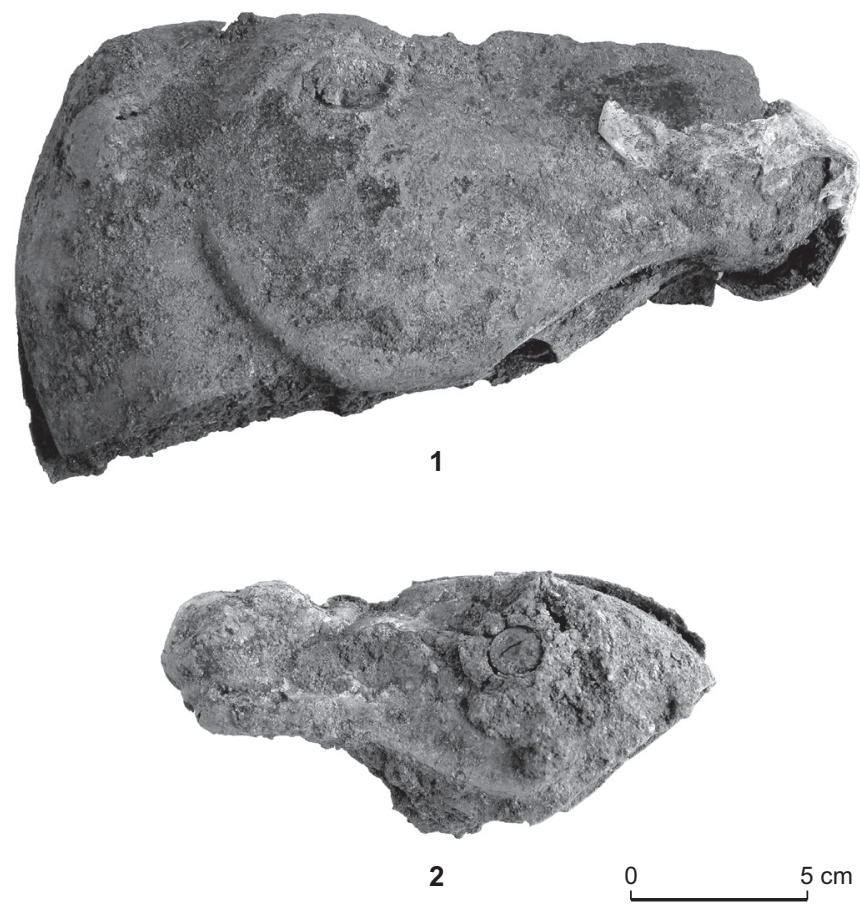

Fig. 28 - Têtes d'animaux : 1, tête de cheval 2149-253 constituée de tôles de bronze repoussées ; 2 , tête d'animal non identifié 2149364, constituée de tôles de bronze assemblées, après nettoyage et consolidation en laboratoire (clichés : P. Ernaux, INRAP).

Une des deux têtes d'animaux a été identifiée comme appartenant à un cheval. L'autre, en revanche, est restée plus mystérieuse.

La tête de cheval, longue de $240 \mathrm{~mm}$ et haute de $105 \mathrm{~mm}$, a été découverte en limite sud de la fosse (fig. 28, $n^{\circ} 1$ ). Elle est composée de deux tôles en alliage cuivreux, correspondant chacune à une face, martelées et probablement soudées entre elles. Cet élément a fortement souffert, plus du fait de la dégradation du métal que d'éventuelles mutilations. Il a subi en outre un écrasement important dû au poids des terres. Cependant l'une des faces est restée bien reconnaissable. L'emplacement des yeux est occupé par un matériau différent qui a en grande partie disparu et qui reste à identifier. L'oreille, non retrouvée, faite sans doute d'une tôle rapportée, devait être fixée à l'aide d'un rivet dont l'emplacement est marqué par un trou, au niveau d'une petite bosse, au-dessus et à l'arrière de l'œil.

La tête d'un autre animal a été découverte près de l'angle sud-est de la fosse (fig. 28, $\mathrm{n}^{\circ} 2$ ). Longue de $150 \mathrm{~mm}$ et haute de $70 \mathrm{~mm}$, elle est constituée de deux tôles travaillées au repoussé. L'animal représenté possède un museau allongé, doté dans sa partie supérieure de sortes de protubérances. Là encore, à l'emplacement de la pupille 


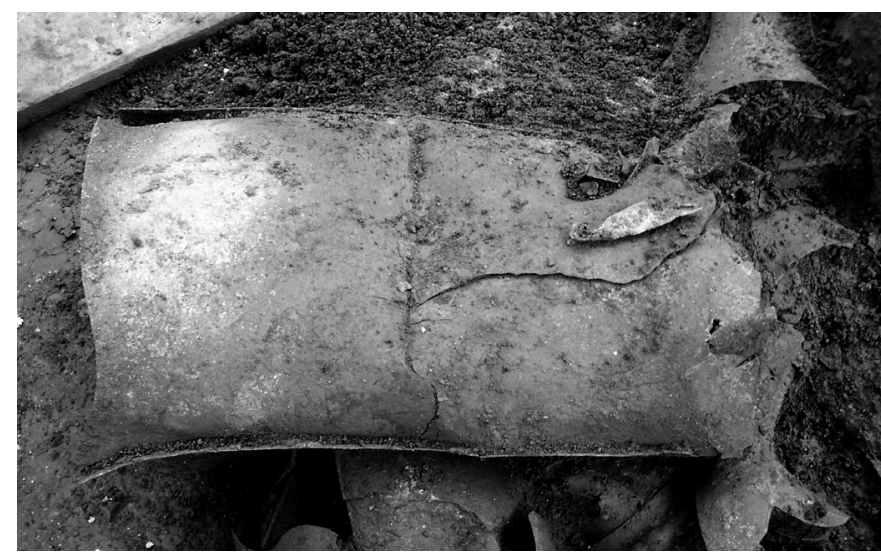

Fig. 29 - Corps d'animal 2149-407 constitué de deux tôles de bronze assemblées (cliché : F. Loubignac, Université Bordeaux-III).

se trouve un matériau noir qui pourrait être du lignite. Le pourtour de l'œil, en revanche, est composé d'un métal que la corrosion a fait gonfler. À l'arrière de la tête, un trou circulaire correspond sans doute à l'emplacement des oreilles. Une ouverture en biais à l'arrière devait permettre de fixer cette tête sur son corps ${ }^{14}$. Il pourrait s'agir d'un animal issu du bestiaire fantastique des Celtes.

Entre trois et cinq tôles de bronze pourraient avoir constitué une partie du corps d'un animal. Certaines, qui n'ont pas été observées précisément, n’ont peut-être pas eu ce rôle. L'une de ces tôles, longue de $340 \mathrm{~mm}$ et large de $180 \mathrm{~mm}$, découverte à plat, presque à la surface du dépôt, sous les fragments de lames et de fourreaux d'épée, était bien un demi-corps d'animal (fig. 14, no 3). C'est du moins ce que semblent indiquer les déformations symbolisant les muscles de la partie haute des pattes. C'est la face interne qui a été dégagée, la face externe étant tournée vers le bas et reposant sur les autres objets en bronze. Sur cette tôle est encore fixé le départ d'une patte longue de $175 \mathrm{~mm}$, constituée d'une tôle enroulée plus épaisse.

Un autre corps d'animal conserve pour sa part les deux coques en alliage cuivreux qui le composent encore en connexion ${ }^{15}$ (fig. 29). Ces tôles, longues de $330 \mathrm{~mm}$ et larges de $190 \mathrm{~mm}$, prennent une forme convexe ; celle qui se trouve dessus paraît avoir reçu des coups (donnés avec le tranchant d'une épée ?). Les deux pattes arrière de l'animal semblaient encore liées à ce corps, au nord (fig. 30). Longues

14. D'après F. Duranthon, conservateur au Muséum d'histoire naturelle de Toulouse, il pourrait s'agir d'un oiseau et plus précisément d'un petit pingouin dénommé Alca torda, oiseau menacé mais qui existe encore sur les côtes françaises. Ceci reste bien entendu à confirmer.

15. L'espace entre les deux tôles était comblé de sédiment qui n'a pas encore été retiré.

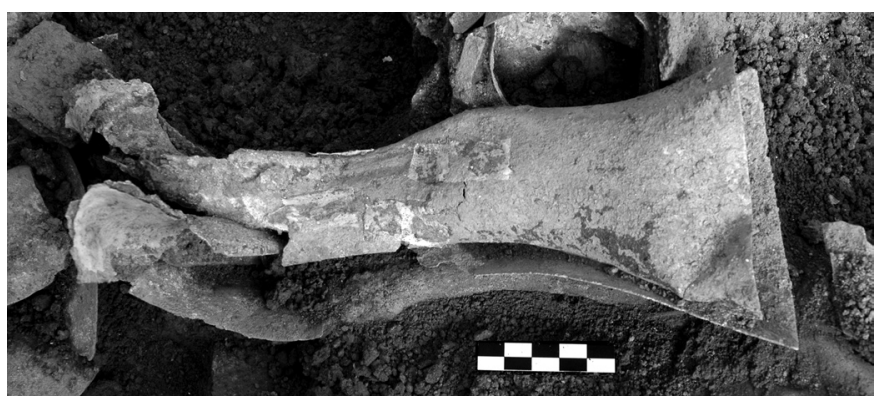

Fig. 30 - Pattes postérieures 2149-330 et 2149-412 constituées de tôles de bronze (cliché : P. Ernaux, INRAP).

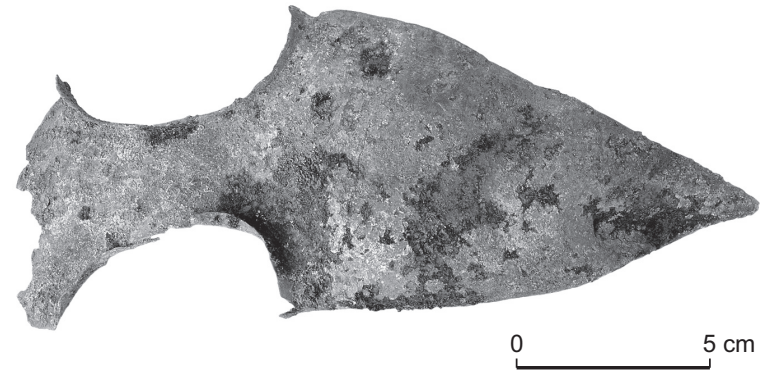

Fig. 31 - Tôle de bronze découpée 2149-310 ayant pu entrer dans la composition d'un animal-enseigne (cliché : P. Ernaux, INRAP).

de près de $270 \mathrm{~mm}$, elles reposaient l'une sur l'autre. Elles sont formées de tôles de bronze martelées enroulées sur elles-mêmes. Elles sont abîmées à leur extrémité distale. Il est difficile de dire aujourd'hui si cette dégradation est due ou non à une mutilation volontaire.

L'une des pattes reposait sur un autre élément en tôle de bronze qui n'a pas été identifié formellement, mais qui pourrait correspondre à une autre patte d'animal qui aurait subi une détérioration importante.

Deux autres tôles de bronze ont été retrouvées dans l'extension circulaire nord-ouest de la fosse. La première, de dimensions modestes (230 $\mathrm{mm}$ sur $83 \mathrm{~mm}$ ) et de forme triangulaire, présente à une extrémité deux échancrures semi-circulaires correspondant à l'emplacement des pattes postérieures (fig. 31). Il s'agit d'une languette ventrale d'animal en bronze identique à celles mises au jour à Neuvy-en-Sullias dans le Loiret ou à Ilonse dans les AlpesMaritimes (Catalogue d'exposition, 2007, p. 63-72).

Une autre grande tôle de bronze reposait à plat sur la précédente et occupait presque toute l'excroissance circulaire de la structure. Longue de $445 \mathrm{~mm}$ et large de $180 \mathrm{~mm}$, elle présente une bordure arrondie au nord. Rien ne permet d'être certain que cette tôle appartienne à un animal en alliage cuivreux. 


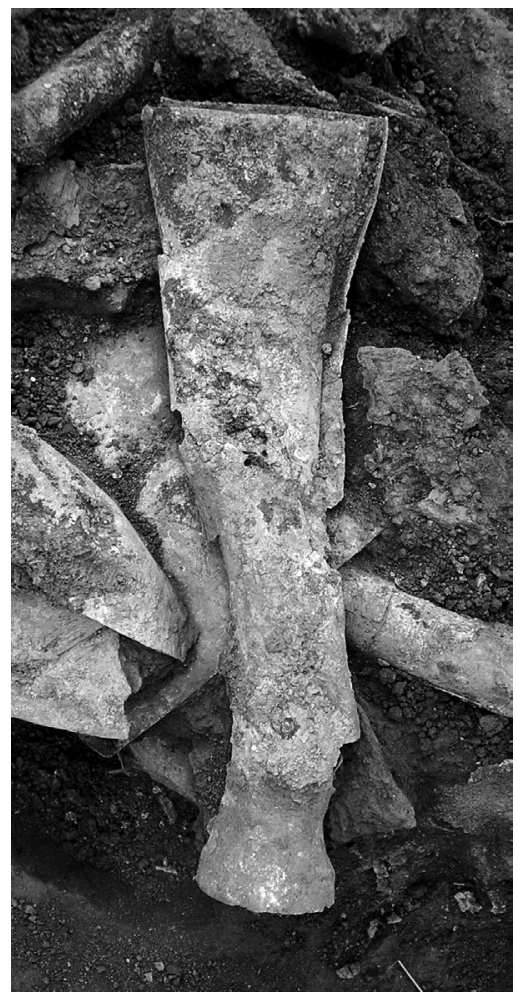

Fig. 32 - Patte antérieure 2149-265 constituée d'une tôle de bronze enroulée sur elle-même (cliché : E. Walthert, Université Paris-IV).

Une dernière tôle se trouvait en partie à plat et en partie en position verticale, près de l'angle sud-est de la fosse. Très fine, elle a dû être prélevée en plusieurs morceaux. Elle présente des bordures convexes en arc de cercle à l'ouest et concaves à l'est et au nord. De ce côté-là, elle est dotée d'une sorte d'ourlet. Des rivets et trous de rivets percent cette tôle en plusieurs endroits. La fonction précise de cet élément ne peut être établie.

Une patte en bronze a été mise au jour dans la partie nord de la fosse, sous les faisceaux de lames et de fourreaux d'épée. Constituée d'une tôle enroulée sur elle-même, elle mesure $265 \mathrm{~mm}$ de long et $50 \mathrm{~mm}$ à $80 \mathrm{~mm}$ de diamètre (fig. 32). Moins abîmée que les autres, cette patte pourrait être identifiée, de par sa morphologie, comme une patte antérieure de cheval.

Un peu plus au sud, un autre élément composé de deux demi-tôles en alliage cuivreux, soudées, formait également une patte d'animal. Plus petite que la précédente $(150 \mathrm{~mm}$ de longueur et $30 \mathrm{~mm}$ à $40 \mathrm{~mm}$ de diamètre), elle n'était pas brisée.

Les différents fragments d'animaux ont été déposés en deux temps. La plupart ont été placés dans la fosse immé- diatement après les casques et avant les disques ; d'autres ont été apportés plus tard, après le chaudron et avant les lames et fourreaux d'épée disposés en faisceaux.

Ces animaux en métal ont vraisemblablement été démontés avant leur dépôt. Il faut voir dans ce démontage un acte rituel. Les différentes parties d'animaux ont-elles été frappées et délibérément abîmées comme c'est le cas pour les armes et les casques? Nous avons vu que la partie la plus complète de corps d'animal portait une trace de coup linéaire. Il est possible aussi que la tête de l'animal mal identifié ait reçu un coup.

\section{Éléments de comparaison}

Parmi les animaux en tôle de bronze connus en Gaule, plusieurs sangliers et quelques chevaux ont été répertoriés. Ces découvertes sont souvent anciennes et les contextes rarement bien définis.

Des fragments d'un cheval en tôle de fer ont été découverts dans un sanctuaire de l'oppidum de Manching en Bavière (Krämer, 1985 ; Sievers, 1991, p. 153). Seules la tête et deux jambes, dont l'une avec le sabot, ont été retrouvées. Il pourrait avoir été exposé avant sa destruction à la fin de La Tène moyenne.

D'autres têtes de chevaux, en bronze coulé, ont été découverts à Eysses (Villeneuve-sur-Lot, Lot-et-Garonne) ou à Stanwick (Yorkshire, Grande-Bretagne) (Duval P.-M., 1977, fig. 217). Elles sont datées approximativement du changement d'ère.

À ces représentations de chevaux de grande taille, on en ajoutera d'autres, plus petites. Le cheval en bronze de Guerchy (Yonne) a été mis au jour au XIX s., vraisemblablement dans une tombe de guerrier incinéré qui comprenait une épée tordue et un umbo de bouclier datable de La Tène C (Corot, 1925). Haut de $175 \mathrm{~mm}$ et long de $220 \mathrm{~mm}$, il reposait sur un socle en tôle de fer cerclé d'une feuillure de bronze.

Le petit cheval (longueur : $210 \mathrm{~mm}$, hauteur : $120 \mathrm{~mm}$ ) en tôle de bronze de Pogny (Marne) était disposé à l'origine sur un socle disparu. Un trou rectangulaire sous le ventre pourrait être le témoignage du passage d'une hampe, s'il s'agit d'une enseigne militaire (Lantier, 1939). Un autre petit cheval de bronze a été retiré du Rhône près de Lyon en 1870 (Reinach, 1984, inv. 14699).

Quelques petites statuettes de chevaux en bronze coulé existent à la fin de La Tène, comme celle de l'oppidum de Jœuvres à Saint-Maurice-sur-Loire (Loire) datée du $\mathrm{I}^{\mathrm{er}}$ s. av. J.-C. (Déchelette, 1927, p. 813 et pl. XII, no 24). 
En ce qui concerne les représentations métalliques d'animaux, l'ensemble le plus important reste celui découvert, en 1861, à Neuvy-en-Sullias, dans le Loiret, qui regroupait dans une fosse parementée de tegulae, datée du $\mathrm{III}^{\mathrm{e}}$ s. apr. J.-C., des objets des périodes gauloise et galloromaine (Mantellier, 1866 ; Duval P.-M., 1977 ; Catalogue d'exposition, 2007). En dehors de statuettes de petits personnages et d'une trompette en bronze, trois sangliers et un probable boviné (dont la tête manquait) constitués de tôles de bronze ont été mis au jour. Deux sangliers sont de petite taille avec des hauteurs de $250 \mathrm{~mm}$ et $270 \mathrm{~mm}$ de hauteur, le dernier, grandeur nature, mesure $800 \mathrm{~mm}$ de haut. Ces animaux martelés étaient associés à un cheval de 1,03 m de hauteur fabriqué en bronze coulé.

Des fragments de crêtes ainsi qu'une extrémité de groin et plusieurs petites oreilles de sangliers-enseignes (ou de carnyx ?) ou de figurations zoomorphes ont également été mis au jour, au XIX ${ }^{\mathrm{e}}$ s., en contexte cultuel à Mandeure dans le Doubs (Catalogue d'exposition, 2007, p. 226-228).

On peut ajouter le sanglier en tôle chaudronnée de Soulac-sur-Mer (Gironde), découvert fortuitement en 1989 (Moreau et al., 1995). Constitué de tôles d'alliage cuivreux martelé, il avait été démonté et les différentes pièces avaient été placées entre les deux tôles composant la tête et le corps avant son enfouissement. Il a été daté, mais sans argument convainquant, du $\mathrm{I}^{\mathrm{er}}$ s. av. J.-C.

Un autre sanglier en tôle de bronze a été mis au jour en 1995 à Ilonse (Alpes-Maritimes) dans un contexte inconnu (Lavergne, 2000). Il avait également été démonté et était doté, comme celui de Soulac-sur-Mer, de soies dorsales matérialisées par une tôle décorée. Il ne possédait vraisemblablement pas de socle emmanché pouvant en faire une enseigne.

Enfin, à la fin des années 1980, les fragments d'un sanglier, également composé de tôles de bronze, ont été retrouvés à Naintré (Vienne) accompagnés d'armes et d'objets de parure (Lejars, 2007).

La fonction des représentations d'animaux de grande taille mises au jour en contexte cultuel reste souvent incertaine. S'agit-il de statues de culte, d'offrandes ou d'enseignes militaires? Il est possible que les deux types de représentations aient existé. Le cheval de Manching, peut être interprété comme une statue. En revanche, le sanglier de Soulac-sur-Mer conservait divers éléments (butée de hampe, clous du socle et traversant les pattes) qui indiquent qu'il s'agissait bien d'une enseigne. Ces enseignes pouvaient être entreposées dans les sanctuaires en temps de paix. On peut imaginer qu'elles étaient utilisées lors des processions

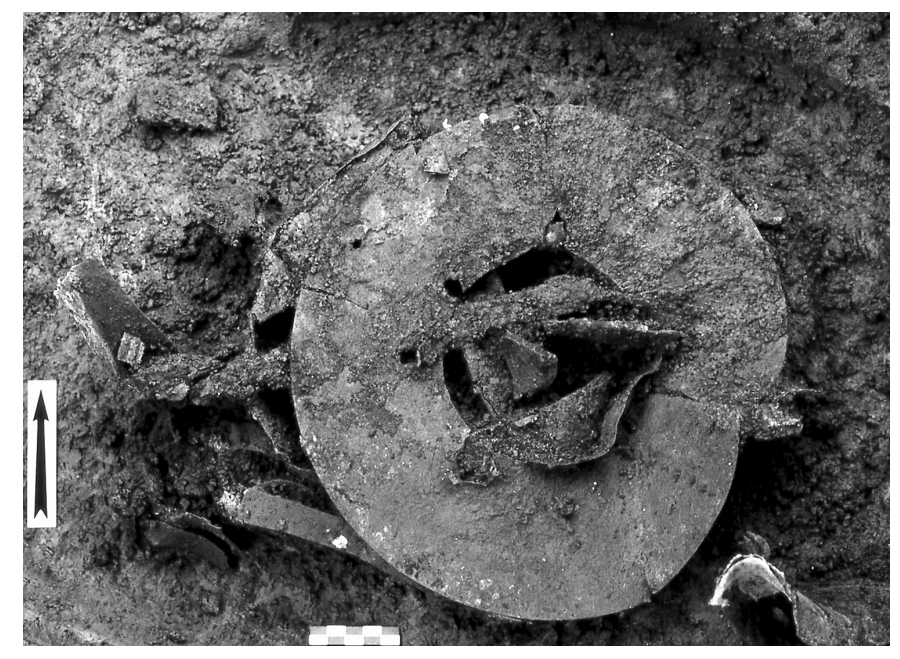

Fig. 33 - Disque en alliage cuivreux 2149-372 portant des traces d'arrachement de clous (cliché : P. Ernaux, INRAP).

rituelles guerrières qui s'y déroulaient périodiquement. On peut aussi voir dans les enseignes trouvées en contexte de sanctuaire des prises de guerre offertes par les vainqueurs en guise d'action de grâce. Elles pouvaient y être exposées sous la forme de trophées, comme en témoignent certaines représentations telles celles de l'arc d'Orange, bien qu'il s'agisse là d'une représentation commémorant une victoire des Romains sur les Barbares.

Dans le dépôt de Tintignac, la fonction des animaux de bronze reste à définir. Toutes les pièces du dépôt méritent d'être minutieusement examinées pour déterminer si certaines peuvent être interprétées comme des pièces de fixation des animaux sur une hampe d'enseigne. Un disque mis au jour dans l'excroissance circulaire au nord-ouest de la fosse pourrait avoir servi de socle à un animal-enseigne (fig. 33). En tôle de bronze assez épaisse, de $270 \mathrm{~mm}$ de diamètre, il est percé en son centre d'un trou de $110 \mathrm{~mm}$ de diamètre, sur le pourtour duquel sont visibles des traces d'arrachement de clous. On peut imaginer que le trou médian permettait le passage de la hampe et que les clous fixaient la butée sur la plaque circulaire.

\section{LES CARNYX}

Une trentaine d'objets découverts dans le dépôt de Tintignac ont été attribués à des carnyx. Les carnyx sont de grandes trompettes de guerre, de la taille d'un homme, utilisées par les Gaulois qui contribuaient, selon Polybe et Diodore de Sicile, au "tumulte guerrier ». Ces trompettes étaient tenues verticalement et dotées, à l'extrémité 
supérieure, d'un pavillon en forme de tête d'animal par la gueule ouverte duquel s'échappait le son. On les connaît aujourd'hui essentiellement par des représentations sur des monnaies gauloises ou des deniers de la période césarienne, ou bien encore sur des monuments triomphaux galloromains. Les découvertes effectives de carnyx se limitent à quelques dizaines de fragments - pas toujours identifiés comme tels -, tous anciens et dont le contexte est inconnu ou mal identifié.

À Tintignac, quatre fragments plus ou moins importants dotés de hures de sanglier sont assurément des portions de trompettes de guerre, ainsi qu'un cinquième muni, quant à lui, d'une tête de serpent. Deux têtes de sanglier en bronze coulé ont aussi sans doute constitué des pavillons de cet instrument.

Ces carnyx, les plus grands fragments du moins, font partie des premiers objets déposés dans la fosse, en même temps que les casques. D'autres fragments plus petits ont été apportés ensuite, après la mise en place du chaudron, avec l'umbo de bouclier.

\section{LES PAVILLONS}

\section{Les carnyx dotés de têtes de sanglier en tôle de bronze martelée}

Les quatre trompettes de guerre dotées de têtes de sanglier reposaient avec le casque-cygne sur le fond de la structure.

Le mieux conservé de ces instruments, retrouvé au centre de la fosse, mesure près de $0,74 \mathrm{~m}$ de longueur. La base de l'instrument, c'est-à-dire l'embouchure et le départ du tube, manque (fig. 34). La partie supérieure, linéaire puis coudée, du tube est conservée et encore en connexion avec le pavillon en forme de hure de sanglier. Elle conserve deux colliers de raccord moulés encore en place à chaque extrémité de la partie courbe du tube et un troisième, fragmenté, en partie médiane, à l'endroit où le tube est brisé. Une dernière bague, plus simple, enserre le tube près de son extrémité.

Un autre fragment de tube, long de $535 \mathrm{~mm}$, reposant presque perpendiculairement sur cet élément de carnyx, possède une bague de raccord identique à la dernière mentionnée (fig. 34). Ces éléments ont fait partie du même instrument. La longueur totale de ce dernier dépassait 1,60 m. Le tube, comme la tête de sanglier, est construit à l'aide de tôles de bronze martelées et soudées. La tête, longue de $270 \mathrm{~mm}$, est constituée de deux tôles corres-

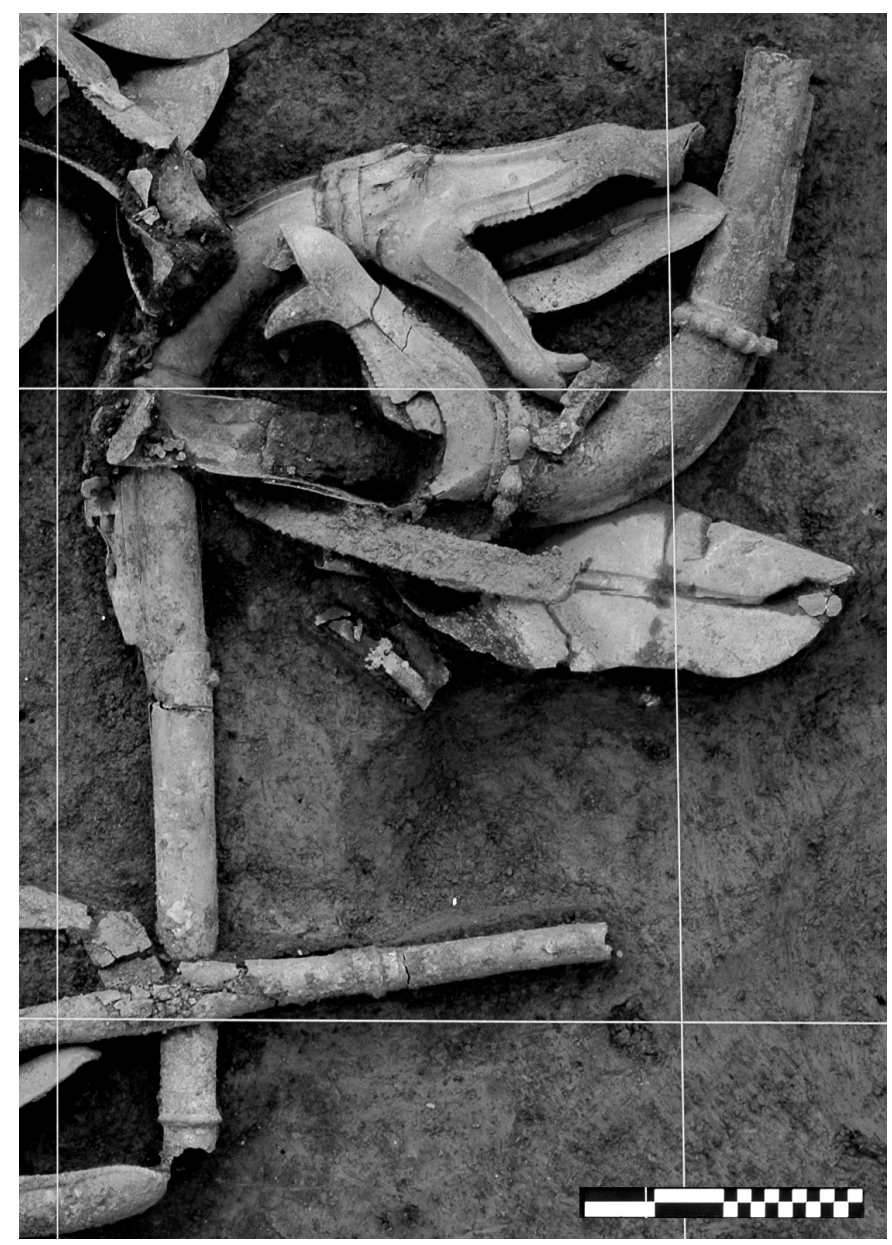

Fig. 34 - Les carnyx 2149-467 et 2149-463 (cliché : P. Ernaux, INRAP).

pondant à chaque face de l'animal. La gueule est grande ouverte. La mâchoire supérieure se termine par un boutoir plat sur lequel les naseaux sont évoqués par des cupules et une simple déformation obtenue par martelage symbolise les défenses supérieures (grès). Les dents sont stylisées sur le pourtour de la gueule. La mâchoire inférieure est dotée en outre de deux défenses saillantes découpées dans la tôle. Les muscles sont rendus par des lignes martelées et une larme apparaît sous chaque œil. Ceux-ci sont matérialisés par des cavités dans lesquelles un matériau non identifié devait prendre place. Au-dessus des yeux, deux trous circulaires recevaient, à l'origine, les oreilles (écoutes). Ces dernières avaient apparemment été retirées avant le dépôt de ce morceau de carnyx.

Dans la partie supérieure de la tête, entre les écoutes, une pièce de bronze recevait une tôle reproduisant l'échine du sanglier. Celle-ci subsiste en dessous de la partie courbe 


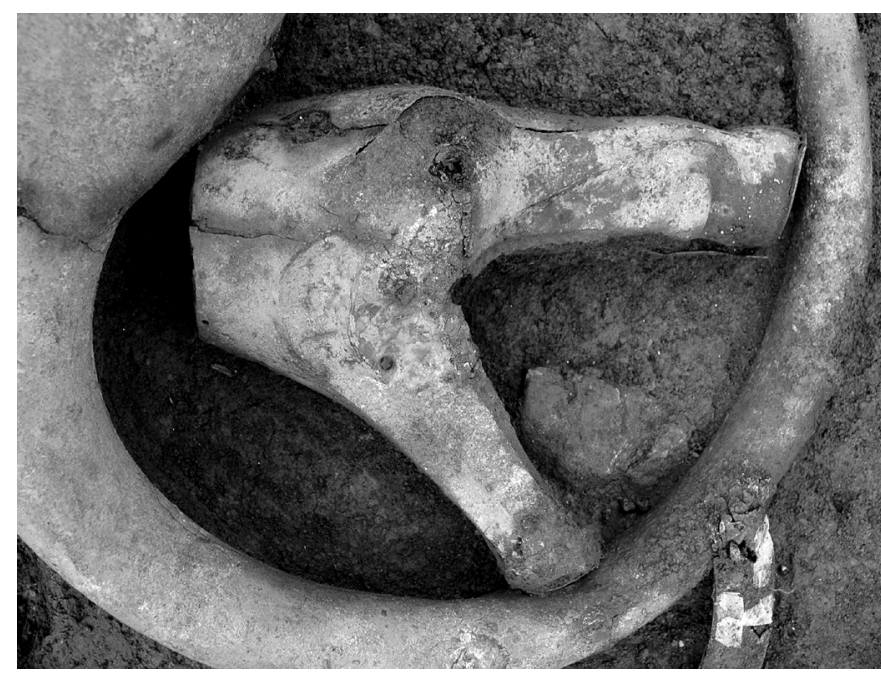

Fig. 35 - La tête de sanglier stylisée 2146-461 en tôles de bronze (cliché : P. Ernaux, INRAP).

du tube où elle est abîmée et repliée sur elle-même. Elle est constituée d'une tôle de bronze ajourée qui s'insère entre les deux demi-cylindres composant le tube de l'instrument.

Une autre extrémité distale de carnyx reposait dans le dépôt contre le précédent, orientée différemment avec le pavillon au nord (fig. 34). Ce pavillon est encore en connexion avec la partie courbe du tube et une portion droite, le tout atteignant une longueur totale de $700 \mathrm{~mm}$. Deux colliers de raccord sont encore en place, à la base de la tête et à la base de la partie coudée. L'ensemble du tube conservé est constitué de deux coques semi-cylindriques, soudées entre elles et renforcées par des bagues en bronze moulé. Il est brisé de façon nette à son extrémité sud, sans écrasement apparent. Le pavillon ressemble fortement à celui du carnyx précédent. Les défenses, saillantes, sont un peu plus développées. La partie supérieure de la gueule a subi une déformation. L'extrémité d'une lame d'épée a été retrouvée enfoncée jusqu'au fond de la gueule de l'animal. La présence de cette lame est-elle liée à un acte rituel, ou bien, cette lame, insérée entre les objets déjà placés dans le dépôt dans la phase finale, a-t-elle par hasard pénétré dans le pavillon et entraîné sa déformation?

Un troisième pavillon de carnyx représentant une tête de sanglier a été retrouvé sur le fond de la fosse, dans l'enroulement du cou du casque en forme de cygne (fig. 35). Il était seul, totalement désolidarisé du tube qui l'accompagnait à l'origine. Il est constitué, comme les précédents, de deux tôles martelées représentant chaque face et soudées entre elles. Au niveau du cou de l'animal, des trous de rivets, sans

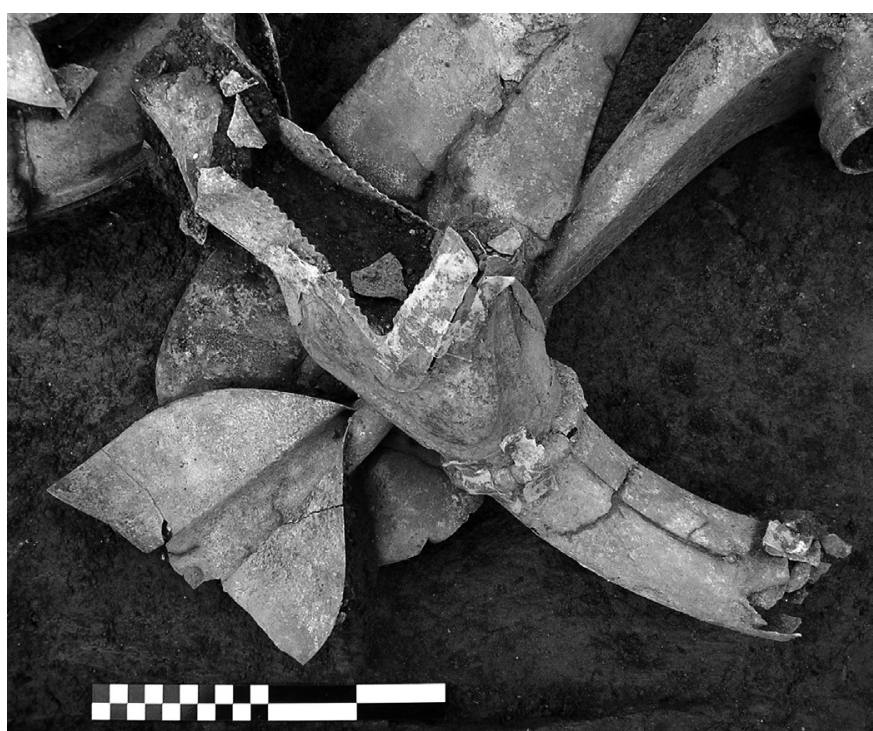

Fig. 36 - Le carnyx 2149-256 doté de l'oreille 2149-377 encore en connexion (cliché : E. Walthert, Université Paris-IV).

traces d'arrachement, semblent indiquer un démontage consciencieux de l'instrument préalablement à son dépôt. Là encore, un matériau différent occupe l'emplacement des yeux. Les défenses sont, contrairement aux pavillons précédents, constituées de petites tôles indépendantes (malheureusement brisées) soudées à l'intérieur de la gueule de l'animal. À l'arrière des yeux, deux trous bien circulaires correspondent à l'emplacement des écoutes. Un tenon en fer, soudé intérieurement au niveau de l'oreille gauche, devait renforcer son attache avec la tête. Ce tenon a sans doute été placé là suite à la cassure de l'oreille, lors d'une réparation.

Le dernier pavillon de carnyx avait été déposé en bordure sud de la fosse. Il est apparu par sa face antérieure, la gueule ouverte vers le haut (fig. 36). Les extrémités de sa hure et des mâchoires supérieure et inférieure étaient abîmées. Son boutoir avait d'ailleurs disparu ainsi que ses défenses. Il ressemble morphologiquement aux autres pavillons à tête de sanglier mis au jour dans le dépôt. Il est encore en connexion avec la partie courbe du tube. La longueur totale conservée de l'instrument est de $440 \mathrm{~mm}$ dont $180 \mathrm{~mm}$ de tube. Ce dernier semble avoir été brisé assez violemment à son extrémité. Là encore, un collier en bronze coulé subsiste à la jonction de la tête et du tube. Un matériau différent occupe la cavité de l'œil gauche. La particularité de ce pavillon réside dans le fait qu'il est encore en connexion avec l'une de ses oreilles. Celle-ci, enroulée sous la forme d'un tube à l'extrémité qui pénètre dans la tête de 
l'animal, se développe au-delà sous la forme d'une large et longue feuille de bronze munie d'une gorge médiane ; bien que brisée à son extrémité distale, sa longueur dépassait $300 \mathrm{~mm}$ pour une largeur de $165 \mathrm{~mm}$. Seule l'extrémité proximale de l'oreille gauche, en forme de tube entrant dans la tête, est conservée. La présence de telles oreilles, démesurées, était jusqu'à ce jour totalement insoupçonnée. Le son sortant par la gueule ouverte de l'animal devait aussi se propager par les trous au niveau des oreilles et être guidé par le canal aménagé sur l'axe de celles-ci. On peut donc très sérieusement envisager un rôle acoustique pour ces oreilles, dont le mouvement et les vibrations pouvaient moduler le son émis.

\section{Le carnyx à tête de serpent}

L'un des carnyx possède un pavillon en forme de serpent (fig. 37) ; il avait été déposé dans l'angle nord-est de la fosse après les autres instruments à têtes de sanglier en tôle de bronze, en même temps que les premiers casques.

Cette portion d'instrument, longue de $570 \mathrm{~mm}$, est entièrement constituée de tôles en alliage cuivreux, rivetées entre elles. La tête de l'animal pourrait avoir été moulée. Le pavillon et la partie courbe du tube sont conservés. Ce dernier n'a pas été soigneusement démonté mais semble plutôt avoir été violemment brisé, peut-être à l'aide du tranchant d'une épée, ce qui a entraîné son écrasement à l'extrémité. Le tube porte en outre, en partie médiane, une trace linéaire probablement due à un coup qui a provoqué un enfoncement ponctuel.

Deux anneaux, à la base du pavillon et au milieu du tube, maintiennent ensemble les tôles enroulées sur ellesmêmes et emboîtées les unes dans les autres. Ces colliers avaient également un rôle esthétique car ils masquent les raccords entre les diverses tôles. De petites plaques de renfort relient ces anneaux sur la face supérieure et sur la jointure inférieure. L'œil apparaît en léger relief, contrairement aux yeux des autres têtes d'animaux qui étaient en creux et avaient reçu des matériaux spécifiques. La bouche est ouverte et une petite tôle rajoutée, ornée de stries symbolisant des dents, forme un ourlet sur son pourtour.

Sur la tête et sous le cou, deux petites tôles de forme triangulaire, fixées à l'aide de rivets, sont ajourées de trois petits cercles disposés en triangle. Elles avaient très vraisemblablement un rôle esthétique.

Une bande rivetée relie, de part et d'autre de la tête, la commissure de la bouche au premier anneau de raccord.

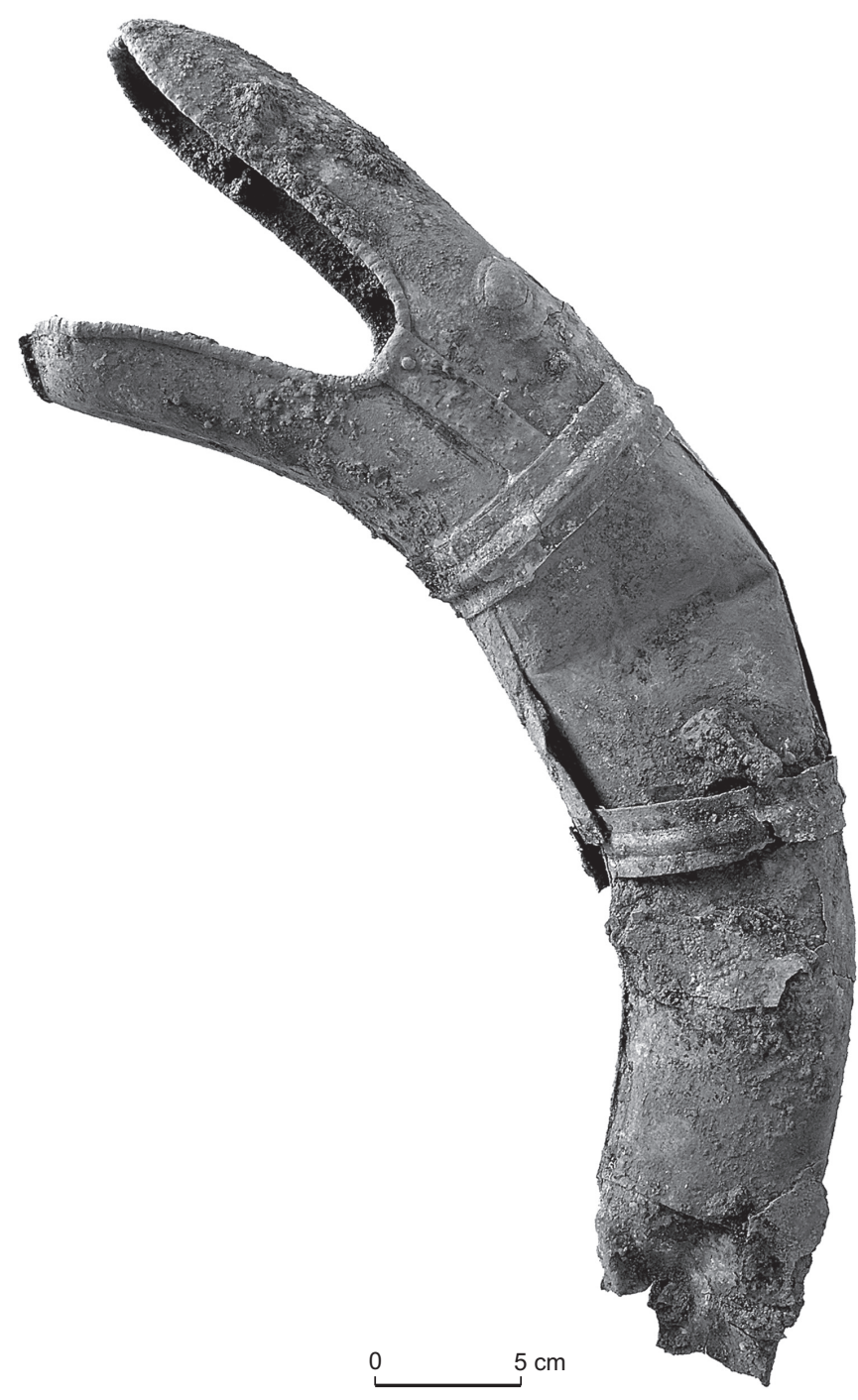

Fig. 37 - Le carnyx en forme de serpent (2149-459) après nettoyage et consolidation en laboratoire (cliché : P. Ernaux, INRAP).

Entre ce dernier et les yeux, neufs petits trous de rivets disposés en deux lignes courbes indiquent qu'un élément y était rattaché. S'agissait-il d'un diadème ou de cornes ? On connaît en effet l'importance du serpent doté de cornes de bélier qui est l'un des monstres principaux du répertoire celtique laténien.

\section{Les têtes de sanglier en bronze coulé}

Deux têtes de sanglier en bronze moulé ont été découvertes dans le dépôt (fig. $38, n^{\text {os }} 1$ et 2). Quasiment identiques, elles étaient disposées le long de la bordure nord du creusement. Longues de $240 \mathrm{~mm}$ et hautes de $90 \mathrm{~mm}$, elles 


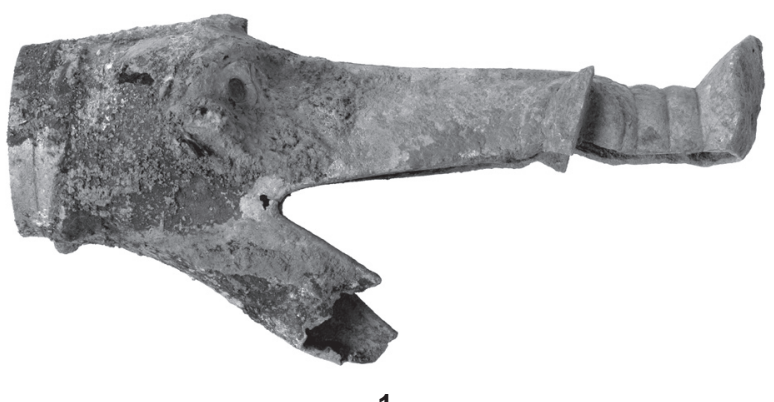

1

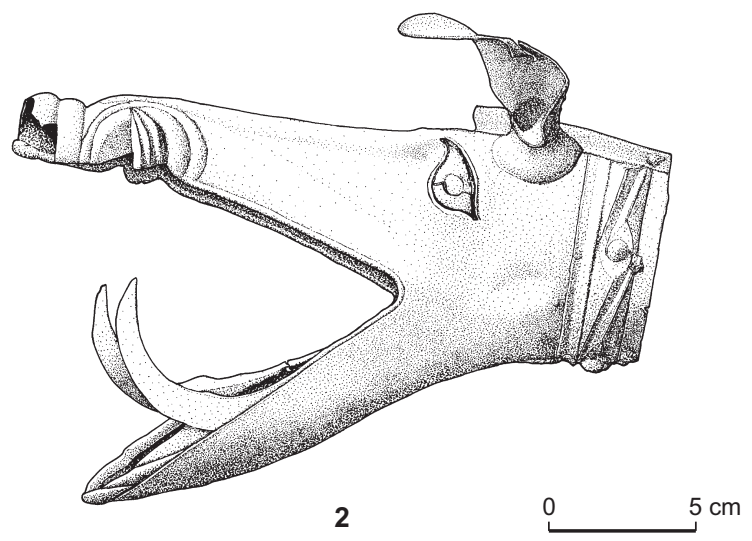

Fig. 38 - Têtes de sanglier : 1, tête 2149-334 en bronze moulé après nettoyage et consolidation en laboratoire ; 2, tête 2149-388 dotée de l'oreille 2149-410 (cliché : P. Ernaux, INRAP; dessin : C. Fouilloud, INRAP).

sont très réalistes, en particulier au niveau de la partie supérieure de la gueule de l'animal, du boutoir et des grès. La gueule est grande ouverte. À l'arrière de la tête, un collier décoré, de $70 \mathrm{~mm}$ de diamètre, devait s'emboîter sur un autre élément.

Alors que l'extrémité de la mâchoire inférieure manque sur l'une des hures, c'est l'extrémité de la mâchoire supérieure et le boutoir qui sont cassés sur l'autre. Les morceaux manquants n'ont pas été retrouvés dans la fosse. Une sorte de glissière est aménagée dans la partie supérieure du crâne, destinée vraisemblablement à encastrer une tôle verticale qui devait matérialiser une crête. Au niveau des yeux, l'emplacement de la pupille est occupé par un matériau noir (probablement du jais ou du lignite) qui s'insère dans une plaquette d'os découpée formant le reste de l'œil. Des petits trous de part et d'autre du sommet de la tête indiquent la présence initiale d'oreilles fixées à l'aide de rivets. Une seule de ces oreilles a été retrouvée encore en connexion avec une tête. La partie circulaire était en contact avec la hure. L'oreille elle-même, brisée, mesure plus de $70 \mathrm{~mm}$ de longueur pour $50 \mathrm{~mm}$ de largeur.

La fonction de ces hures de sanglier mérite discussion. En effet, elles avaient dans un premier temps été interprétées comme des gueules d'animaux-enseignes militaires, mais il s'agit plutôt, après réflexion, là encore, de pavillons de carnyx. Deux arguments tendent à aller dans ce sens. Tout d'abord, l'animal a la gueule grande ouverte, ce qui n'est pas le cas sur les enseignes connues. On pourrait cependant expliquer cela par la volonté de donner à l'animal une apparence plus féroce. La seconde raison est la présence, à l'arrière de la tête, d'un collier circulaire qui laisse envisager la connexion avec un tube plutôt qu'avec le corps d'un animal. Le poids de ces pièces pouvait aussi remettre en question leur utilisation comme pavillons de carnyx. En effet, tous ceux mis au jour dans le dépôt de Tintignac sont fabriqués à l'aide de tôles de bronze alors que ceux-ci, moulés, pouvaient sembler en comparaison, trop lourds pour être placés au sommet d'une trompette de plus de 1,50 m de hauteur. Leur poids, atteint $480 \mathrm{~g}$, ce qui paraît acceptable pour un pavillon de carnyx. Une première estimation du poids total (2 $500 \mathrm{~g})$ de l'instrument, constitué uniquement de pièces moulées, ne paraît pas considérable et rend l'interprétation envisageable.

\section{LES OREILLES}

Quatre grandes tôles découvertes dans le dépôt de Tintignac, présentant rigoureusement la même forme que celle rattachée au pavillon, peuvent dès lors être interprétées assurément comme des oreilles de carnyx. Elles ne présentent pas toutes les mêmes dimensions. Ainsi, un fragment découvert à mi-hauteur, au nord de la fosse, mesure $160 \mathrm{~mm}$ sur $130 \mathrm{~mm}$, mais seule l'extrémité distale est préservée. Les trois autres oreilles mises au jour reposaient sur le fond de la fosse. L'une d'entre elles, en forme de feuille dotée d'un canal médian, se trouvait sous le pavillon d'un carnyx, mais il n'est pas certain que les deux aient fonctionné ensemble (fig. 34). La partie proximale manque là encore. Ses dimensions sont assez " réduites » avec une longueur de près de $210 \mathrm{~mm}$ pour une largeur de $90 \mathrm{~mm}$.

Une autre tôle, intacte, représente une oreille entière (fig. 39, $\mathrm{n}^{\mathrm{o}} 1$ ). La partie proximale enroulée en forme de tube se trouvait à l'est et la partie plane avec la gorge médiane se développait à l'ouest. Sa longueur totale atteint $360 \mathrm{~mm}$ et sa largeur $160 \mathrm{~mm}$.

Enfin, l'oreille la plus impressionnante par ses dimensions (fig. 39, $\mathrm{n}^{\text {o }} 2$ ) reposait partiellement sur le bec du 

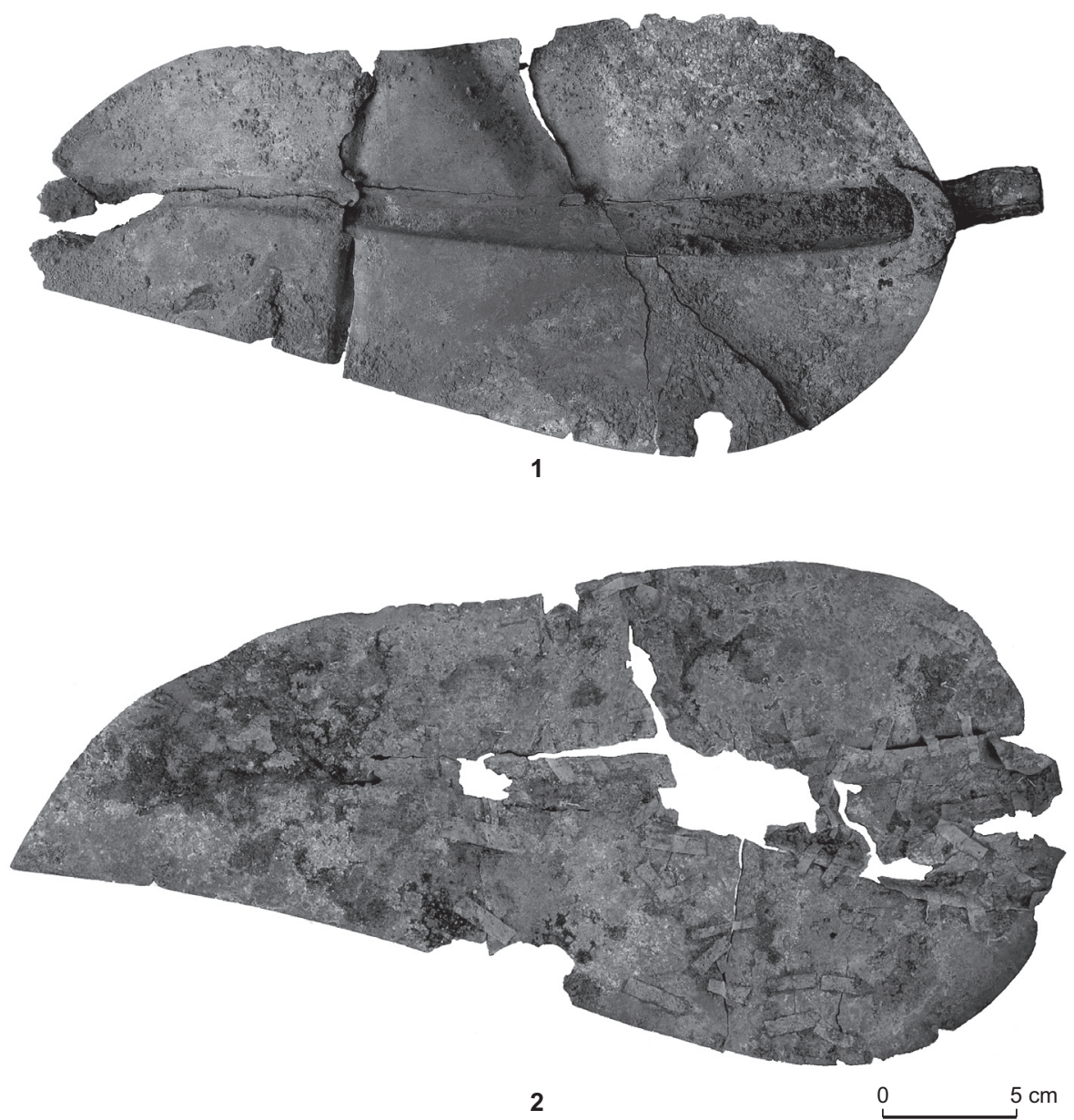

Fig. 39 - Oreilles en tôle de bronze après nettoyage et consolidation en laboratoire : 1 , oreille $2149-464 ; 2$, oreille 2149-460 de carnyx (clichés : P. Ernaux, INRAP).

casque en forme de cygne. Seul le tube pénétrant à l'origine dans le pavillon du carnyx manque. Cette tôle conserve une longueur de $410 \mathrm{~mm}$ et une largeur de $200 \mathrm{~mm}$.

Ces grandes oreilles sont à associer aux pavillons à têtes de sanglier en tôle de bronze martelée. Celles des instruments en bronze moulé sont, on l'a vu, beaucoup plus petites et ne présentent pas de canal permettant la circulation de l'air. Le carnyx à tête de serpent ne devait a priori pas posséder d'oreilles. Dans le cas contraire, il ne peut pas s'agir des grandes tôles décrites ici.

\section{LES ÉCHINES}

Les carnyx à tête de sanglier sont pourvus d'une échine constituée d'une tôle de bronze ajourée. Très fragiles, ces éléments ont le plus souvent été retrouvés sous la forme de fragments dispersés dans la fosse. Hormis celui encore en connexion avec l'un des carnyx, six morceaux de crêtes similaires ont été dénombrés. Le fragment le plus important, découvert près de l'angle sud-ouest de la structure, se présente sous la forme d'une tôle, longue de $330 \mathrm{~mm}$ et large de $85 \mathrm{~mm}$, aux bordures courbes dont l'une est doublée d'un ourlet (fig. 40). La forme de cette tôle semble correspondre à la base de la crête qui se développe sur la partie courbe du tube du carnyx et sur la partie haute du tube droit. Cet élément pourrait avoir fonctionné avec deux autres fragments de tôle découpée situés juste au-dessus dans le dépôt ou à proximité immédiate.

Une autre extrémité d'échine, longue de $150 \mathrm{~mm}$ et large de $55 \mathrm{~mm}$, a été dégagée au nord-est, près du chaudron. De forme triangulaire, l'un de ses bords est également pourvu d'un ourlet. Deux autres fragments de tôle, ajourée de façon 


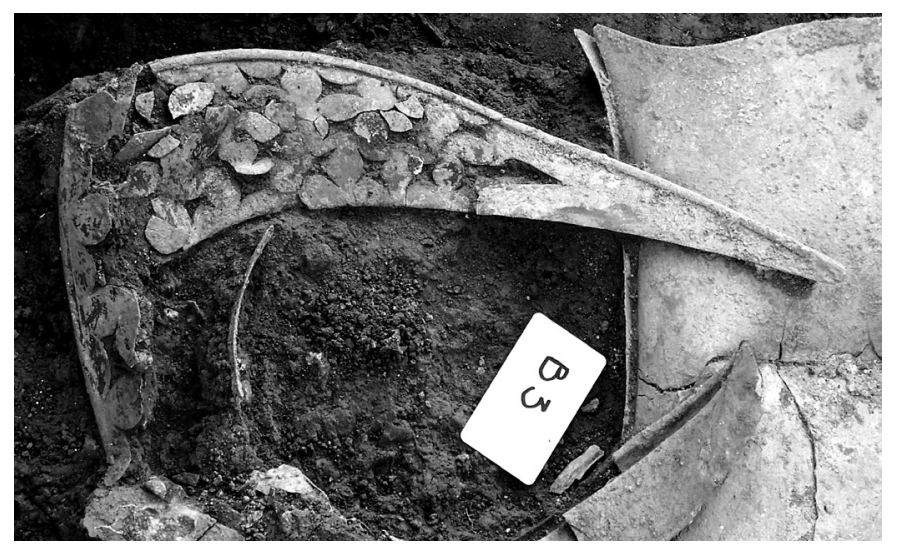

Fig. 40 - Échine 2149-254 de carnyx constituée d'une tôle de bronze ajourée (cliché : F. Loubignac, Université Bordeaux-III).

semblable, ont été extraits du dépôt, l'un dans l'excroissance circulaire de la structure et l'autre en surface.

Ces crêtes, toutes semblables, appartiennent aux carnyx à têtes de sanglier travaillés au repoussé. Le carnyx à tête de serpent en semblait dépourvu. Les têtes en bronze moulé sont, quant à elles, équipées en partie supérieure d'une glissière destinée à recevoir une échine. Soit les deux types de carnyx disposaient de crêtes identiques, soit celles des instruments en bronze coulé n'ont pas été déposées dans la fosse.

\section{LES BOUTOIRS}

Les hures de sanglier qui agrémentent les pavillons des carnyx en tôles de bronze sont dotées d'un boutoir plat à l'extrémité de leur mâchoire supérieure, constitué d'une petite tôle de bronze indépendante, quasiment circulaire (fig. 41). Une pièce de ce type, portant les petites dépressions qui matérialisent les naseaux, a été découverte sur le tube d'un carnyx. Cette pièce de $50 \mathrm{~mm}$ de diamètre est soudée perpendiculairement à une autre tôle qui a dû servir de renfort. Ce boutoir pourrait avoir appartenu au carnyx conservant son oreille, le seul dont le groin a disparu.

\section{LES TUBES}

On a pu constater que, tandis que la plupart des tubes de carnyx sont fabriqués à partir de tôles de bronze martelées, quelques autres ont été coulés. En dehors de ceux qui étaient encore en connexion avec les pavillons, neuf portions isolées ont été extraites du dépôt dont deux en bronze coulé.

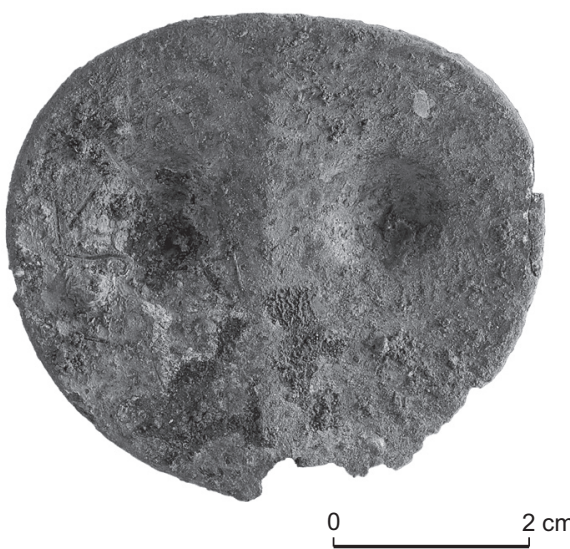

Fig. 41 - Disque en alliage cuivreux représentant l'extrémité distale de la mâchoire supérieure (boutoir) d'une hure de sanglier stylisée constituant le pavillon des carnyx (cliché : P. Ernaux, INRAP).

Le fragment le plus important se trouvait dans l'angle sud-est de la fosse, dans la partie supérieure, directement sous les fragments d'épées et de fourreaux (fig. 42). Long de $390 \mathrm{~mm}$ et d'un diamètre variant de 50 à $80 \mathrm{~mm}$, il s'agit de la partie courbe du tube, celle qui se connectait directement sur le pavillon. Un léger décor de triangles réalisé au repoussé couvre le tube de part et d'autre de l'emplacement originel de l'échine. Cet élément semble avoir été déboîté à chaque extrémité et conserve une bague de raccord ornée. Cette dernière ressemble à celle d'un autre tube qui reposait au nord de la fosse, sur l'une des têtes de sanglier en bronze coulé.

Une portion de tube, longue de près de $600 \mathrm{~mm}$, avait été délibérément insérée dans l'autre tête de sanglier en bronze coulé et rangée avec cette dernière le long de la bordure septentrionale de la fosse (fig. 43). Ce tube tronconique en tôle de bronze martelée est serti de raccords dont l'un conserve sa bague. Cette dernière est semblable à celle d'un autre tube, long de $350 \mathrm{~mm}$, qui avait été, quant à lui, placé à l'intérieur de la calotte du casque en forme de cygne.

Un autre fragment de tube a été dégagé entre les tôles composant le corps d'un animal et les fourreaux et lames d'épée supérieurs. Long de $375 \mathrm{~mm}$, il conserve lui aussi deux raccords intermédiaires mais pas de bagues en bronze coulé. Enfin, le dernier fragment de tube, plus petit, reposait, écrasé, sur le fond de la fosse.

Deux tubes ont la particularité d'avoir été coulés. Longs respectivement de $285 \mathrm{~mm}$ et $200 \mathrm{~mm}$, ils sont de forme légèrement tronconique et leur diamètre est compris entre $35 \mathrm{~mm}$ et $40 \mathrm{~mm}$. Le premier conserve deux bagues de 


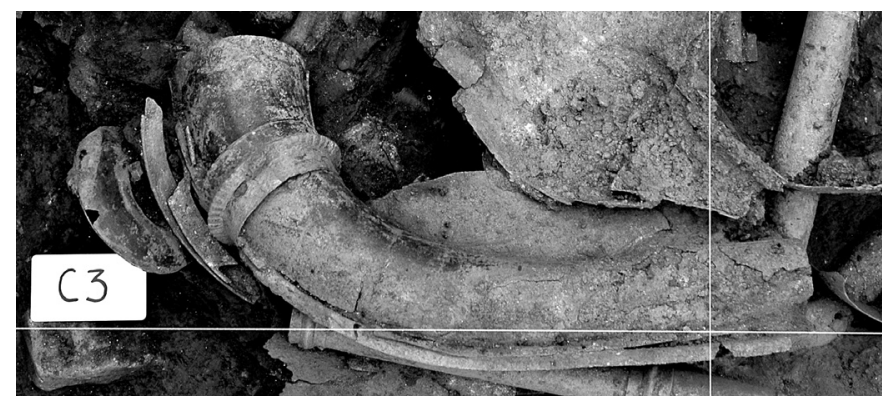

Fig. 42 - Tube 2149-288 de carnyx en tôle de bronze (cliché : P. Ernaux, INRAP).

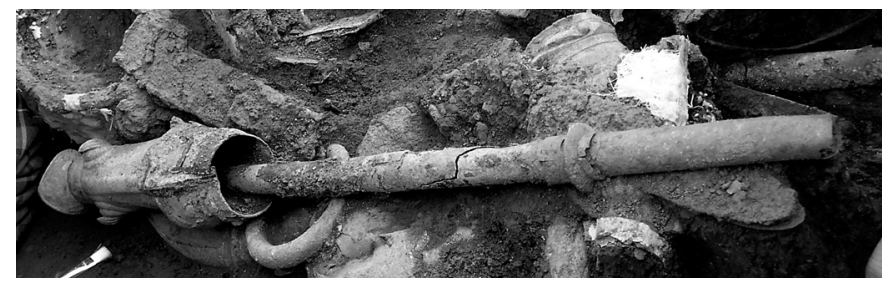

Fig. 43 - Tube 2149-333 de carnyx pénétrant dans la tête de sanglier 2149-334 (cliché : F. Loubignac, Université Bordeaux-III).

raccord encore en place et le second une seule. Étant donné la ressemblance de ces bagues, il est très probable que ces deux portions de tube appartenaient à l'origine au même instrument qui a été soigneusement démonté.

\section{LES BAGUES DE RACCORD}

Le dépôt de Tintignac a livré sept anneaux ou fragments d'anneaux en alliage cuivreux, probablement des bagues de raccord de tubes de carnyx, disséminés dans la fosse (fig. 44). Leur diamètre varie entre $60 \mathrm{~mm}$ et $75 \mathrm{~mm}$ et leur hauteur avoisine $20 \mathrm{~mm}$ à $30 \mathrm{~mm}$. Ils se trouvaient pour la plupart à mi-hauteur et font partie des derniers éléments de carnyx déposés.

\section{LES EMBOUCHURES}

Une embouchure droite d'instrument de musique a été mise au jour dans la fosse (fig. 45). Démontée avant son dépôt, elle appartenait très vraisemblablement à l'origine à un carnyx, faute d'autres types d'instruments de musique reconnus. Longue de $115 \mathrm{~mm}$ et de $25 \mathrm{~mm}$ à $35 \mathrm{~mm}$ de diamètre, elle est constituée d'un alliage cuivreux moulé. À l'opposé de l'embouchure proprement dite, un léger biseau laisse supposer son insertion initiale dans un autre tube.

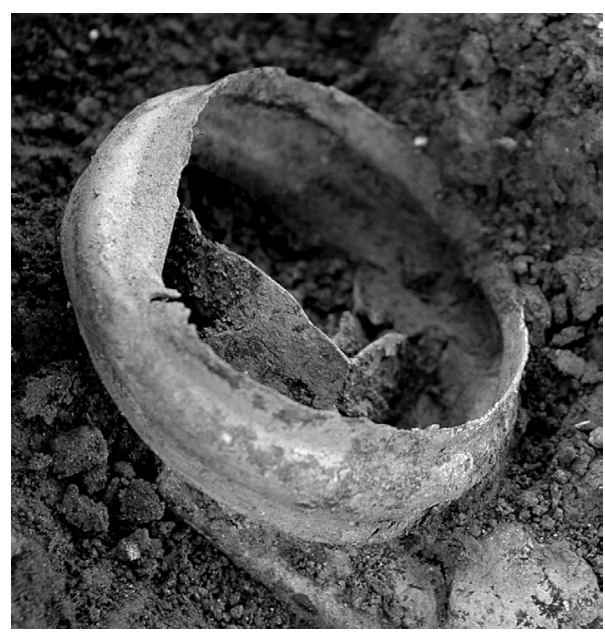

Fig. 44 - Anneau de raccord 2149-42 en tôle de bronze (cliché : P. Ernaux, INRAP).

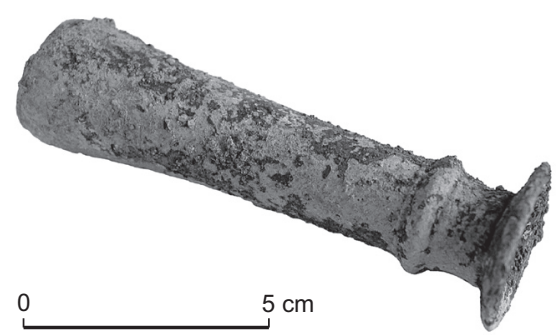

Fig. 45 - Embouchure 2149-309 de carnyx en bronze coulé (cliché : P. Ernaux, INRAP).

La radiographie du carnyx le plus complet a permis de percevoir, à l'intérieur et au milieu de la partie droite du tube, une autre embouchure qui aurait été placée dans la gueule du pavillon et se serait coincée dans le tube (fig. 46). Cette seconde embouchure semble identique à la première ${ }^{16}$.

Cette découverte est exceptionnelle car aucune embouchure de carnyx n'avait jusqu'à présent été interprétée comme telle. Ceci a très souvent entraîné des erreurs dans les restitutions de ces instruments. Étant donné la taille de l'instrument, une embouchure courbe pouvait paraître plus adaptée à son utilisation. Or, il n'en est rien. La découverte de Tintignac permet d'affirmer que les carnyx étaient en fait dotés d'embouchures droites. L'inexactitude est due en partie au fait que l'extrémité inférieure du carnyx n'apparaît que sur quelques monnaies. La scène du chaudron de Gundestrup, avec ses trois joueurs de carnyx, peut, quant à elle, être soumise à discussion.

16. Le travail en laboratoire n'a pas encore permis d'extraire cet élément collé par la corrosion. 


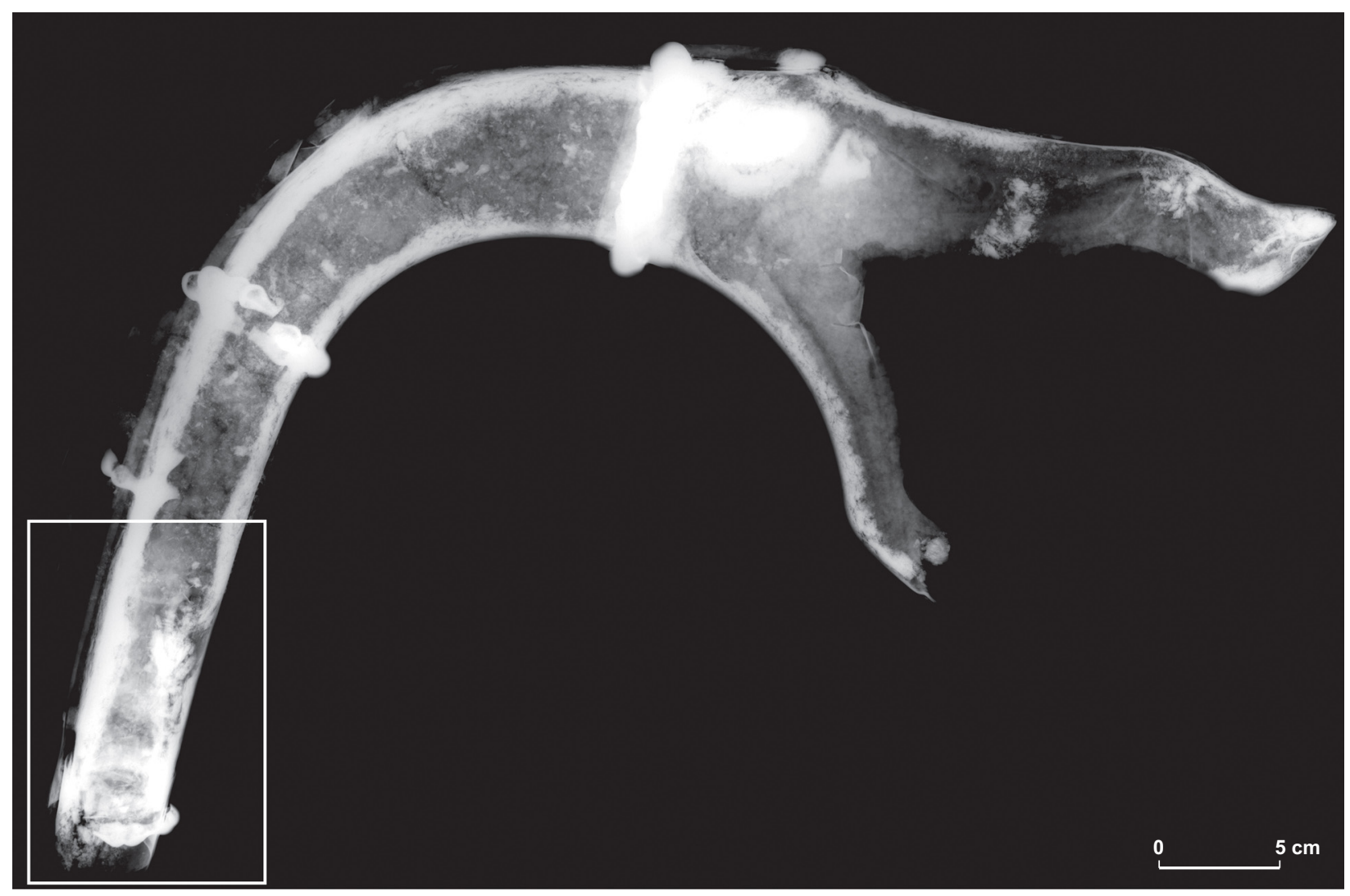

Fig. 46 - Radiographie du carnyx 2149-467. Une embouchure semble coincée à l'intérieur, dans la partie inférieure (radio. : C. Gargam, laboratoire Materia Viva).

\section{REMARQUES SUR LES CARNYX}

Ce sont donc au total sept carnyx qui ont été extraits du dépôt de Tintignac. Presque tous sont dotés d'un pavillon figurant une hure de sanglier et un seul est doté d'une tête de serpent. On connaît l'importance du sanglier à l'époque laténienne. Il est représenté sous la forme de petites statuettes de bronze ou d'enseignes militaires. Cet animal représente l'impétuosité guerrière, la force, la puissance, le courage, les vertus des combattants intrépides.

Nous avons vu que certains tubes de carnyx sont fabriqués à partir de tôles de bronze martelées, et que d'autres ont été moulés. Ces derniers ont-ils fonctionné avec l'une des têtes de sanglier en bronze coulé ? Ceci signifierait que l'on a peut-être affaire à deux générations de carnyx distinctes, les uns étant composés de tôles de bronze et les autres de portions moulées.

Une première tentative de reconstitution des carnyx a permis de déterminer que la taille originelle de l'instrument devait avoisiner $1,80 \mathrm{~m}$ du sommet du pavillon à la base de l'embouchure. Les instruments n'ont donc pas été intégralement déposés dans la fosse. En effet, l'addition des longueurs de tous les fragments de tubes, en connexion ou non avec les pavillons, égale 5,35 m. Le nombre de tubes est donc tout à fait insuffisant pour remonter tous les carnyx.

On pourra faire la même constatation à propos du nombre d'oreilles, qui s'élève à cinq. Nous avons vu que les hures de sanglier en bronze coulé étaient dotées d'oreilles plus petites et plus réalistes (une seule a été découverte) que celles en tôle martelée. Si l'on ne prend en compte que ces dernières, en excluant bien sûr le carnyx en forme de serpent, ce sont huit oreilles et non cinq qui auraient dû être retrouvées dans le dépôt.

Le nombre de découvertes effectives de fragments de carnyx reste très faible dans l'ensemble du domaine celtique laténien. Elles sont souvent anciennes et leur contexte n'est jamais parfaitement connu. Le dépôt de Tintignac est donc à ce titre exceptionnel. Le contexte est parfaitement bien défini et la mise au jour de plusieurs instruments dont toutes les parties sont représentées est unique à ce jour. 


\section{Éléments de comparaison}

Seuls deux autres pavillons de carnyx sont connus dans le monde celtique. L'un d'eux a été découvert en 1816 à Deskford en Ecosse dans une tourbière (Piggott, 1959, p. 24-29 ; Hunter, 2001, p. 78-85). Représentant une tête de sanglier en tôle de bronze martelée, il était doté à l'origine d'une langue mobile en bois. Ce pavillon ne ressemble cependant guère à ceux de Tintignac. Aucun fragment de tube ne l'accompagnait. Daté du I ${ }^{\mathrm{er}} \mathrm{s}$. apr. J.-C., cet instrument (?) était utilisé par les tribus calédoniennes dans une région située hors de l'influence romaine.

L'autre pavillon de carnyx découvert en 1883 sur le sanctuaire de Mandeure dans le Doubs présente en revanche des ressemblances troublantes avec les nôtres (Barral et al., 2005, p. 33-35 ; Catalogue d'exposition, 2007, p. 77 et p. 226). Il s'agit en fait d'une seule face de pavillon en tôle de bronze repoussé qui était accompagné lors de son dégagement d'un lot de monnaies gauloises et romaines. Comme sur les carnyx de Tintignac, de longues nervures courbes ont été martelées le long de la mâchoire de l'animal et une pointe sur le maxillaire figure la canine éversée. L'emplacement de l'œil et le trou circulaire destiné à recevoir l'oreille sont bien visibles. La datation de ce pavillon reste incertaine. Celle du dépôt dans lequel il se trouvait est estimée entre le $\mathrm{I}^{\mathrm{er}} \mathrm{s}$. av. J.-C. et le I ${ }^{\mathrm{er}} \mathrm{s}$. apr. J.-C.

En ce qui concerne les oreilles, des tôles similaires à celles de Tintignac par la forme et les dimensions ont été découvertes sur d'autres sites archéologiques mais n'avaient pas jusqu'à présent trouvé d'interprétation satisfaisante. On supposait qu'il s'agissait de feuilles d'arbres cultuels celtiques, semblables à celui, de dimensions beaucoup plus modestes, découvert sur l'oppidum de Manching. Il n'en est rien.

De telles tôles en alliage cuivreux sont ainsi issues du sanctuaire de Mandeure (Barral dir., 2007). Leurs dimensions paraissent cependant moins importantes, avec une longueur de $150 \mathrm{~mm}$ à $200 \mathrm{~mm}$. Une oreille de ce type a été mise au jour sur le site de La Tène (Duval P.-M., 1977, p. 156 ; Vouga, 1923, pl. 19, I, p. 63-64) ; elle ressemble parfaitement à celles de Tintignac. Datée a priori du $\mathrm{III}^{\mathrm{e}} \mathrm{s}$. ou du début du $\mathrm{II}^{\mathrm{e}} \mathrm{s}$. av. J.-C., elle mesure près de $450 \mathrm{~mm}$ de longueur. Un «élément foliacé », plus courbe, provenant également de La Tène, pourrait également s'apparenter à une oreille de carnyx (Egloff, 1991, p. 370). Enfin, une autre paire a été mise au jour dans une tombe de Atbentheurer Hütte près de Birkenfeld en Allemagne (Jacobsthal, 1944, $\mathrm{n}^{\mathrm{o}} 154$, pl. 93, p. 182).
Dans un article récent concernant le sanctuaire de Mandeure et son mobilier, J.-P. Guillaumet et M. Schönfelder reprennent, concernant lesfeuilles de bronze (qu'ils préfèrent appeler «flammes»), les anciennes interprétations (décors de casques, feuilles d'arbre...), remettant en question celle d'oreilles de carnyx du fait des dimensions réduites de celles de Mandeure par rapport à celles de Tintignac, de La Tène ou d'Abentheuer. Ils ajoutent cependant que « toute l'iconographie des carnyx connue [...] montre des carnyx dotés de petites oreilles» (Guillaumet, Schönfelder, 2007, p. 386). Se basant sur deux articles parus en 2005 (Maniquet, 2005a et c), ils écrivent qu'« à la base du dépôt de Tintignac, deux feuilles semblent en connexion à la base de l'embouchure de l'instrument ». Or, ces articles stipulent très clairement qu'une seule de ces tôles était " encore en connexion avec un pavillon " et en aucun cas avec une embouchure (Maniquet, 2005c, p. 32)... En ce qui concerne les oreilles de Tintignac, si les plus grandes atteignent une quarantaine de centimètres, les autres ne devaient guère dépasser $0,25 \mathrm{~m}$, ce qui les rapproche de celles de Mandeure. La morphologie de ces éléments et leur association avec des éléments de carnyx ne peuvent remettre en question leur utilisation comme des oreilles dotant à l'origine ces instruments, à Tintignac comme à Mandeure.

La présence d'une échine apparaît très clairement sur certaines représentations de carnyx et en particulier sur le chaudron de Gundestrup. Parmi les découvertes archéologiques, il est souvent difficile de déterminer s'il s'agit de crêtes de sanglier-enseigne ou bien de crêtes de carnyx, les deux symbolisant les soies dressées du sanglier agressif. Seule la courbure du fragment permet éventuellement de faire cette distinction. Plusieurs crêtes de sanglier ont été mises au jour en Gaule. On signalera celle de Naintré (Vienne), en bronze et plomb composée d'une gouttière qui enserre une plaque ajourée (Bertrand, Maguer dir., 2007, p. 239). Elle serait plutôt à rattacher à une enseigne, tout comme celle découverte avec le sanglier démonté de Soulac-sur-Mer (Gironde) ou dans le dépôt de Neuvy-enSullias (Loiret) qui renfermait une trompe antique mais aucun carnyx gaulois. Il en est sans doute de même pour celle découverte en forêt de Compiègne (Oise) en alliage cuivreux étamé et argenté, associée à une patte de sanglierenseigne et à deux sabots (Catalogue d'exposition, 2007, p. 238 et p. 240).

En revanche, un fragment de crête découvert à Mandeure et un autre, plus important, provenant du sanctuaire du Gué-de-Sciaux à Antigny (Vienne) ont sans doute appartenu à des trompettes gauloises (Bertrand, 2005 ; 
Catalogue d'exposition, 2007, p. 79, p. 236 et p. 238). En effet, celui du Gué-de-Sciaux, constitué d'une plaque en fer ajourée ourlée sur un bord d'une tôle en alliage cuivreux, possédait une courbure proche de celle que forme le tube du carnyx à l'arrière du pavillon. On notera le caractère cultuel des lieux de découverte.

Des tubes attribuables à des trompettes gauloises ont déjà été retrouvés sur d'autres sites archéologiques mais n'avaient pas trouvé d'interprétation satisfaisante en l'absence des autres parties de l'instrument. Pour cette raison, ils n'ont que rarement été publiés. On pourra cependant mentionner la découverte d'une portion de tube, longue de $220 \mathrm{~mm}$, sur le site de l'Atbentheurer Hütte en Allemagne (Jacobsthal, 1944, no 154, pl. 93, p. 182). Un tube presque complet a été découvert au XVIII ${ }^{\mathrm{e}}$ s. en Grande-Bretagne, dans la rivière Witham à Tatershall-Ferry (Piggott, 1959, p. 19-24). L'embouchure et le pavillon de l'instrument manquaient malheureusement et l'objet a aujourd'hui disparu. On ajoutera la découverte, entre 1921 et 1931, de la partie courbe d'un autre tube de carnyx, accompagnée d'autres objets métalliques, dans une tourbière, à Kappel-Durnaü en Allemagne (Fischer, 1959). Réalisé avec deux tôles de bronze martelées et rivetées, ce fragment est doté à sa base d'une bague destinée à recevoir la partie inférieure. L'ensemble du mobilier a été daté du I ${ }^{\mathrm{er}} \mathrm{s}$. av. J.-C.

En ce qui concerne les embouchures, celles de Tintignac sont les seules inventoriées comme éléments de carnyx gaulois. La présence d'embouchures d'instruments de musique sur les lieux de culte plus tardifs n'est cependant pas rare (Vendries, 2007, p. 138).

En fait, jusque-là, les carnyx étaient principalement connus par des représentations aussi bien sur des monnaies gauloises ou républicaines, que sur des monuments romains ou gallo-romains. Sur nombre de ces représentations, cependant, l'embouchure est cachée. Quand elle ne l'est pas, elle est systématiquement droite hormis sur le chaudron de Gundestrup où cela peut paraître moins évident. Un statère des Lémovices (LT 4551, 4552), daté du $\mathrm{II}^{\mathrm{e}}$ s. ou du I ${ }^{\mathrm{er}}$ s., ainsi que plusieurs deniers découverts sur le sanctuaire gaulois de Tintignac représentent au revers un cheval devant un carnyx et au-dessus d'une tête d'homme. Les oreilles du carnyx paraissent particulièrement développées et l'embouchure est droite. Deux deniers de César (Cr. 468/1 et 468/2), frappés en 45 av. J.-C., montrent au revers un trophée gaulois formé d'un casque, d'une cuirasse, de boucliers, de lances et de deux carnyx, au pied duquel deux Gaulois sont assis. Sur l'un des deux deniers (Cr. 468/2) les extrémités droites des instruments sont bien visibles. Un autre denier de César (Cr. 452/2), frappé en 48 av. J.-C., montre également au revers un trophée doté d'un carnyx entier bien dessiné. On ajoutera encore un denier de Iunius Brutus Albinus (Cr. 450/1a), de la même date, au revers duquel apparaissent deux boucliers et deux carnyx complets entrecroisés sur lesquels l'échine, les bagues de raccord et les embouchures droites sont très nettes. En 48 av. J.-C., Lucius Hostilius Saserna a fait frapper à Rome un denier (Cr. 448/3) portant sur l'avers une tête féminine "à la chevelure libre », symbolisant la Gaule, et un carnyx à l'embouchure droite en position quasi verticale à sa gauche.

Enfin, le revers d'une monnaie d'or, de la première moitié du I ${ }^{\mathrm{er}}$ s. apr. J.-C., de Tasciovanus, roi des Catuvellauni, représente un cavalier qui tient dans sa main gauche un carnyx dont l'embouchure est manifestement droite (Megaw, 1991, p. 645).

Les trompettes gauloises n'apparaissent pas seulement sur des monnaies. En effet, dans une tombe à incinération de la nécropole de Bouy (Marne) datée du I ${ }^{\mathrm{er}}$ s. av. J.-C., un petit pendentif en forme de pavillon de carnyx (doté d'une hure de sanglier à la gueule ouverte) a été découvert en 1975 (Clodoré, Vendries, 2002, p. 106-107). Était-il utilisé comme amulette?

De nombreux décors de monuments gallo-romains montrent des carnyx. Ces derniers symbolisent la nation gauloise soumise. L'une des représentations les plus célèbres est sculptée sur l'arc de triomphe d'Orange édifié en 22-23 apr. J.-C. où pas moins de 37 carnyx sont associés à des amas d'armes gauloises ou encore à des trophées (Duval, in Amy et al., 1962, p. 157 ; Picard, 1992, p. 131-132). Sur l'arc de Glanum, daté de 20 av. J.-C., un carnyx, renversé devant un trophée, est associé à un amoncellement d'armes gauloises sur lequel est assise une femme, allégorie de la Gaule vaincue (Rolland, 1977, pl. 25, pl. 27 et pl. 49-1). On retrouve encore des trompettes gauloises sur le trophée de La Turbie (Alpes-Maritimes) édifié par Auguste vers 6 av. J.-C. (Formigé, 1949, photo. no 47), ou sur le trophée augustéen de la Brague à Biot, près d'Antibes, où sont représentés, sur deux blocs, le corps et le pavillon d'un carnyx (Dor de la Souchère, 1988, pl. VII).

Le carnyx est également présent sur de nombreux monuments à Rome. On citera, entre autres, la colonne trajane, la cuirasse de la statue de Trajan (Vendries, 1993b, p. 72) et celle d'Auguste de Prima Porta (datée de 20-15 av. J.-C.) sur laquelle une femme (la Gaule) tient un carnyx, et un sanglier-enseigne est déposé à ses pieds (Moreau et al., 1995, p. 25). 


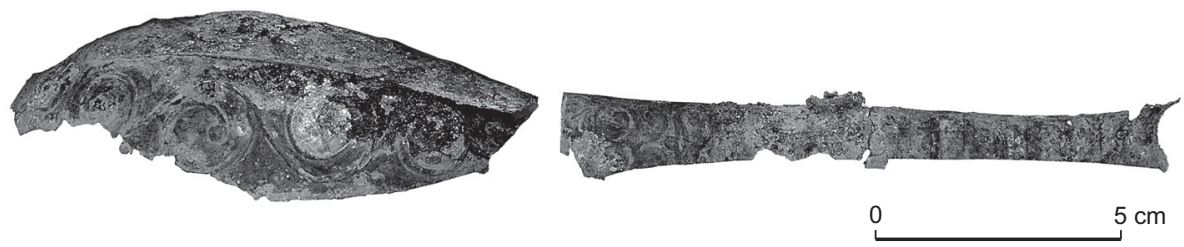

Fig. 47 - Élément 2149-147 en tôle de bronze décorée au repoussé (cliché : P. Ernaux, INRAP).

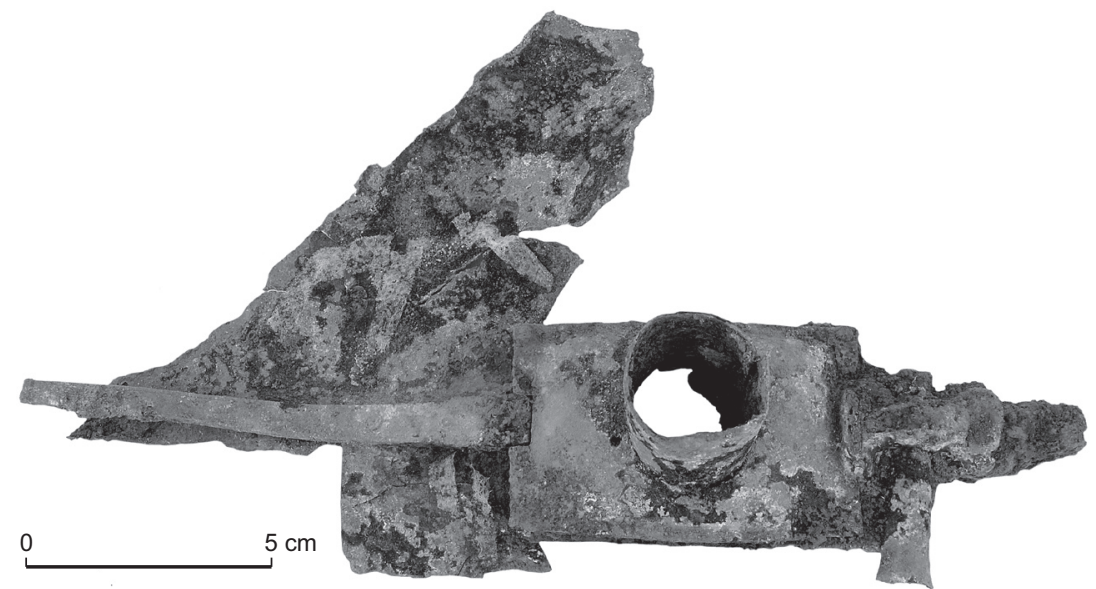

Fig. 48 - Le mécanisme fixé sur la tôle 2149-269 (cliché : P. Ernaux, INRAP).

\section{LES OBJETS NON IDENTIFIÉS}

De nombreux objets n'ont pas à ce jour trouvé d'identification satisfaisante. Quelques-uns d'entre eux, assez particuliers, seront néanmoins abordés ici de manière provisoire.

Un objet en forme de cuillère a été mis au jour dans la partie supérieure de la fosse (fig. 47). Long de $260 \mathrm{~mm}$, il possède une partie oblongue évasée (large de $55 \mathrm{~mm}$ ) et concave, et une partie plus fine (large de $15 \mathrm{~mm}$ ), allongée, pouvant s'apparenter à un manche. Il était malheureusement brisé à chaque extrémité. Cet objet en alliage cuivreux est orné au repoussé. Sur la partie élargie, le décor, peu accentué, associe des esses et des volutes réparties symétriquement de part et d'autre d'une nervure centrale. Le «manche » quant à lui est pourvu d'ondulations régulières.

Des cuillères de bronze sont connues au $\mathrm{I}^{\mathrm{er}} \mathrm{s}$. apr. J.-C, en Angleterre et en Irlande notamment (Déchelette, 1927, p. 782-783 ; Proinsias, 1991, p. 602), mais également, accompagnées d'une patère, dans une sépulture de Pogny (Marne) où elles semblent dater du $\mathrm{III}^{\mathrm{e}}$ s. av. J.-C. (Kruta, 2000, p. 779). Elles ne possèdent pas un manche rectiligne mais sont plutôt pourvues d'une excroissance semi-circu- laire servant de poucier. Ces cuillères sont pour certaines percées au fond ou sur un bord. Ces instruments étaient très vraisemblablement destinés à des pratiques rituelles.

Une autre hypothèse peut être proposée. L'objet pourrait avoir servi à protéger la spina d'un bouclier. C'est du moins ce que pourrait indiquer sa forme particulière. Si tel est le cas, la présence d'un décor sur la partie bombée indique que l'élément recouvrait l'umbo. Il ressemblerait dès lors aux garnitures de bouclier découverts outre-Manche et datées des $\mathrm{II}^{\mathrm{e}}$ s. et I ${ }^{\mathrm{er}} \mathrm{s}$. av. J.-C. : dépôt votif dans une tourbière de Llyn Cerrig Bach (Anglesey) (Green, 1991, p. 609), dans la Tamise à Wandsworth (Middlesex), ou encore umbo du bouclier découvert dans la Witham (Lincolnshire) (Megaw, Megaw, 2005, p. 9, p. 182 et p. 214).

Dans l'espace circulaire au nord-ouest de la fosse cultuelle, une tôle de bronze déchirée et relativement abîmée était dotée d'un mécanisme assez élaboré (fig. 48). Elle était écrasée par une grosse pierre déposée sensiblement en même temps que les lames et fourreaux d'épée. Deux éléments rectangulaires longs de $70 \mathrm{~mm}$ et larges de $45 \mathrm{~mm}$ sont composés d'une partie cylindrique creuse attenante à une petite plaque bombée et percée. Sur l'un 
d'entre eux une fine tôle de bronze, également percée, est encore fixée (soudée ?). De l'autre côté de cette tôle, deux petits éléments apparaissent. L'un d'entre eux se présente comme une chape, attache en bronze dans laquelle un axe ou une clavette peut être passé ; l'autre est composite, en fer et en bronze. Cet objet n'a été observé que sur le terrain et mérite une attention particulière afin d'appréhender son fonctionnement et éventuellement sa fonction.

Un autre objet étrange a été déposé avec les derniers casques. Il se compose de deux tôles de bronze martelées, vraisemblablement soudées entre elles. À l'origine il devait former une sphère d'environ $130 \mathrm{~mm}$ de diamètre qui a subi de nombreuses déformations. Cet objet ne présente pas de système de suspension ni d'ouverture. L'hypothèse d'un instrument de musique, de type hochet, a été évoquée mais ne paraît pas satisfaisante étant donnée l'absence de moyen de préhension.

Un anneau creux est constitué de deux demi-coques en alliage cuivreux assemblées. Son diamètre atteint $105 \mathrm{~mm}$ et l'espace interne semblait légèrement excentré. La fonction de cet objet demande encore à être élucidée. Déposé en même temps que les mors, il pourrait avoir fait partie du harnachement du cheval.

\section{DATATION}

\section{LA DATATION DES OBJETS}

\section{LES CASQUES}

En ce qui concerne leur datation, les différents éléments découverts ne semblent pas contemporains.

Les casques font partie des éléments les plus anciens. Ils forment un ensemble homogène, avec une forme de calotte identique, des couvre-nuques rivetés et des paragnathides semblables. Or, les seuls casques qui offrent des caractéristiques datables pourraient, d'après leur décor, appartenir à La Tène moyenne (casque en fer et bronze), voire à La Tène ancienne (casque à résille).

En effet, le décor de style plastique du casque en fer se retrouve sur plusieurs objets datés du $\mathrm{III}^{\mathrm{e}}$ s. av. J.-C. On mentionnera en particulier les anneaux de cheville en bronze à oves creux de Klettham (Bavière), de Nuremberg (Jacobsthal, 1944, p. 101), de Plaňany (Sankot, 1991b, p. 414), de Horní Kšeli (Sankot, 1991a, p. 271), de Záběhlice (Bohême) (Kruta et al., 2004, p. 143), de Rajrad (Neustupní, 1961, p. 71), ou encore de Uhřice (Moravie, République tchèque) (Kruta, 2000, p. 849). Les garnitures de char de la tombe de Mezek (Bulgarie) présentent une ornementation assez proche (Duval P.-M., 1977), bien que celles du casque de Tintignac restent apparemment totalement abstraites, aucun masque en relief n'étant visible. Plus près de nous, plusieurs objets décorés de façon semblable ont été découverts dans le monde celtique. On mentionnera, entre autres, des bracelets dans le département du Tarn et en Allemagne dans la tombe IV de Straubing-Alburg (Megaw, Megaw, 2005, p. 135), un torque en bronze dans une tombe de Villeseneux (Marne) (Duval A., 1983, p. 52 ; Kruta et al., 2004, p. 144), divers éléments de char dans une tombe de Roissy (Val-d'Oise) (Kruta et al., 2004, p. 90 ; Lejars, 2003), les appliques de bouclier à décor abstrait du Plessis-Gassot (Val-d'Oise) (Ginoux, 2004, p. 185). Les objets décorés ainsi sont issus principalement de sépultures de Bohême, de Moravie, de Slovaquie ou de Champagne et d'Île-de-France, mais restent encore très rares dans l'ouest et le sud de la Gaule. Ils sont tous attribués à La Tène moyenne.

Le casque mis au jour en 1841 à Amfreville-sous-lesMonts (Eure) dans un bras mort de la Seine possédait, comme celui découvert à Tintignac, une résille ajourée appliquée sur un timbre en bronze (légèrement étiré vers le haut). Les parties inférieure et supérieure de son timbre étaient constituées d'une double résille en fer et en bronze dans les cavités de laquelle étaient fixés, à l'aide de rivets, des cabochons d'émail rouge collés à l'aide de résine de bouleau (bétuline). Le couvre-nuque du casque d'Amfreville-sous-les-Monts était rapporté et fixé par des rivets et son cimier avait disparu. Son décor attribuable au style végétal continu a permis de le dater à peu près du milieu du IV ${ }^{\mathrm{e}}$ s. av. J.-C. (Duval A. et al., 1986 ; Lourdeaux-Jurietti, 2003, p. 119).

La résille couvrant le casque de Tintignac n'est pas non plus sans rappeler la décoration gravée du fourreau de Bölcske Madocsahegy, Tolna (Hongrie) (Megaw, Megaw, 2005, p. 129) ou encore du fourreau GSA 2624 de Gournaysur-Aronde (Oise), qui comporte sur l'avers trois résilles rivetées et est daté de La Tène B2 (Lejars, 1994, p. 219).

\section{LES CARNYX}

Le collier dont sont dotées les hures de sanglier en bronze coulé est décoré d'un motif abstrait qui pourrait appartenir au style plastique ou, du moins, s'en inspirer. L'une d'elles conserve une plaquette en os au niveau d'un oil qui devra faire l'objet d'une datation au carbone radioactif. Sur la tête et sous le cou du pavillon de carnyx en forme de serpent, les deux petites tôles de forme triangulaire ressemblent aux 
appliques rapportées sur les fourreaux GSA 1826, 1860/2651, 1863 et 2666 de Gournay-sur-Aronde datés de La Tène C1.

Si l'on s'en tient aux décors, ces instruments pourraient remonter au $\mathrm{III}^{\mathrm{e}} \mathrm{s}$. av. J.-C. Il s'agirait dès lors des plus anciennes trompes de ce type. On sait que le carnyx existait déjà à cette époque car il apparaît sur le revers d'une monnaie des Grecs d'Étolie où une femme personnifiant l'Étolie écrase un carnyx sous ses pieds. Cette frappe monétaire devait commémorer la résistance des Étoliens face à l'invasion des Gaulois de Brennus en 279 av. J.-C. (Jenkins, no 546 ; Vendries, 1993a, p. 28). Il apparaît ensuite sur un denier frappé vers 206-200 av. J.-C., à la période où Rome s'efforce de soumettre les Gaulois implantés en Cisalpine, sur lequel deux cavaliers foulent aux pieds de leur monture un bouclier et un carnyx (Crawford, 1974, vol. I, no 128, p. 207 et vol. II, pl. XXIII, no 10).

Ceci n'implique cependant pas forcément une datation aussi haute pour les autres trompes en tôles de bronze. On peut en effet imaginer que plusieurs générations de trompettes ont été rassemblées dans le dépôt, de la même façon que l'on a pu observer le décalage chronologique entre les différents types d'objets (casques et épées par exemple).

Les objets les plus anciens déposés sur le sanctuaire de Tintignac peuvent donc être attribués à une période remontant au plus tôt à La Tène B2 ou La Tène C1.

\section{LES ÉPÉES}

D’après une première observation rapide de T. Lejars, les épées et fourreaux pourraient être moins anciens que les casques. Ils constituent des ensembles a priori cohérents qui pourraient dater du milieu du $\mathrm{II}^{\mathrm{e}} \mathrm{s}$. av. J.-C. (La Tène C2/D1). Elles constituent dès lors les pièces datables les plus récentes du dépôt.

En effet, les disques-phalères, les carnyx en tôle, les animaux en tôle de bronze ne peuvent être replacés chronologiquement par manque de références ou d'éléments caractéristiques. La petite fosse à l'angle de l'enclos du sanctuaire de Tintignac recelait donc des objets non contemporains, dont la datation est comprise entre La Tène B2 et La Tène C2/D1. Si l'on considère que les éléments déposés dans la fosse sont des instruments cultuels employés lors de rites guerriers menés sur le sanctuaire, ou s'ils constituaient des armes-reliques d'ancêtres prestigieux, ces différences de datation sont compréhensibles ${ }^{17}$.

17. On rappellera ainsi qu'aujourd'hui encore, les reliques de saints conservées par le clergé judéo-chrétien sont souvent anciennes de

\section{LA DATATION DU SANCTUAIRE}

Hormis les objets du dépôt, aucun vestige mis au jour sur l'espace du sanctuaire ne semble, pour le moment, remonter aussi haut dans le temps. La céramique et les amphores n'indiquent pas une occupation antérieure au début du $\mathrm{I}^{\mathrm{er}}$ s. av. J.-C., soit la fin de La Tène D1. Les monnaies datées du milieu du $\mathrm{II}^{\mathrm{e}}$ s. av. J.-C. semblent avoir beaucoup circulé avant d'arriver sur le sanctuaire. Les fibules les plus anciennes apportent, quant à elles, une datation de La Tène D2.

Il est cependant difficile de savoir si cette datation correspond vraiment à la mise en place du sanctuaire, car les fossés les plus anciens qui, rappelons-le, ne sont pas des fossés ouverts, sont complètement stériles en mobilier et il n'est pas possible de savoir si le bâtiment central en bois existait dès l'origine.

L'abandon définitif du sanctuaire, vers la fin du III $^{\mathrm{e}}$ s. apr. J.-C., est marqué par l'incendie de plusieurs édifices gallo-romains. Le sanctuaire gaulois semble, quant à lui, être abandonné dans les dernières décennies avant notre ère pour être rebâti sous une forme différente, en employant des matériaux et des techniques empruntés à l'architecture romaine.

Le nivellement du sanctuaire protohistorique est matérialisé, nous l'avons vu, par une couche charbonneuse, relativement riche en mobilier qui vient sceller le dépôt et les fossés de l'enclos et qui a livré des deniers de Marc-Antoine, dont l'un a été daté de 32-31 av. J.-C. Ceci signifie que le sanctuaire est transformé au plus tôt au début de la période augustéenne. Cependant, les premiers vestiges " galloromains » ne semblent pas remonter avant 10 av. J.-C. C'est probablement aux alentours de cette date que la reconstruction du sanctuaire a eu lieu.

L'enclos cultuel gaulois de Tintignac aurait donc subsisté durant quasiment tout le $\mathrm{I}^{\mathrm{er}}$ s. av. J.-C.

\section{LA DATATION DE L'ENFOUISSEMENT}

À quel moment ces objets ont-ils été enfouis dans l'angle de la plate-forme sacrée du sanctuaire gaulois ? Est-ce lors de la construction de ce dernier, lors d'une cérémonie particulière, ou lors d'une destruction ou d'un remaniement majeur?

plusieurs siècles et remontent parfois au XII ${ }^{\mathrm{e}}$ s., voire avant. Il est donc tout à fait envisageable que les éléments enfouis aient été conservés durant deux à quatre siècles comme de précieuses reliques, sans doute exhibées lors de cérémonies majeures. 
Si ces objets avaient été enfouis lors de la fondation du sanctuaire ou au cours d'un rituel important, on aurait pris le temps d'ouvrir une cavité de dimensions plus importantes et surtout de la colmater avec soin, afin de la rendre invisible et inaccessible depuis la surface. Or, les objets situés dans la partie supérieure du dépôt devaient affleurer le niveau de circulation interne du sanctuaire. C'est l'apport volontaire d'une couche charbonneuse qui a permis de les cacher à la vue. Or, ce niveau scelle également les remplissages de l'angle nord-est des enclos successifs, ce qui signifie que la palissade périphérique était déjà détruite. C'est donc très certainement lors de la destruction du lieu de culte indigène et avant sa transformation, dans les décennies précédant notre ère, que les objets ont été déposés.

On peut dès lors proposer, malgré la présence d'objets relativement anciens, que l'acte de déposition a été réalisé au cours de la seconde moitié du I ${ }^{\mathrm{er}} \mathrm{s}$. av. J.-C. et sans doute dans le dernier quart.

Il est vraisemblable, dès lors, que certains objets, nantis sans doute d'un caractère sacré, ont été amenés sur le sanctuaire après sa construction et pourraient avoir été conservés ou exposés sur le lieu de culte en mémoire d'une bataille victorieuse ou en l'honneur d'ancêtres valeureux au combat (Brunaux, 2000).

\section{PREMIÈRES INTERPRÉTATIONS}

L'évolution du site de Tintignac, du moins celle de son temple, depuis sa mise en place jusqu'à sa destruction par incendie à la fin du $\mathrm{III}^{\mathrm{e}}$ s. apr. J.-C., commence à être bien cernée. Sa morphologie avant notre ère, avec ses enclos quadrangulaires, trouve de nombreuses comparaisons dans le monde celtique. Le bâtiment de bois au centre de la plate-forme sacrée, moins courant, a fait l'objet d'une fouille minutieuse rendue complexe du fait des multiples reconstructions. Dans l'angle nord-est de l'espace sacré, la découverte d'un riche dépôt, bien repéré spatialement dans un contexte tout aussi bien appréhendé, est une source d'information majeure.

\section{LES OBJETS DANS LA FOSSE}

La petite fosse cultuelle a donc livré 9 épées brisées et autant de fourreaux ${ }^{18}, 8$ fers de lance, 1 umbo de bouclier, 10 ou 11 casques mutilés, 1 mors de cheval, 7 disques

18. D'après le nombre d'entrées, bien que le nombre de bouterolles et d'extrémité de lames soit insuffisant. (d'ornement de harnachement), 2 têtes, 4 corps et 6 pattes d'animaux en tôles de bronze, 1 chaudron et 7 carnyx incomplets, sans compter toutes les pièces qui n'ont pas encore pu être correctement identifiées.

Les armes en fer restent tout à fait conventionnelles 19 et ne diffèrent pas de celles découvertes sur d'autres sanctuaires laténiens. Les casques, en revanche, sont beaucoup plus exceptionnels, tels celui doté de trois anneaux ou celui en forme de cygne. S'agit-il véritablement d'armes de combat ou bien sont-elles uniquement destinées à participer à des cérémonies rituelles à caractère guerrier ? En ce qui concerne les carnyx, là encore, leur découverte relève de l'extraordinaire dans la mesure où ces instruments n'étaient représentés que par quelques fragments dont deux pavillons présentés dans les musées européens. Certains objets découverts anciennement près de Bonn en Allemagne ou sur le site de La Tène en Suisse peuvent enfin être interprétés comme des tubes ou des oreilles de trompettes gauloises. La fouille du dépôt de Tintignac a en outre permis, pour la première fois, la mise au jour d'embouchures de ces instruments de musique.

Il est étonnant de ne pas avoir retrouvé de monnaies au sein du dépôt. En effet, nous avons vu que lors de l'utilisation du sanctuaire protohistorique, au moment de la conquête romaine, de nombreuses monnaies ont été apportées à proximité du bâtiment central en bois. Quelques-unes ont été mises au jour dans les niveaux qui scellent le dépôt, mais aucune n'accompagnait les armes et instruments de ce dernier. On peut dès lors imaginer qu'elles possédaient un statut différent aux yeux des officiants. Elles n'étaient sans doute pas considérées comme des objets cérémoniels, attributs de la divinité, mais comme des offrandes apportées par les pèlerins, dans le cadre de vœux individuels ou collectifs.

En ce qui concerne la céramique, seulement cinq petits tessons de panse ont été découverts dans la fosse, dont deux d'amphore et trois de céramique commune grossière de tradition indigène, indatable.

On notera, en outre, l'absence totale d'ossements animaux dans le dépôt. Cette absence peut s'expliquer par l'acidité du terrain local qui les a fait presque totalement disparaître. Les dents d'ovicapridés sont les ossements les mieux conservés sur le site. Seule une plaquette en os entrait dans la composition de l'œil d'une hure de sanglier ${ }^{20}$.

19. Mise à part l'épée dotée d'une poignée de bronze.

20. Le sédiment qui accompagnait les objets fera lui aussi l'objet d'analyses diverses (palynologie, carpologie, anthracologie, ${ }^{14} \mathrm{C}$, etc.) . 


\section{ORDRE ET MUTILATIONS}

L'ensemble du mobilier déposé dans cette fosse a été soigneusement sélectionné. Les objets ont été rangés avec visiblement l'ambition d'en loger un maximum dans le creusement. Comme nous l'avons vu, des tubes ont été enfilés dans des pavillons de carnyx ou dans des casques. Le colmatage après leur dépôt semble avoir été assez rapide, empêchant le déplacement des objets après enfouissement. Seules quelques lames d'épée semblent avoir glissé en bord de fosse, le long des parois. La présence de matière organique (cuir, bois), en abondance dans la structure, aurait inévitablement entraîné un tassement, même léger au-dessus du dépôt.

La fouille a démontré que tous les objets ont été enterrés ensemble. L'ordre dans lequel ils ont été déposés montre une succession réfléchie de ceux-ci. En effet, le casque en forme de cygne a été peu mutilé et déposé en premier et suivi de près par les carnyx les mieux conservés. Ces pièces avaient-elles davantage de valeur aux yeux des officiants ? Quoi qu'il en soit, cette organisation particulière au sein de la fosse révèle qu'une cérémonie très organisée devait guider la mise en terre de chaque objet. On imagine aisément que les actes de mutilation, les coups portés à l'aide de lances et d'épées, aient fait partie intégrante de cette cérémonie. Ainsi, si les épées et lances retrouvées dans le dépôt sont les armes qui ont servi à mutiler les autres objets (casques et carnyx), il est logique qu'elles se retrouvent dans la partie supérieure de la fosse. On rappellera que les épées et fourreaux ont pour la plupart été brisés en deux, les traces de torsion n'apparaissant que sur quelques fourreaux.

Les armes (épées, fourreaux, casques, umbo de bouclier) ont toutes subi des mutilations sévères qui les ont parfois complètement écrasées. Les coups portés sur les carnyx, le chaudron ou sur les tôles des animaux de bronze sont beaucoup moins nombreux et violents. Les carnyx ont été scindés en plusieurs fragments de tailles diverses mais ils n'ont pas, malgré leur fragilité relative, été rendus méconnaissables comme certains casques. Le sacrifice des armes semble dès lors avoir été privilégié. Sur le reste du site, les monnaies d'argent ont quasiment toutes été mutilées mais pas les monnaies de bronze. Les monnaies d'argent, de valeur supérieure, étaient vraisemblablement plus susceptibles d'être pillées pour être réutilisées. Au même titre, il fallait empêcher toute réutilisation des armes dédiées à la divinité.

Un autre point mérite une attention particulière : aucun objet n'a été déposé dans son intégrité. Tous étaient brisés et tous les fragments n'ont pas été déposés dans cette fosse. Où sont les embouchures, tubes et oreilles de carnyx manquants, les pattes absentes des animaux en tôles de bronze ? Ont-ils été déposés dans une autre fosse, ailleurs sur le site ? La campagne de fouille 2005 qui s'est portée sur l'angle sud-est du sanctuaire protohistorique a permis d'exclure l'existence d'un autre dépôt dans cette zone. Cependant, rien ne permet d'affirmer que les parties manquantes ont été enterrées. Ont-elles été conservées ? Ont-elles été volontairement ou involontairement abandonnées lors de la mutilation des objets ? Si ces derniers ont constitué un trophée guerrier, ces éléments ont peut-être été brisés pendant le combat et exposés incomplets sur le sanctuaire.

Une autre question se pose alors : les armes et objets ont-ils été mutilés avant leur exposition ou avant leur enfouissement ? On aurait tendance à penser qu'ils ont été brisés, tout comme les monnaies découvertes sur le site, lors de leur mise en terre. Ceci permettait à ces objets de conserver leur nature d'offrande tout en les soustrayant à l'usage des mortels.

\section{LA POSITION PRIMAIRE DES OBJETS}

Les amas d'armes découverts à Gournay-sur-Aronde montrent que des panoplies prestigieuses prises à l'ennemi étaient offertes aux dieux sur les lieux mêmes où on les honorait habituellement, voire directement sur le champ de bataille, là où l'ennemi s'était incliné (Brunaux, 2000, p. 105). Deux questions se posent alors, si le dépôt d'armes de Tintignac devait être considéré comme un trophée. Est-on sur l'emplacement d'une bataille oubliée qui aurait eu lieu vers le milieu du $\mathrm{II}^{\mathrm{e}}$ s. av. J.-C., et au terme de laquelle les vainqueurs auraient pris les armes à l'ennemi et les auraient conservés comme reliques jusqu'au moment de leur enfouissement ? On peut également imaginer que ces armes aient été rapportées sur le territoire de la tribu, dans le sanctuaire, afin de les offrir à la divinité en guise de remerciement pour la victoire accordée. Dans un cas comme dans l'autre, cette éventuelle bataille n'a pas laissé de traces dans les textes. Opposait-elle les Lémovices à une autre tribu?

Les éléments enfouis se trouvaient-ils en position primaire sur le sanctuaire, apportés pour être offerts à la divinité en les enterrant, ou bien en position secondaire ? Dans ce dernier cas, où se trouvaient les objets avant leur enfouissement? 
Ces armes et instruments ont pu être exposés sur le sanctuaire à la vue de tous, avant d'être enfouis. Cette exposition pouvait se faire de diverses manières : soit sous la forme de trophées, soit suspendus aux palissades ou au porche d'entrée du sanctuaire (Brunaux, 2000, p. 145-146). Une telle exposition sur le sanctuaire tenait lieu de prière perpétuelle en attirant l'attention du dieu. On ne peut imaginer que l'on ait attendu leur rupture ou leur chute progressive pour les enterrer les uns après les autres car l'enfouissement s'est fait en une seule phase et, de plus, dans un ordre réfléchi lié à la nature des objets.

$\mathrm{Au}$ nord-ouest de la structure recevant les objets se développe une excroissance circulaire. Ce creusement circulaire recevait-il à l'origine un poteau, ancré peu profondément dans le sol $(0,30 \mathrm{~m})$, qui aurait été retiré et au pied duquel on aurait creusé une extension quadrangulaire aux angles arrondis ? L'ensemble du creusement présente un fond plat sans surcreusement ni dénivellation. Le cas échéant, cette hypothèse privilégierait l'interprétation d'une exposition initiale de ces objets, sous forme de trophée. Ces panoplies guerrières constituées d'armes et d'objets (tuniques, étendards...), généralement fixées sur un poteau de bois, sont souvent représentées sur des monnaies romaines ou des monuments triomphaux galloromains. L'encyclopédiste Elien, du $\mathrm{II}^{\mathrm{e}} \mathrm{s}$. apr. J.-C., écrivait : «Mais surtout ils [les Celtes] érigent des trophées à la façon des Grecs, autant pour célébrer leurs hauts faits guerriers que pour laisser derrière eux des monuments de leur vertu [guerrière]"(Elien, Histoire variée, XII, 23).

Le trou de poteau mis au jour à l'ouest a-t-il fonctionné avec cet éventuel trophée ou lui est-il postérieur ? La présence d'un gros objet de bronze sur son fond aurait tendance à l'assimiler à une même phase d'occupation.

\section{LA FONGTION INITIALE DES OBJETS}

On constate qu'une grande partie des objets possède un caractère guerrier : il s'agit d'armes offensives (épées, fourreaux, fers de lance) ou défensives (umbo de bouclier, casques). Certains autres se rattachent vraisemblablement au cavalier, indissociable de la guerre (mors et phalères), et au cheval.

Les animaux en bronze pourraient, quant à eux, correspondre à des enseignes guerrières mais la possibilité de leur utilisation comme statues de culte ne peut être écartée. Les carnyx sont eux aussi à rattacher au combat, car ces trompettes sont d'après les auteurs antiques utilisées lors des assauts guerriers ou lors de la tenue d'assemblées. En fait, le seul élément qui n'entre pas dans un protocole guerrier reste le chaudron qui possède un aspect cultuel indubitable. Sur un sanctuaire comme celui de Tintignac, le chaudron a pu être utilisé lors des banquets rituels.

On peut imaginer que les objets que renfermait le dépôt de Tintignac étaient utilisés à l'origine au cours de cérémonies rituelles guerrières menées sur le sanctuaire. Le cas échéant, les animaux en tôle de bronze pouvaient être utilisés comme statues de culte et non comme enseignes guerrières. Le rituel pouvait être dirigé par un clergé armé et casqué, et rythmé par le son des trompettes. De telles assemblées sont connues sur les sanctuaires, en particulier grâce au texte de Hirtius, dans le livre VIII de la Guerre des Gaules, qui indique que les Bellovaques, suite à la mort de Corréos et la perte de leur cavalerie, convoquent une assemblée au son des trompettes et proclament qu'il faut envoyer à César des députés et des otages (César, Guerre des Gaules, VIII, 20).

Sur l'une des plaques de métal interne du bassin cérémoniel de Gundestrup, trois joueurs de carnyx suivent un homme portant sur l'épaule une grande épée et une troupe de six fantassins armés d'une lance et d'un grand bouclier avancent vers la gauche en direction d'un chien dressé sur ses pattes postérieures. Au-dessus, et séparé d'eux par un rameau fleuri, deux groupes de deux cavaliers se dirigent vers la droite, derrière un serpent à tête de bélier. Ils arborent sur leurs casques différents emblèmes : roue, cornes, sanglier et oiseau. À l'extrême gauche, un personnage vêtu d'un justaucorps et dont les cheveux sont rassemblés en une longue tresse occupe toute la hauteur de la plaque. Il saisit par la taille et par une jambe un petit personnage qu'il semble vouloir plonger la tête la première dans un grand récipient (un chaudron ?) figuré devant lui.

De nombreux éléments illustrés sur cette plaque ont été retrouvés dans le dépôt de Tintignac : les carnyx, les armes (épées, fourreaux, umbo, casques...), les éléments de harnais de chevaux et surtout le chaudron. Ne pourrait-on dès lors voir dans ce dépôt l'ensemble des ustensiles utilisés au cours de la cérémonie représentée sur le chaudron de Gundestrup ? Certains ont considéré que le grand personnage pouvait représenter un prêtre ou une divinité. Dans ce dernier cas, il pourrait s'agir de Teutatès. En effet, la légende veut que l'on plonge, lors des rites qui lui sont consacrés, un personnage la tête la première dans une vaste cuve. Pour certains, ce rituel magique permet d'acquérir l'immortalité et le chaudron symbolise la résurrection. Strabon en particulier parle d'un usage barbare des Cimbres selon lequel des femmes recevaient, le glaive à la main, les prisonniers de 
guerre, les couronnaient et les menaient auprès d'un grand bassin de bronze. Installées au sommet d'une échelle, elles les égorgeaient au-dessus du bassin. Du sang qui coulait, elles tiraient des prédictions. D’après Jan de Vries, la scène $\mathrm{du}$ bassin de Gundestrup indique que le chaudron est au centre d'un rite : des hommes vont au chaudron, y sont plongés et en repartent soldats à cheval. Il considère à juste titre que plutôt qu'une résurrection des morts, il faille y voir un rite d'initiation qui sépare deux phases de la vie du guerrier. «En ce cas, les hommes à cheval pourraient être les jeunes gens de la tribu qui viennent d'être faits "chevaliers" »(De Vries, 1975, p. 55). Les objets découverts dans le dépôt de Tintignac participaient peut-être de ce genre de rituel pratiqué sur le sanctuaire au son des trompettes. Teutatès est considéré comme le dieu de la tribu, protecteur de la communauté dont l'unité se manifeste avant tout sous les armes. "Ce dieu, par nature présent chez chaque peuple, peut revêtir des identités assez diverses, jouir de fonction assez variées, suivant la sensibilité, l'histoire de chacune de ces populations »(Brunaux, 2005, p. 201). Il fut assimilé à l'époque romaine tantôt à Mars, tantôt à Mercure. Plusieurs indices tendent à révéler qu'à Tintignac, l'ensemble monumental gallo-romain qui remplacera le sanctuaire protohistorique pouvait être voué à Mars.

Les objets mis au jour possédaient donc vraisemblablement un caractère sacré et étaient peut-être utilisés périodiquement lors de cérémonies d'initiation guerrière. Ils auraient alors été enfouis lors d'une période de trouble ou lors d'un changement des mentalités et des rituels lié à la romanisation. Les objets métalliques ont alors certainement été enterrés parce que le culte auquel ces éléments étaient associés était en danger ou sur le point de disparaître. Dans ce cas-là, on pourrait considérer que le dépôt n'avait rien de votif mais pour seule ambition de laisser à la divinité du lieu ce qui lui appartenait et de protéger les objets du pillage.

\section{LE SANCTUAIRE DE TINTIGNAC DANS L'ESPACE LÉMOVICE}

Le dépôt du sanctuaire de Tintignac est une découverte exceptionnelle qui ne semble cependant pas devoir indiquer un statut particulier du lieu de culte. Sans vouloir atténuer l'importance de ce dernier dont l'emplacement sera repris et monumentalisé à l'époque gallo-romaine, on notera qu'il a livré relativement peu de mobilier en dehors des monnaies mutilées. En effet, la céramique est en général grossière et ne témoigne d'aucun critère de luxe ou de richesse. En outre, le dernier fossé d'enclos a livré des tessons d'amphore, mais la quantité reste bien inférieure à ce qui provient d'autres sanctuaires de cette période. Bien que les inventaires ne soient pas tous réalisés à ce jour, il demeure impossible d'imaginer à Tintignac les gigantesques banquets tels ceux qui ont dû être organisés au puy de Corent dans le Puy-de-Dôme (Poux, 2004).

L'emplacement du sanctuaire dans l'espace lémovice, excentré vers le sud mais bien situé dans le département de la Corrèze, pourrait en faire le sanctuaire principal d'un pagus du peuple lémovice. Il a sans doute constitué, au début de notre ère, le pôle de romanisation principal des populations rurales de ce pagus. En effet, aucun espace urbain suffisamment conséquent aux alentours ne semble pouvoir exercer ce rôle. On sait cependant, par les prospections menées à proximité, que la population est nombreuse et qu'une partie d'entre elle est certainement attachée à l'exploitation aurifère toute proche.

D’autres sanctuaires protohistoriques identiques à celui de Tintignac seront, à n'en pas douter, découverts dans le futur sous certains ensembles monumentaux gallo-romains limousins.

L'oppidum de Villejoubert à Saint-Denis-des-Murs (HauteVienne), doté de son sanctuaire, au cœur de la civitas et très probablement capitale de cité, précède la fondation de la ville nouvelle d'Augustoritum (Limoges), distante de $25 \mathrm{~km}$, qui sera, quant à elle, le point de romanisation de l'ensemble du peuple lémovice.

En conclusion, le dépôt d'objets de Tintignac, d'un intérêt majeur du point de vue scientifique, n'est pas forcément le signe d'une richesse remarquable du sanctuaire. Des conditions particulières de transformation du lieu de culte, de conservation et de recherche archéologique ont permis la découverte de ce dépôt extraordinaire ${ }^{21}$.

21. Merci à P. Barral, G. Kaenel, T. Lejars et S. Verger pour la relecture de cet article. 


\title{
BIBLIOGRAPHIE
}

\author{
SOURCES ANTIQUES
}

CÉSAR J.

1997 : Guerre des Gaules, livre VIII, trad. L.-A. Constans, Paris, Les Belles Lettres.

\section{ÉLIEN}

Histoire variée, livre XII, trad. R. Hercher, Paris, Firmin Didot.

\begin{abstract}
AMY R., DUVAL P.-M., FORMIGÉJ., HATT J.J., Piganiol A., Picard G., PICARD G.-C.

1962 : L'Arc d'Orange, Paris, CNRS Éditions (coll. Suppl. à Gallia, 15), 2 vol., 163 p. et $111 \mathrm{pl}$.
\end{abstract}

\section{ANTIKE HELME}

1988 : Antike Helme. Sammlung Lipperheide und andere Bestände des Antikenmuseums Berlin, Mainz, Verlag des RömischGermanischen Zentralmuseums (coll. Monographien, 14).

\section{ARCELIN P., BRUNAUX J.-L. (DIR.)}

2003 : «Dossier : Cultes et sanctuaires en France à l'âge du Fer », Gallia, 60, p. 1-268.

\section{ARCELIN P., RAPIN A.}

2002 : «Images de l'aristocratie du second âge du Fer en Gaule méditerranéenne : autour de la statuaire d'Entremont ", in GUICHARD V., PERRIN F. (DIR.), L'Aristocratie celte à la fin de l'âge du Fer (II ${ }^{e}$ s. av. J.-C.-Ir s. apr. J.-C.), Actes de la table ronde internationale de Centre archéologique du Mont-Beuvray, 1999, Glux-en-Glenne (coll. Bibracte, 5), p. 29-66.

\section{BALUZE E.}

1717 : Historiae Titelensis, livre III.

\section{BARRAL P. (DIR.)}

2007 : «Epomanduodurum, une ville chez les Séquanes : bilan de quatre années de recherche à Mandeure et Mathay (Doubs)», Gallia, 64, p. 353-434.

Barral P., Bossuet G., Kuhnle G., MARC J.-Y., MOUGIN P.

2005 : «Nouvelles données sur l'agglomération antique d'EpomanduodurumMandeure (Doubs) ", Extrait des Mémoires de la Société d'Émulation de Montbéliard, 127, 2004, p. 27-129.
BARRAL P., MARC J.-Y., MOUGIN P.

2004 : «Nouvelles recherches sur le site d'Epomanduorum-Mandeure (Doubs)", Revue archéologique, Bulletin de la Société française d'archéologie classique, XXXV, 2002-2003, fasc. 1, p. 180-188.

\section{BÉMONT C.}

1979 : « Le bassin de Gundestrup : remarques sur les décors végétaux », Études celtiques, XVI, p. 69-99.

\section{BERTRAND I.}

2005 : «Au-delà des apparences... Les restes d'un sanglier-enseigne en métal dans le sanctuaire du Gué-de-Sciaux (Antigny, Vienne) ", in Le Pays chauvinois, Bulletin de la Société de recherches archéologiques du Pays chauvinois, 43, p. 138-142.

Bertrand I., MAGUer P. (DIR.)

2007 : De pierre et de terre : les Gaulois entre Loire et Dordogne, Catalogue d'exposition, Musées de la ville de Chauvigny (Vienne), 15 mai-14 oct. 2007, Chauvigny, Association des Publications chauvinoises (coll. Mémoire, XXX).

\section{BIZIEN-JAGLin C., LeJARS T.}

1991 : «Le sanctuaire armoricain des SeptPerthuis à Saint-Malo ", in BRUNAUX J.-L. (DIR.), Les Sanctuaires celtiques et le monde méditerranéen, Actes du colloque de SaintRiquier, 8-11 nov. 1990, Paris, Errance (coll. Dossiers de Protohistoire, 3), p. 133-135.

\section{BÖKÖNYI S.}

1991 : «L'élevage », in Les Celtes, Catalogue d'exposition, Venise, Palais Grassi, Milan, éd. Bompiani, p. 429-435.

\section{BOUDET R.}

1996 : Rituels celtes d'Aquitaine, Paris, Errance (coll. Archéologie aujourd'hui), 123 p.
BROUQUIER-REDDÉ V., GRUEL K. (DIR.)

2004: « Le sanctuaire de Mars Mullo chez les Aulerques Cénomans (Allonnes, Sarthe), $\mathrm{V}^{\mathrm{e}}$ s. av.J.-C.-IV ${ }^{\mathrm{e}}$ s. apr. J.-C. : état des recherches actuelles », Gallia, 61, p. 291-396.

BRUN P.

2001 : « Le cheval, acteur privilégié des cérémonies ", in BRUN P. (DIR.), Le Cheval : symbole de pouvoirs dans l'Europe préhistorique, Catalogue d'exposition, Nemours, Musée de Préhistoire d'Île-de-France, 31 mars-12 nov. 2001, p. 69-71.

\section{BRUNAUX J.-L.}

1986 : Les Gaulois, sanctuaires et rites, Paris, Errance, $154 \mathrm{p}$.

1990 : « La chronologie des armes laténiennes : systèmes chronologiques utilisés pour les armes de La Tène ", in DUVAL A., MOREL J.-P., ROMAN Y. (DIR.), Gaule interne et Gaule méditerranéenne aux II ${ }^{e}$ et $I^{\text {er }}$ siècles avant J.-C. : confrontations chronologiques, Bordeaux (coll. Suppl. à la Revue archéologique de Narbonnaise, 21), p. 167-191.

1991a : Les Sanctuaires celtiques et leurs rapports avec le monde méditerranéen, Actes du colloque de Saint-Riquier, 8-11 nov. 1990, Paris, Errance (coll. Dossiers de Protohistoire, 3).

1991b : "Le sanctuaire de Gournay », in Les Celtes, Catalogue d'exposition, Venise, Palais Grassi, Milan, éd. Bompiani.

2000 : Les Religions gauloises : nouvelles approches sur les rituels celtiques de la Gaule indépendante, Paris, Errance, 272 p.

2005 : Les Gaulois, Lonrai (coll. Guide Belles Lettres des Civilisations).

BRUNAUX J.-L., LAMBOT B.

1987 : Guerre et armement chez les Gaulois, 450-52 avant J-C., Paris, Errance.

BRUNAUX J.-L., MÉNIEL P.

1997 : La Résidence aristocratique de Montmartin 
(Oise) du III e au II siècle av. J.-C., Paris, Maison des sciences de l'homme (coll. Documents d'archéologie française, 64), $270 \mathrm{p}$.

\section{BRUNAUX J.-L., MÉNIEl P., POPLIN F.}

1985 : Gournay-sur-Aronde -I-Les Fouilles sur le sanctuaire et l'oppidum (1975-1984), Paris (coll. Suppl. à la Revue archéologique de Picardie, $\mathrm{n}^{\mathrm{o}}$ spécial), $268 \mathrm{p}$.

\section{BRUNAUX J.-L., RAPIN A.}

1988: Gournay-sur-Aronde-II-Boucliers et lances, dépôts et trophées, Paris, Errance, 245 p.

\section{BUCHSENSCHUTZ O., BULARD A.,} CHARDENOUX M.-B., GINOUX N.

2003 : Décors, images et signes de l'âge du Fer européen, Actes du XXVIe colloque de l'Association française pour l'étude de l'âge du Fer, Paris et Saint-Denis, 9-12 mai 2002, Tours (coll. Suppl. à la Revue archéologique du Centre de la France, 24).

\section{Catalogues D'Expositions}

1983 : L'Art celtique en Gaule, Catalogue d'exposition, Marseille, Paris, Bordeaux, Dijon 1983-1984, Paris, Direction des Musées de France (coll. des Musées de Province).

1991 : Les Celtes, Catalogue d'exposition, Venise, Palais Grassi, Milan, éd. Bompiani.

1993 : Le Carnyx et la lyre : archéologie musicale en Gaule celtique et romaine, Catalogue d'exposition, Musées de Besançon, Orléans et Évreux, 1993-1994, Besançon, Musée des Beaux-Arts et d'Archéologie de Besançon.

2002 : Préhistoire de la musique : sons et instruments de musique des âges du Bronze et $d u$ Fer en France, Catalogue d'exposition, Nemours, Musée de Préhistoire d'Île-deFrance, 17 mars-10 nov. 2002, Nemours, Musée de Préhistoire d'Île-de-France.

2003 : Forgerons et ferrailleurs : fer et savoir-faire à l'époque celtique, Catalogue d'exposition, Musée de la Civilisation celtique de Bibracte, été 2003, Glux-en-Glenne, Bibracte, $28 \mathrm{p}$.

2004 : Gaulois des pays de Garonne : II ${ }^{e}-I^{e r}$ siècle avant J.-C., Catalogue d'exposition, Musée Saint-Raymond, Musée des Antiques de Toulouse, 22 mai 2004-9 janv. 2005, Toulouse, Musée Saint-Raymond.

2007 : Le Cheval et la danseuse : à la redécouverte $d u$ trésor de Neuvy-en-Sullias, Catalogue d'exposition, Orléans, Musée des BeauxArts, 13 mars-26 août 2007 et Musée départemental de Bavay, 15 janv.-15 juin 2008, Orléans, Musée des Beaux-Arts et Paris, Somogy éditions d'art.

\section{Caunet B.}

2004 : L'Or des Celtes du Limousin, SaintLéonard-de-Noblat, éd. Culture et Patrimoine en Limousin.

\section{Chazelles C.-A. De, Feugère M., FERRÉ M.}

1994 : «Découverte d'un casque celtique à décor de corail sur l'oppidum de Montlaurès (Narbonne, Aude) ", Bulletin de la Commission archéologique et littéraire de Narbonne, 45, p. 113-115.

\section{Clodoré T., Vendries C.}

2002 : « Le second âge du Fer et la civilisation celtique (450-52 avant J.-C.) ", in Préhistoire de la musique : sons et instruments de musique des âges du Bronze et du Fer en France, Nemours, Musée de Préhistoire d'Île-de-France, p. 101-128.

\section{Condamin J., Fromenti F.}

1979 : « L'analyse des bronzes antiques en laboratoire ", in Les Bronzes romains, Dijon, éd. Faton (coll. Dossiers histoire et archéologie, 28), p. 109-114.

\section{CORBIN S.}

1960 : « La tradition celtique », in Histoire de la musique, Paris, Gallimard (coll. La Pléiade), vol. 1, p. 622-623.

\section{COROT H.}

1925 : « Le cheval-enseigne de Guerchy au musée d'Auxerre ", Revue des musées et collections archéologiques, 1, mai-juin 1925, p. 6.

\section{COUGNY E., LEBÈGUE $\mathbf{H}$.}

1878-1892 : Extraits des auteurs grecs concernant la géographie et l'histoire des Gaules, 6 vol., Société de l'Histoire de France.

\section{CRAWFORD M. H.}

1974 : Roman Republican Coinage, Cambridge, Cambridge University Press, 2 vol.

\section{CUNLIFFe B.}

2001 : Les Celtes, Paris, Errance.

\section{Daremberg C., SAGlio E.}

1887 : «Carnyx », in Dictionnaire des Antiquités grecques et romaines d'après les textes et les monuments, Paris, Librairie Hachette, p. 926-927.

\section{DÉCHELETTE J.}

1927 (2 éd. 1989) : Manuel d'archéologie préhistorique, celtique et gallo-romaine -IV-Second Age du Fer ou époque de La Tène, Paris, Picard.
DERKS T.

1998 : Gods, Temples and Ritual Practices : the Transformation of Religious Ideas and Values in Roman Gaul, Amsterdam, Amsterdam University Press (coll. Amsterdam Archaeological Studies), 325 p.

\section{DESBORDES J.-M.}

1982: «Un ancien itinéraire de long parcours entre Armorique et Méditerranée ", Travaux d'archéologie Limousine, 3, p. $15-22$.

1995 : «Voies romaines en Limousin», Travaux d'archéologie limousine, suppl. 3

\section{DE VRIES J.}

1975 : La Religion des Celtes, trad. L. Jospin, Paris, Payot.

\section{DOR DE LA SOUCHÈRE R.}

1988 : Travaux pour servir à l'histoire d'Antibes, Antibes, Textes recueillis, classés et publiés par P. Ginestet.

Duval A.

1983 : « L'art celtique en Gaule », Archéologia Préhistoire et Archéologie, 185, p. 48-56.

1990 : «Quelques aspects du mobilier métallique en fer anciennement recueilli à Tronoën, en Saint-Jean-Trolimon (Finistère) ", in DUVAL A., LE BIHAN J.-P., MÉNEZ Y. (DIR.), Les Gaulois d'Armorique : la fin de l'âge du Fer en Europe tempérée, Actes $d u X I I^{e}$ colloque de l'Association française pour l'étude de l'âge du Fer, Quimper, mai 1988, Rennes, Université Rennes-I (coll. Suppl. à la Revue archéologique de l'Ouest, 3), p. 23-45.

DUVal A., Lehoczky L., SchaAf U.

1986: «Zum keltischen Helm von Amfreville», Archäologisches Korrespondenzblatt, 16 , p. 82-83.

\section{DUVAL P.-M.}

1971 : La Gaule jusqu'au milieu du Ve siècle, Paris, 2 vol. (coll. Les Sources de l'histoire de France des origines à la fin du XVe siècle).

1977 : Les Celtes, Paris, Gallimard (coll. L'Univers des formes).

\section{DUVERNOY C.}

1883 : « Note sur une enceinte récemment découverte à Mandeure (Doubs) ", Mémoires de la Société nationale des Antiquaires de France, XLIV, p. 31-41.

\section{EGLOFF M.}

1991 : « L'artisanat celtique d'après les trouvailles de La Tène ", in Les Celtes, Catalogue d'exposition, Venise, Palais Grassi, Milan, éd. Bompiani. 
ESPÉRANDIEU E., LANTIER R.

1907-1938 : Recueil général des bas-reliefs, statues et bustes de la Gaule romaine, vol. I-XI, Paris, Imprimerie nationale.

1947-1949 : Recueil général des bas-reliefs, statues et bustes de la Gaule romaine, vol. XII-XIII, Paris, Presses universitaires de France.

\section{FAUDUET I.}

1992 : Les Bronzes gallo-romains du Musée d'Évreux-Instrumentum, Argenton-surCreuse, Le Trépan.

\section{FERdière A., VILLARD A.}

1993 : La Tombe augustéenne de Fléré-la-Rivière (Indre) et les sépultures aristocratiques de la cité des Bituriges, Saint-Marcel, Musée d'Argentomagus (coll. Mémoires du Musée d'Argentomagus, 2).

\section{FEUGÈre M.}

1994 : Casques antiques: les visages de la guerre de Mycènes à la fin de l'Empire romain, Paris, Errance.

\section{FICHTL S.}

2000 : La Ville celtique : les oppida de 150 av. J.-C. à 15 apr. J.-C., Paris, Errance.

2004 : Les Peuples gaulois : III ${ }^{e}-I^{e r}$ siècles av. J.-C., Paris, Errance.

\section{FISCHER F.}

1959 : Der spätlatenzeitliche Depotfund von Kappel (Kr. Saulgau), Urkunden zur Vorund Frühgeschichte aus Südwürtemberg, Hohenzollern, Heft 1.

\section{FORMIGÉ J.}

1949 : Le Trophée des Alpes (La Turbie), Paris, CNRS Éditions (coll. Suppl. à Gallia, 2), $110 \mathrm{p}$.

\section{FOSTER J.}

1977 : Bronze Boar Figurines in Iron Age and Roman Britain, Oxford, Oxford University Press.

\section{FrÉZOULS E.}

1988 : "Mandeure antique ", in Les Villes antiques de la France: Germanie supérieure, 1, Strasbourg, p. 423-505.

\section{GINOUX N.}

2004 : "Vin et art celtique ", in BRUN J.-P., POUX M., TCHERNIA A. (DIR.), Le Vin : nectar des dieux, génie des hommes, Lyon, Infolio, p. 185-187.

\section{GOMEZ DE SOTO J.}

1986 : « Le casque du IV ${ }^{\mathrm{e}} \mathrm{s}$. avant notre ère de la grotte des Perrats à Agris (Charente) »,
Archäologisches Korrespondenzblatt, 16 , p. 79-183.

1991 : «Le casque d'Agris », in Les Celtes, Catalogue d'exposition, Venise, Palais Grassi, Milan, éd. Bompiani, p. 292-293.

2007 : «Le casque de la grotte des Perrats à Agris ", in Bertrand I., MAguer P. (DIR.), De pierre et de terre : les Gaulois entre Loire et Dordogne, Catalogue d'exposition, Musées de la Ville de Chauvigny (Vienne), 15 mai-14 oct. 2007, Chauvigny, Association des Publications chauvinoises, p. 25-26.

Gomez de Soto J., Milcent P.-Y. ET AL. 2003 : « La France du Centre aux Pyrénées (Aquitaine, Centre, Limousin, MidiPyrénées, Poitou-Charentes) ", in ARCELIN P., BRUNAUX J.-L. (DIR.), « Dossier: Cultes et sanctuaires en France à l'âge du Fer », Gallia, 60, p. 107-138.

\section{GOMEZ DE SOTO J., VERGER S.}

1999 : Le Casque celtique de la grotte d'Agris (IV siècle avant J.-C.), Angoulême, Germa.

\section{GREEN S.}

1991 : « Le dépôt votif de Llyn Cerrig Bach ", in Les Celtes, Catalogue d'exposition, Venise, Palais Grassi, Milan, éd. Bompiani, p. 609.

\section{GRIMAUD R.}

2001 : Nos ancêtres les Gaulois, Rennes, éd. Ouest-France (coll. Mémoires de l'Histoire).

\section{Guillaumet J.-P.}

1996 : «Ustensiles à rôtir de la Saône au musée Denon à Chalon-sur-Saône ", in GROENE M. (DIR.), La Préhistoire au quotidien : mélanges offerts à Pierre Bonenfant, Grenoble, Millon, p. 311-321.

\section{GUILlaUmet J.-P., SCHÖNFELdER M.}

2007 : "Feuilles, carnyx et enseignes ", in BARRAL P. (DIR.), "Epomanduodurum, une ville chez les Séquanes : bilan de quatre années de recherche à Mandeure et Mathay (Doubs) ", Gallia, 64, p. 384-387.

\section{HickmanN E., LaUfS I., EichmanN R.} (DIR.)

1998 : Studien zur Musikarchäologie -IIMusikarchäologie Früher Metallzeiten, $1^{\text {st }}$ Symposium of the International Study Group on Music Archaeology at Monastery Michaelstein, 18-24 may 1998, Rahden/ Westf., Marie Leidorf GmbH (coll. Orient-Archäologie, 7), p. 55-86.
HUNTER F.

2001 : " The Carnyx in Iron Age Europe ", The Antiquaries Journal, 81, p. 77-108.

\section{JACOBSTHAL P.}

1944 (rééd. 1969) : Early Celtic Art, Oxford, Oxford University Press, 2 vol., 242 p. et 279 pl.

JENKINS G. K.

1972 : Les Monnaies grecques, Fribourg (coll. L'Univers des monnaies), 327 p., 695 ill.

\section{JOACHIM H.-E.}

1995 : Waldalgesheim : das Grab einer keltischen Fürstin, Cologne, Rheinland-Verlag GmbH.

JOLY M., BARRAL P.

2007 : « Le sanctuaire de Mirebeau-surBèze (Côte-d'Or) : bilan des recherches récentes ", in BARRAL P. ET AL., L'Âge $d u$ Fer dans l'arc jurassien et ses marges : dépôts, lieux-sacrés et territorialité à l'âge $d u$ Fer, Actes du XXIX colloque international de l'Association française pour l'étude de l'âge du Fer, Bienne, 5-8 mai 2005, Besançon, vol. 1, p. 55-72.

KING A., SOFFE G.

1994 : "Recherches récentes sur les temples romano-celtiques de Grande-Bretagne : l'exemple de Hayling Island ", in Les Sanctuaires de tradition indigène en Gaule romaine, Actes du colloque d'Argentomagus, 8-10 oct. 1992, Clamecy, Errance, p. $33-48$.

\section{KLINDT-JENSEN O.}

1953: Bronzekedelen fra Brå. The Bronze Cauldron from Brå. Early Celtic Influences in Denmark, Aarhus, Universitetsforlaget (coll. Jyst arkaeologisk Selskabs Skrifter, III).

\section{KOSSACK G.}

1954 : Studien zum Symbolgut der Urnenfelder und Hallstattzeit Mitteleuropas, Berlin, De Gruyter (coll. Römish-germanische Forschungen, 20).

\section{KRÄMER W.}

1985 : Die Grabfunde von Manching und die latènezeitlichen Flachgräber in Südbayern : die Ausgrabungen in Manching 9 (1985), Taf. 38,$12 ; 47$ A ; 53, 3. $10 ; 60.6$.

\section{KRUTA V.}

1971 : Le Trésor de Duchcov dans les collections tchécoslovaques, Severočeské, nakladatelství, Útí nad Labem.

1975 : L’Art celtique en Bohême : les parures métalliques $d u V^{e}$ au II siècle avant notre ère, Paris, 
Bibliothèque de l'École des hautes études en sciences sociales, $324 \mathrm{p}$.

1976-1977 : « Le casque d'Amfreville-sous-lesMonts (Eure) et quelques problèmes de l'art celtique du IV $\mathrm{e}$. avant notre ère ", Études celtiques, XV, p. 405-424.

1987a : «L'armement des Celtes cisalpins », in Les Celtes en Italie, Dijon, éd. Faton (coll. Dossiers histoire et archéologie, 112), p. 74-77.

1987b : "Les phalères de Manerbio ", in Les Celtes en Italie, Dijon, éd. Faton (coll. Dossiers histoire et archéologie, 112), p. 64-65.

2000 : Les Celtes : histoire et dictionnaire, Paris, Robert Laffont.

\section{Kruta V., Bertuzzi D., Forman W.,} LESSING E.

2004 : Les Celtes, Luçon, éd du Chêne.

\section{LAING L., LAING J.}

1992 : L'Art celte, Paris, Thames and Hudson.

\section{LALANDE P.}

1885 : " Ruines romaines de Tintignac (Corrèze) ", Bulletin de la Société scientifique, historique et archéologique de la Corrèze, VII, p. 632-713.

\section{LAMBOT B.}

2002 : Maisons et société à Acy-Romance (Ardennes), Reims (coll. Mémoire de la Société archéologique champenoise, 16), p. 115-124.

\section{LANTIER R.}

1939 : « La tombe royale de Sutton Hoo (Suffolk) ", Revue archéologique, 14, p. 239.

LATOUR B. DE

1633 (2 $2^{\mathrm{e}}$ éd. 1636 : Toulouse) : Institutio ecclesiae Tutelensis, trad. F. Bonnélye sous le titre Histoire de l'église de Tulle et de Notre-Dame de Rocamadour, Tulle (1858).

LA TOUR H. DE, FISCHER B.

1999 (3e éd.) : Atlas des monnaies gauloises, Paris.

\section{LAVERGNE D.}

1999 : Découverte d'un sanglier en tôle de bronze d'époque antique à Ilonse (06), Nice (coll. Mémoires de l'Institut de Préhistoire et d'Archéologie des Alpes-Maritimes, 41), p. 7-10.

2000 : « Le sanglier d'Ilonse », in CHAUSSERIELAPRÉE J. (DIR.), Le Temps des Gaulois en Provence, Martigues, Musée Ziem, p. 254-255.
LE BOHEC Y.

1989 : L’Armée romaine sous le Haut-Empire, Paris, Picard.

\section{LEJARS T.}

1989 : « Les armes des sanctuaires poitevins d'époque préromaine de Faye-l'Abbesse (Deux-Sèvres) et de Nalliers (Vendée) ", Gallia, 46, p. 1-41.

1991 : «L'apparition des grands sanctuaires au $\mathrm{III}^{\mathrm{e}}$ siècle avant notre ère », in « Les Celtes au III $^{\mathrm{e}}$ siècle avant J.-C., partie I, Actes du IX ${ }^{\mathrm{e}}$ congrès international d'études celtiques, Paris, 8-12 juillet 1991 ", Études celtiques, XXVIII, p. 237-257.

1994 : Gournay-sur-Aronde -III- Les Fourreaux d'épées, Paris, Errance (coll. Archéologie aujourd'hui).

2001 : «Les installations cultuelles celtiques : un aperçu de la recherche en France ", in VITRI S., ORIOLO F. (DIR.), I Celti in Carnia e nelle'arco alpino centro orientale, Atti della giornata di studio, Tolmezzo, 30 aprile 1999, Trieste, p. 245-277.

2003 : "La nécropole celtique de Roissy », Pour la Science, 306, p. 58-64.

2007 : «Un dépôt d'objets métalliques à Vieux-Poitiers (Vienne) et les origines gauloises de l'agglomération antique ", in Bertrand I., MAguer P. (DIR.), De pierre et de terre : les Gaulois entre Loire et Dordogne, Catalogue d'exposition, Musées de la ville de Chauvigny (Vienne), 15 mai-14 oct. 2007, Chauvigny, Association des Publications chauvinoises (coll. Mémoire, XXX), p. 131-132.

LE ROUX F., GUYONVARC'H C.-J.

1990 : La Civilisation celtique, Rennes, éd. Ouest-France.

\section{LERAT L.}

1956 : Les Fibules gallo-romaines, Catalogue des collections archéologiques de Besançon, vol. II, Paris, Les Belles Lettres (coll. Annales littéraires de l'Université de Besançon, 2e série, Archéologie 3).

\section{LOURDEAUX-JURIETTI S.}

2003: "L'utilisation du corail sur le casque de la grotte des Perrats à Agris (Charente) ", in Décors, images et signes de l'âge du Fer européen, Actes du XXVI colloque de l'Association française pour l'étude de l'âge du Fer, Paris et Saint-Denis, 9-12 mai 2002, Levroux, Tours, FERACF (coll. Suppl. à la Revue archéologique du Centre de la France, 24).

Maguer P., Gherel A.-F., Auxiette G.

2003 : «Nouvelles données sur les habitats de l'âge du Fer dans le nord de la Sarthe (commune de Vivoin, autoroute A28) ", in MANDY B., SAUlce A. DE (DIR.), Les Marges de l'Armorique à l'âge du Fer, Actes du XXIII colloque de l'Association française pour l'étude de l'âge du Fer, Musée Dobrée, Nantes, 13-16 mai 1999, Rennes, Association pour la diffusion des recherches archéologiques dans l'ouest de la France (coll. Suppl. à la Revue archéologique de l'Ouest, $10)$, p. 213-234.

\section{MAIER F.}

1991 : «Les oppida celtiques », in Les Celtes, Catalogue d'exposition de Venise, Palais Grassi, Milan, éd. Bompiani, p. 410-425.

\section{MANIQUET C.}

2004 : Le Sanctuaire antique des Arènes de Tintignac, Limoges, éd. Culture et Patrimoine en Limousin.

2005a : "Découverte d'un formidable dépôt gaulois : les carnyx de Tintignac ", Archéologia, 419, févr. 2005, p. 16-23.

2005b : «The Tintignac Celtic Warrior Hoard ", Minerva, 16, 4, juillet-août 2005.

2005c : «Un dépôt d'armes et d'objets gaulois exceptionnel découvert sur le sanctuaire de Tintignac à Naves (Corrèze) ", Archéopages, 16, juillet, p. 26-33.

\section{MANTELLIER P.}

1866 : «Mémoire sur les bronzes antiques de Neuvy-en-Sullias », Mémoires de la Société archéologique de l'Orléanais, IX, p. 206.

\section{MatTingly H., Sydenham E. A.}

1968 : Roman Imperial Coinage, Londres, Spink.

\section{MEDUNA J.}

1991 : "La cruche de Brno-Maloměřice ", in Les Celtes, Catalogue d'exposition, Venise, Palais Grassi, Milan, éd. Bompiani, p. $376-377$.

\section{MEGAW V.}

1968 : « The Earliest Musical Instruments in Europe ", Archaeology, 21, p. 124-132.

1991 : « La musique et les Celtes », in Les Celtes, Catalogue d'exposition, Venise, Palais Grassi, Milan, éd. Bompiani.

MEgaW R., MEgaW V.

2005 : Art de la Celtique : VII ${ }^{e}$ siècle av. J.-C.VIII ${ }^{e}$ siècle apr. J.-C., Paris, Errance.

\section{MÉRIMÉE P.}

1838 (rééd. 1971) : Notes d'un voyage en Auvergne, Notes de voyage publiées en 1838, présentées par P.-M. Auzac, Paris, Hachette. 


\section{METZLER J.}

1984 : " Treverische Reitergräber von Goeblingen-Nospelt, Trier », Augustusstadt der Treverer, p. 87-99 et p. 289-299.

\section{Metzler J., GAeng C.}

2008 : Goeblange-Nospelt : une nécropole aristocratique trévire, Luxembourg, Musée national d'Histoire et d'Art (coll. Dossiers d'archéologie du Musée national d'Histoire et d'Art).

\section{MOREAU J., ANKNER D., BOUDET R.,} DHENIN M., FECHT M.

1995 : Le Sanglier-enseigne gaulois de Soulac-sur-Mer, Soulac-sur-Mer, Musée archéologique de Soulac-sur-Mer (Gironde).

\section{NeUSTUPNÝ E., NeUSTUPNÝ J.}

1961 : Czechoslovakia before the Slavs, Londres, Thames and Hudson (coll. Ancient Peoples and Places, 22).

\section{Petres E.}

1974 : " Amgaben zum römerzeitlichen Fortleben der keltichen Plastik in Pannonien ", in The Celts in Central Europe, Szekesfehervar (coll. Bulletin du musée du roi Saint-Étienne, série A, 20), p. 225-234.

\section{PICARD G.-C.}

1957 : Les Trophées romains : contribution à l'histoire de la religion et de l'art triomphal à Rome, Paris, De Boccard.

1992 : «L'idéologie de la guerre et ses monuments dans l'Empire romain », Revue archéologique, 1992/1, p. 111-141.

\section{Piggott S.}

1959 : "The Carnyx in Early Iron Britain ", The Antiquaries Journal, 39, p. 19-32.

\section{Poux M.}

2004 : LẦge du vin : rites de boisson, festins et libations en Gaule indépendante, Montagnac, Monique Mergoil.

2006 : "Religion et société : le sanctuaire arverne de Corent ", in Goudineau C. (DIR.), Religion et société en Gaule, Paris, Errance.

\section{PRIEUR J.}

1988 : Les Animaux sacrés dans l'Antiquité, Rennes, Ouest-France.

\section{Proinsias M.-C.}

1991 : «Religion et mythologie celtiques ", in Les Celtes, Catalogue d'exposition de Venise, Palais Grassi, Milan, éd. Bompiani, p. 596-604.
RAPIN A.

1983 : "L'armement du guerrier celte au deuxième âge du Fer ", in L'Art celtique en Gaule, Catalogue d'exposition, Marseille, Paris, Bordeaux, Dijon, 1983-1984, Paris, Direction des Musées de France (coll. des Musées de Province), p. 69-79.

\section{REINACH S.}

1894 : Antiquités nationales : description raisonnée du musée de Saint-Germain-enLaye -2- Bronzes figurés de la Gaule romaine, Paris, Firmin Didot.

1921 (2e éd. : 1926) : Catalogue illustré du musée des Antiquités nationales au château de Saint-Germain-en-Laye, Paris, Musées nationaux, vol. II.

\section{RICHARD C.}

1983 : Gué-de-Sciaux, Antigny-Vienne : une ville gallo-romaine, fouille d'un sanctuaire, Chauvigny, Société de recherches archéologiques de Chauvigny (coll. Mémoire, IV).

\section{ROLLAND H.}

1977 : L'Arc de Glanum (Saint-Rémy-de-Provence), Paris, CNRS Éditions (coll. Suppl. à Gallia, 31), 72 p., 77 pl.

\section{ROLLey C.}

1978 : " La technique de fabrication des bronzes antiques ", in "Les Bronzes romains ", Dossiers de l'archéologie, 28, mai-juin 1978, p. 9-18.

\section{RUSU M.}

1969 : « Das keltische Fürstengrab von Ciumesti in Rumänien », Germania, 50, p. 267-300.

\section{SANKOT P.}

1991a : "La Bohême », in Les Celtes, Catalogue d'exposition, Venise, Palais Grassi, éd. Bompiani Milan, p. 270-272.

1991b : « Motifs zoomorphes dans l'art laténien de la Bohême au III $^{\mathrm{e}}$ siècle avant J.-C. ", in « Les Celtes au III ${ }^{\mathrm{e}}$ siècle avant J.-C., partie I, Actes du IX ${ }^{\mathrm{e}}$ congrès international d'études celtiques, Paris, 8-12 juillet 1991 », Études celtiques, XXVIII, p. $401-433$.

\section{SANQUER R.}

1973 : « La grande statuette de bronze de Kerguilly-en-Dinéault (Finistère) », Gallia, 31,1 , p. $61-80$.

\section{SANTROT J. ET AL.}

1996 : «Bronzes et fers de Dax, Landes ", Gallia, 53, p. 289-291.

\section{SCHAAF U.}

1974 : « Keltiche Einsenhelme aus vorrömi- scher Zeit ", Jahrbuch des römisch-germanischen Zentralmuseums Mainz, 2, p. 152-171.

\section{SChMitT L., PRIEUR M.}

2004 : Les Monnaies romaines, Paris, éd. Les Chevaux légers.

\section{SIEVERS S.}

1991: «Armes et sanctuaires à Manching », in BRUNAUX J.-L. (DIR.), Les Sanctuaires celtiques et le monde méditerranéen, Actes du colloque de Saint-Riquier, 8-11 nov. 1990, Paris, Errance, p. 146-155.

\section{SZABÓ M.}

1991 : «Mercenariat », in Les Celtes, Catalogue d'exposition, Venise, Palais Grassi, Milan, éd. Bompiani, p. 333-336.

\section{Szabó M., Petres E. F.}

1992 : Decorated Weapons of the La Tène Iron Age in the Carpathian Basin, Budapest, Magyar Nemzetí Múzeum (coll. Inventaria Praehistorica Hungariae, V), 259 p.

\section{TOLEDO I MUR A.}

2005 : «Une mine d'or protohistorique : le Puy des Angles aux Angles-sur-Corrèze (Corrèze) », Gallia, 62, p. 171-214.

\section{VENCLOVA N.}

1991 : «Structure et fonction de l'enclos de Msecke Zehrovice ", in BRUNAUX J.-L. (DIR.), Les Sanctuaires celtiques et le monde méditerranéen, Actes du colloque de SaintRiquier, 8-11 nov. 1990, Paris, Errance (coll. Dossiers de Protohistoire, 3), p. 139-145.

\section{VENDRIES C.}

1993a : "Les Gaulois et la musique au second âge du Fer ", in Le Carnyx et la lyre : archéologie musicale en Gaule celtique et romaine, Catalogue d'exposition, Musées de Besançon, Orléans et Évreux, 1993-1994, Besançon, Musée des Beaux-Arts et d'Archéologie de Besançon, p. 27-33.

1993b : "Survivances musicales indigènes et particularités organologiques ", in $L e$ Carnyx et la lyre : archéologie musicale en Gaule celtique et romaine, Catalogue d'exposition, Musées de Besançon, Orléans et Évreux, 1993-1994, Besançon, Musée des Beaux-Arts et d'Archéologie de Besançon, p. 71-77.

1999 : « La trompe, le gaulois et le sanglier », Revue des études anciennes, 101, 3-4, p. 367-391.

2007 : « La trompe de Neuvy : anatomie d'un objet sonore ", in Le Cheval et la danseuse : à la redécouverte du trésor de Neuvy-en-Sullias, Catalogue d'exposition, Orléans, Musée des 
Beaux-Arts, 13 mars-26 août 2007 et Musée départemental de Bavay, 15 janv.-15 juin 2008, Orléans, Musée des Beaux-Arts et Paris, Somogy éditions d'art, p. 120-145.

\section{VITALI D.}

1982 : «L'elmo della tomba 14 di Monte Bibele a Monterenzio (prov. di Bologna) ", Études celtiques, XIX, p. 35-49.
VoUGA P.

1923 : La Tène, Monographie de la station publiée au nom de la commission des fouilles de La Tène, Leipzig, Hiersemann. 